\title{
The influence of forgiveness and apology on cardiovascular reactivity to mental stress
}

\author{
Matthew C. Whited \\ West Virginia University
}

Follow this and additional works at: https://researchrepository.wvu.edu/etd

\section{Recommended Citation}

Whited, Matthew C., "The influence of forgiveness and apology on cardiovascular reactivity to mental stress" (2009). Graduate Theses, Dissertations, and Problem Reports. 2872.

https://researchrepository.wvu.edu/etd/2872

This Dissertation is protected by copyright and/or related rights. It has been brought to you by the The Research Repository @ WVU with permission from the rights-holder(s). You are free to use this Dissertation in any way that is permitted by the copyright and related rights legislation that applies to your use. For other uses you must obtain permission from the rights-holder(s) directly, unless additional rights are indicated by a Creative Commons license in the record and/ or on the work itself. This Dissertation has been accepted for inclusion in WVU Graduate Theses, Dissertations, and Problem Reports collection by an authorized administrator of The Research Repository @ WVU.

For more information, please contact researchrepository@mail.wvu.edu. 
The Influence of Forgiveness and Apology on Cardiovascular Reactivity to Mental Stress

Matthew C. Whited, MS

\author{
Dissertation submitted to the \\ Eberly College of Arts and Sciences \\ at West Virginia University \\ in partial fulfillment of the requirements \\ for the degree of \\ Doctor of Philosophy \\ in \\ Psychology
}

Kevin T. Larkin, PhD, Chair

T. Anne Hawkins, PhD

Julie Hicks Patrick, PhD

Dan W. McNeil, PhD

Tracy L. Morris, PhD

Department of Psychology

Morgantown, West Virginia

2009

Keywords: Forgiveness; Apology; Cardiovascular Reactivity; Cardiovascular Recovery; Harassment. 


\begin{abstract}
The Influence of Forgiveness and Apology on Cardiovascular Reactivity to Mental Stress

Matthew C. Whited
\end{abstract}

This study sought to investigate the relation between forgiveness and cardiovascular reactivity and recovery in the laboratory as influenced by apology. Men $(n=29)$ and women $(n=50)$ were chosen for participation based on scoring in the top or bottom third of the Forgiving Personality Inventory. Participants were exposed to an interpersonal transgression (i.e., harassment by the experimenter) while performing a serial subtraction task. Cardiovascular activity was measured before, during, and following the task. Also following the task, approximately half of the participants received an apology from the experimenter for his/her scripted rude behavior. No reactivity differences during the serial subtraction task were observed across groups (all $p \mathrm{~s}>$ $.05)$. During the recovery period, however, persons high in forgiveness displayed more rapid diastolic and mean arterial blood pressure recovery $(p s<.05)$. This effect was most prominent directly following the apology, where women high in forgiveness who received an apology benefitted the most in diastolic and mean arterial blood pressure recovery $(p \mathrm{~s}<.01)$ as compared to females low in forgiveness who were not influenced by the apology $(p s>.05)$. Regarding the overall effects of the apology, women who received an apology recovered from the transgression more quickly than women who did not receive an apology $(p s<.05)$. Surprisingly, the effect was in the opposite direction for men who displayed higher diastolic and mean arterial blood pressure upon recovery from the transgression if they received an apology $(p s<.05)$. These results indicate that that the potentially healthful benefits associated with forgiveness and apology may be moderated by sex. 
This work is dedicated to Mario Creany, who showed me the value of scholarship and perseverance, and Minnie Whited who truly embodied love and forgiveness. I see you both around the next bend in the river. 


\section{Acknowledgements}

I would first like to thank my committee for their feedback and ideas concerning this project. Thank you to Kevin Larkin especially, who has helped me greatly in developing my academic skills and abilities as a psychologist. Thank you to Amanda Wheat who once again devoted her precious time to a project I could not have completed without her aid. Foremost, I once again thank my parents for their unwavering support and constant education. 
Table of Contents

Abstract ii

Dedication iii

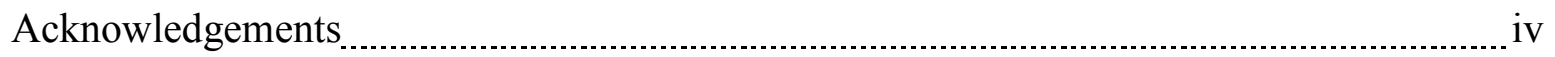

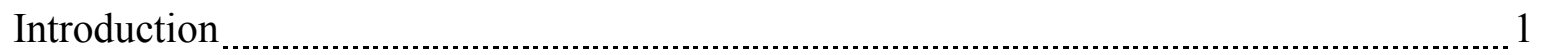

Forgiveness and Health

The Physiology of Stress

The Physiology of Forgiveness

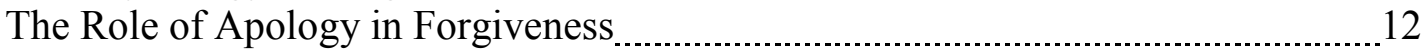

Method

Participants

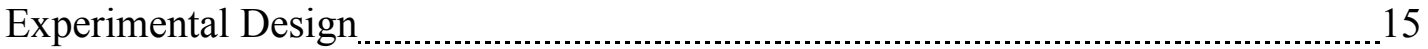

Experimental Measures

Procedure

Results

Data Reduction $\ldots$

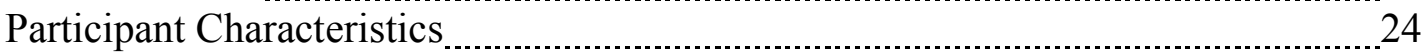

Resting Cardiovascular Measures

Cardiovascular Reactivity to Mental Stress $\ldots \ldots \ldots$

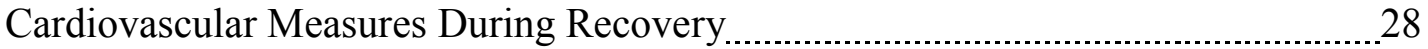

Measures of Affect

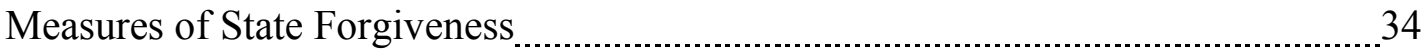

Post-Experimental Questionnaire

Discussion

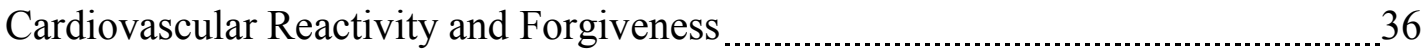

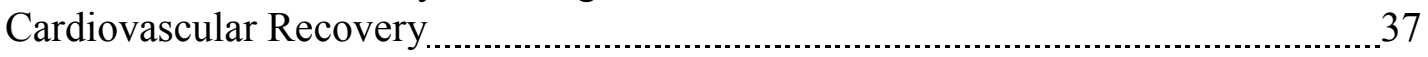

Forgiveness and Physiological Health

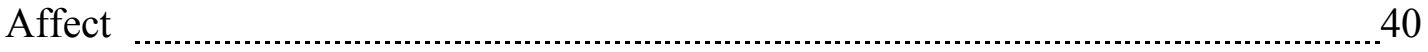

State Forgiveness

Perceptions of the Task and Experimenter

Limitations

Future Directions

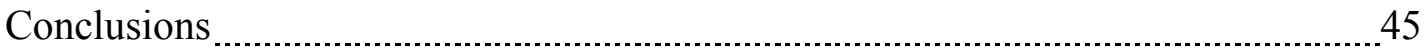

References

Tables

Figures

Appendices 
Forgiveness, as discussed by McCullough, Pargament, and Thoresen (2000), can be difficult to define. Although a consensus regarding its definition has yet to be achieved, researchers and clinicians interested in forgiveness have agreed that there are several things that forgiveness is not. First, forgiveness is not considered to occur when the person excuses or accepts his or her transgressor's actions. In other words, if a person forgives a transgressor for their actions, it does not equate to an admission that the transgressor's actions were acceptable. Second, forgiveness should not be considered using the colloquial terms of "forgive and forget," as denying the transgression occurred does not constitute forgiveness. Rather, forgiveness involves remembering the transgression, but in a new way. Third, forgiveness is not excusing or pardoning, as pardon is a legal term in which a justifiable punishment is excused. Engaging in forgiveness occurs independently with respect to decisions of pardoning. Finally, forgiveness does not require reconciliation of the relationship between transgressor and victim. Although true reconciliation may require forgiveness, forgiving another for a transgression does not require the re-establishment of a previous relationship.

Mention of a developmental model of forgiveness (e.g., Huang \& Enright, 2000) is also warranted when considering defining the construct. According to Huang and Enright, earlier developmental levels of forgiveness involve forgiving due to some sort of external pressure applied to the victim (e.g., forgiving to relieve guilt, as a religious mandate, or being told to forgive by an authority figure) with the highest level of development being forgiveness driven by an unconditional positive regard towards all persons, despite their actions. The earlier levels of this developmental model may not be considered "forgiveness" by some investigators, but the importance of taking a developmental perspective on forgiveness is likely a critical factor when examining the physiology of forgiveness. 
Operational definitions of forgiveness among researchers are actually more alike than they are different, and common elements can be used to create a broader, more universally acceptable, definition of forgiveness. Definitions of forgiveness by various researchers focus on emotional aspects of forgiveness (i.e., abandonment of negative emotions, the fostering of positive emotions), overt and covert behavioral changes such as engaging in prosocial behaviors towards the transgressor, or restructuring thoughts to include more positive cognitions in relation to the transgressor. Still others focus on the process of forgiveness as it occurs over time or the belief that forgiveness requires deliberate effort on the part of the victim (McCullough, et al., 2000). An analysis of the common themes included in the definition of forgiveness was conducted by Wade and Worthington (2005), who reported that clinicians facilitating interventions targeting forgiveness commonly agreed that forgiveness was "a positive method of coping with a hurt or offense that primarily benefits the victim through a reorientation of emotions, thoughts, and/or actions toward the offender" ( $p .160)$. The authors go on to state that "forgiveness is a process that leads to the reduction of unforgiveness and the promotion of positive regard for the offender" (p. 160). This general definition of forgiveness will be adopted throughout the following review of the forgiveness literature.

Until recently, concern for forgiveness was shown mostly in the clinical literature, and primarily in articles focused on faith-based mental health care, such as pastoral counseling. In fact, it was rare to find forgiveness mentioned in the field of psychology outside of a religious context until the early 1980s (Rye et al., 2000). At that point in time, forgiveness research expanded through the work of researchers in many different areas of psychology. Currently, there is a call for directed research on forgiveness in several areas of psychology, as prominent researchers have summarized the known literature on forgiveness and called for further research 
in the areas of psychometrics associated with the measurement of forgiveness (McCullough, Hoyt, \& Rachal, 2000), the examination of neuropsychological processes linked with the forgiveness process (Newberg et al., 2000), life span development of forgiveness behaviors (Mullet \& Girard, 2000), personality characteristics associated with forgiving attitudes and behaviors (Emmons, 2000), and individual and group psychotherapy approaches that foster forgiveness (Gordon, Baucom, \& Snyder, 2000; Malcolm \& Greenberg, 2000; Worthington, Sandage, \& Berry, 2000). Although each of these areas of the literature contain a few contributing studies on the topic of forgiveness, all aspects of forgiveness are in need of further study. The relation between forgiveness and health represents yet another area that is in need of further research, and will be considered in more detail in the following section.

\section{Forgiveness and Health}

Several researchers have suggested that forgiveness is positively associated with health (e.g., Lawler et al., 2005; McCullough \& Witvliet, 2002; Witvliet, 2002; Thoresen, Harris, \& Luskin, 2000) through extrapolating from the known inverse associations between forgiveness and hostility, a well established psychological construct associated with poorer mental and physical health outcomes (e.g., Miller et al., 1996; Smith et al., 2004; Smith, 1992; Vandervort, 2006). Using this logic, because hostile persons exhibit a higher prevalence of cardiovascular disease as well as all-cause mortality (e.g., Cooper \& Waldstein, 2004; Miller et al., 1996; Nelson, Palmer, \& Pederson, 2004) and employ fewer forgiveness responses to transgressions than persons lower in hostility (e.g., Berry et al., 2005; Thompson et al., 2005), it has been hypothesized that forgiveness may also be associated with improved health outcomes. Additionally, inasmuch as holding on to grudges involves frequent rumination concerning perceived transgressions (Witvliet, Ludwig, \& Bauer, 2002; Ysseldyk, Matheson, \& Anisman, 
2007) and that rumination is a core negative cognitive process associated with poorer mental and physical health (Thomsen, Mehlsen, Olesen, et al., 2004; Thomsen, Mehlsen, Hokland, et al., 2004), it follows that people who hold on to grudges live less mentally and physically healthy lives than people who tend to forgive transgressions of others.

Although the hypothesis that forgiveness is associated with positive health outcomes is based on sound conceptual reasoning, empirical support for it is lacking. There have been a few studies in which measures of trait forgiveness have been linked with better health outcomes as indexed by resting physiological measures (Berry \& Worthington, 2001; Seybold et al., 2001) and physiological reactivity (Lawler et al., 2003; Witvliet et al., 2001). However, the relation between forgiveness and health is clearly understudied, and additional empirical work examining the breadth of mental and physical health outcomes associated with the phenomenon of forgiveness is desperately needed.

Understanding the potential psychological or physiological mechanisms linking health and forgiveness would certainly contribute to a more comprehensive understanding of how the changes in attitudes, thoughts, and behaviors associated with forgiveness can result in fewer physical health problems and promote longevity. Thoresen, Harris, and Luskin (2000) and Worthington and Scherer (2004) outlined several possible physiological and psychosocial mechanisms that they hypothesized to link forgiveness and health, including increased selfefficacy and social competence among forgiving persons, which resulted in a reduced experience of hostility and depression, and consequent improvement in a wide range of health behaviors (e.g., less smoking, a healthier diet, regular exercise). According to this perspective, forgiveness results in improved health via improved health behaviors. These authors proposed an alternate model in which the physiological mechanisms associated with the positive relation between 
forgiveness and health involved chronic hyperarousal of the sympathetic nervous system among unforgiving persons who harbored ongoing resentment of transgressions. Over time, this chronic hyperaroused autonomic state resulted in tissue damage among unforgiving persons, similar to the tissue damage observed in chronically-stressed animals by Selye (e.g., Selye, 1955) decades ago.

\section{The Physiology of Stress}

Stressful events, such as harboring resentment and chronic rumination associated with holding grudges, result in a characteristic pattern of arousal in the autonomic nervous system, which is composed of the sympathetic and parasympathetic branches. The autonomic nervous system is responsible for physiological behaviors over which limited conscious control exists. Examples of measures of bodily functions controlled by the autonomic nervous system include heart rate, blood pressure, pupillary dilation, digestive processes, hormone release, and blood flow. The sympathetic branch of the autonomic nervous system is responsible for readying the body for action, which is typically referred to as the "fight or flight" response. When faced with a stressor, the brain signals the body to mobilize by making physiological alterations such as increasing blood flow to the skeletal muscles and reducing digestive action. This response evolved over millennia of inter- and intra-species changes and is very functional when an organism is faced with a life-threatening external stressor. For example, if a human being were confronted by a threatening animal, such as a tiger, the brain registers the presence of the threat and sets off the neurological and hormonal cascade that creates the physiological changes necessary to "fight or flee." As such, the human now has optimized his or her physiological functioning for escaping or combating the tiger. Once the source of threat has been removed, the parasympathetic nervous system is responsible for essentially reversing the effects of the "fight- 
flight" response, calming the body and returning the body's energy to basic homeostatic functions (e.g., maintaining regular breathing rates, digesting food).

The effects of the sympathetic nervous system (SNS) and the fight or flight response in modern humans is more often maladaptive than beneficial. While modern humans will occasionally encounter external contingencies that require a fight or flight response, most modern stressors are not life-threatening in nature and probably do not require the same magnitude of fight or flight responses needed by our ancestors. Frequently, modern humans are confronted by occupational or interpersonal stressors or daily hassles that do not require a fight or flight response. Repeated physiological arousal via the SNS in response to these frequent, but not life-threatening, encounters can create undue strain on a person's body, and result in a variety of health problems, including hypertension (e.g., Larkin, 2005), cardiovascular disease (e.g., Melamed, 2006), gastrointestinal disturbances (e.g., Whitehead, 1992), sleep disorders (e.g., Ekstedt, Åkerstedt, \& Söderström, 2004), cancer (e.g., Stone et al., 1999), and a wide array of health problems associated with compromised immune systems (e.g., Kiecolt-Glaser \& Glaser, 1992).

The ability of the body to adapt and change its functioning in response to an environmental stressor via increased SNS activity as described above has been termed “allostasis" by McEwen and colleagues (McEwen \& Seller, 1993). "Allostatic load" or "allostatic overload" (McEwen \& Wingfield, 2003) describes the various patterns of an organism's stress response that can lead to tissue damage and illness. McEwen (1998) described four observable patterns of allostatic overload. The first pattern was the exposure of the organism to multiple stressors over a short period of time, with no room for recovery in between. The second pattern also involved a repeated exposure to stressors, but in this pattern the organism did 
not habituate to the stressor by reducing allostatic responding. In this pattern, repeated exposure to a stressor resulted in the same level of responding (e.g., increased heart rate) each time the stressor was presented. The third pattern of response described by McEwen was a delayed physiological recovery from a stressor. In this case, physiological hyperarousal in response to a stressor was reduced slowly once the stressor was no longer present, resulting in an elevated physiological response to stress over time. McEwen's fourth and final pattern of allostatic overload was a resultant inadequate and small response to stress, which did not allow for the body to prepare for action and effectively cope with a stressor.

The hypothesis that follows from a review of human physiological functioning is that forgiveness promotes improved health through reduced allostatic load through several possible mechanisms. Forgiving may reduce or eliminate the chronicity of a stressor via decreased rumination over the transgression, which in turn facilitates the normal habituation of physiological stress responses. This reduction in physiological responding to other stimuli associated with the original transgression (e.g., interacting with the transgressor) is based upon McEwen's second pattern of allostatic overload responding. Another possible relation between forgiveness and allostatic load may occur via recovery from a physiologically-arousing transgression. A person with a greater tendency to forgive may engage in the process of forgiveness very soon after a transgression, thus facilitating physiological recovery from the stressor (McEwen's third pattern of allostatic overload). A third possibility is that a predilection to forgive attenuates acute physiological responding to stressful transgressions. Over time, lower stress responses to interpersonal transgressions would mean a lower overall allostatic load. 


\section{The Physiology of Forgiveness}

Although the literature examining the association between forgiveness and health is of recent origin (Lawler, 2005), a few studies have begun to examine the relation between forgiveness and the measures of autonomic arousal, the purported mechanism linking forgiveness with positive health outcomes (e.g., Lawler, et al., 2005; Witvliet, Ludwig, \& Vander Laan, 2001), and an understanding of the physiological effects of forgiveness is necessary in understanding the link between forgiveness and health. Perhaps the most informative of these studies was conducted by Lawler et al. (2003) with a sample of 44 men and 64 women undergraduate students. These researchers investigated blood pressure, heart rate, skin conductance responses (SCR) and forehead electromyography (EMG) responses to interviews in which participants recalled two interpersonal transgressions, one perpetuated by a parent and one perpetuated by a close friend or partner. Results demonstrated that women who reported higher trait forgiveness for a parental transgression had lower systolic blood pressure (SBP) reactivity. Also, diastolic blood pressure (DBP) decreased over the course of the interview for participants who reported forgiving their parental transgressor. EMG responses showed the same pattern as DBP responses. Mean arterial pressure (MAP) analyses also revealed that persons who were more forgiving had lower reactivity relative to persons who were less likely to forgive a transgression. A two minute recovery period following the interview revealed that women who were high in trait forgiveness and also reported greater forgiveness of their parent for the transgression they discussed in the interview displayed faster DBP and MAP recovery. Men who reported higher trait forgiveness displayed lower overall DBP and MAP over the 2 measurements during the recovery period. No heart rate differences were found. 
When participants were interviewed concerning a transgression on the part of a friend or romantic partner, the pattern of results was less remarkable except for DBP and MAP during the recovery period. Over the course of the recovery period, persons with a higher reported trait forgiveness displayed more rapid DBP recovery, and women of higher trait forgiveness displayed more rapid MAP recovery than women of lower trait forgiveness. The results of the Lawler et al. (2003) study suggest that DBP recovery is the most consistent forgiveness-related finding in a situation that involves an interpersonal transgression.

A second investigation specific to the physiology of forgiveness and akin to the Lawler et al. study was a study conducted by Witvliet, Ludwig, and Vander Laan in 2001. This study took a microscopic look at physiological reactions to imagery of forgiveness or unforgiveness scripts over the course of several 16-second trials. Participants in this study consisted of 36 men and 35 women undergraduates. Results indicated that unforgiving imagery, in contrast to forgiving imagery, elicited significantly higher heart rate, MAP, and EMG reactivity during the imagery period. Increased physiological activity was also observed during the recovery period for all measurements except for MAP. Remarkably, these significant differences were observed over the course of a few seconds of imagery, suggesting that ruminating in an unforgiving manner for even a short period of time resulted in increased physiological arousal. Assuming that this elevated arousal is maintained for long periods of time among chronic grudge-holders, it is not surprising that a lack of forgiveness could be harmful to health. Short time intervals in this study may also explain the lack of MAP recovery, as the body may require more than a few seconds of exposure to memories of forgiveness or unforgiveness to decrease MAP.

A recent study by Friedberg, Suchday, and Shelov (2006) corroborated the link between forgiveness and elevated DBP reactivity initially observed by Lawler et al. (2003) with a group 
of 82 women and 17 men with a mean age of 33.8 years. Friedberg et al. found lower DBP at rest and a quicker DBP recovery for persons with higher trait forgiveness following anger recall and serial subtraction stressors. No differences were observed between high and low trait forgiveness groups on measures of heart rate, SBP, cardiac output, total peripheral resistance, or DBP during the stressor tasks.

Although not specifically examining the relation between forgiveness and measures of autonomic reactivity, Huang and Enright (2000) contributed to this body of literature using a developmental model of forgiveness similar to Kohlberg's levels of moral reasoning. According to this developmental perspective, people engage in forgiveness for various reasons, with lower level reasoning associated with restitution and revenge, mid-level reasoning associated with forgiving because others expect them to forgive, and upper level reasoning associated with desires for social harmony and love of others. They compared a matched sample of Taiwanese persons who were at forgiveness level 4 (forgiving because religion demands it) with those at level 6 (forgiving for unconditional love). While these authors were not primarily interested in reactivity and forgiveness, they collected blood pressure recordings while participants were responding to timed questions concerning their typical day (a resting assessment) and an interpersonal transgression. Although no differences were found between groups during the resting session, significant differences in SBP were found between level 4 and 6 participants during the first minute of discussion concerning the interpersonal transgression. Level 4 participants were found to have increased SBP from rest to transgression-reporting period, but Level 6 participants showed no change in SBP from rest to transgression-reporting.

These four recent studies provide evidence for a link between measures of autonomic arousal and forgiveness. Although the reduced physiological arousal among forgiving persons 
has been evidenced across multiple measures of autonomic functioning, the most consistent findings have been observed during diastolic blood pressure recovery periods. The lack of an association between forgiveness and heart rate responding has also been consistently reported. These studies represent different methods and experimental procedures, but they all involved recounting an interpersonal transgression in the laboratory setting. Although these studies provide insight into what occurs during the ruminative component of unforgiveness that follows transgressions, they do not demonstrate what occurs immediately following an actual interpersonal transgression among forgiving and non-forgiving persons. By definition, forgiving and non-forgiving persons engaged in differing responses to the original transgressions that may have occurred weeks, months, or even years before they were asked to recall them in the laboratory. In essence, the methods used in previous studies have examined the outcomes of forgiveness, but have yielded very little information about the physiological responses occurring during the process of forgiveness. In order to examine physiological responses as the process of forgiveness is occurring, it is important for laboratory studies to observe physiological activity during and following an actual transgression. While measuring reactivity to a live laboratory transgression in a controlled environment is likely to provide the data necessary to gain a better understanding of the influence of forgiveness on physiological responding, it is difficult to create realistic interpersonal transgressions that could be conducted in laboratory settings. For example, while one could invite couples to the laboratory so that physiological measures could be made while the partners resolved a betrayal either through forgiveness of the transgression or dissolution of the relationship, this approach would be very difficult due to the (a) lack of control regarding the type and intensity of dialogue used during the interaction; and (b) the variable length of time required to work through the process of forgiveness. In order to overcome these 
obstacles and still capture the physiology of forgiveness while it is happening, the current study employed a standardized and relatively minor transgression often used in applied psychophysiological research: harassment by the experimenter (e.g., Burns, Bruehl, \& Cacares, 2004; García-León, Robles, \& Vila, 2003; Miller, et al., 1998). While the severity of the transgression associated with harassment from an unknown experimenter is minor compared to acts of betrayal in ongoing relationships, harassment is well known to elicit substantial cardiovascular and emotional reactions in comparison to completing experimental tasks without harassment (e.g., Anderson et al., 2006; Smith, Cranford, \& Green, 2001; Burns, Evon, \& StrainSaloum, 1999). As such, this method enables the measurement of physiological response to a brief transgression and the rate of recovery from it, which may differ among persons engaging in forgiveness and those who are not.

The Role of Apology in Forgiveness

Many studies have found evidence for the link between forgiveness and apology (e.g., Bachman \& Guerro, 2006; Darby \& Schlenker, 1982; Enright, Santos, \& Al-Mabuk, 1989; McCullough, Worthington, \& Rachal, 1997), to the degree that apology is considered one of the most effective forms of resolving interpersonal conflicts (Takaku, 2001). Two major theories of why apologies work and what makes an apology effective have been proposed. One theory, states that apologies facilitate forgiveness by altering the perception of the transgression from seeing the transgressor's behavior as the result of a dispositional trait to seeing the behavior as occurring as a result of environmental influences (e.g., Weiner et al., 1991). When a transgressor apologizes, the "victim" is less likely to perceive the transgressor as a "bad" person, but rather that the transgressor is a decent person who misbehaved due to environmental factors (e.g., was misinformed, was under stress, or had no choice). In brief, forgiveness of a transgression 
involves the victim's adherence to the fundamental attribution error. From a related perspective, McCullough and colleagues (e.g., McCullough et al, 1998) believe that apologies promote forgiveness because they enable the victim to experience empathy for the transgressor. Recognition of the transgressor's guilt and remorse for the transgression is purported to increase empathy on the part of the victim and move them towards forgiveness and away from grudgeholding and revenge-seeking.

Regardless of whether apology promotes forgiveness through alterations in attributions or empathy, it is clear that apologies increase forgiveness responses. This makes apology a potent, yet simple, manipulation that could easily be introduced in a laboratory setting that would increase the probability of observing forgiveness. However, no published studies have investigated the influence of apology-moderated forgiveness on physiological reactivity. In a related area, however, Anderson, Linden, and Habra (2006) investigated the influence of apology on physiological reactivity to stress, recovery from stress, and trait hostility. Participants were harassed as they performed a serial subtraction task (sex of the harasser was not reported) while heart rate and blood pressure were measured. Some of the participants received an apology from the harasser while others received no attempt at apology on the part of the harasser. Results indicated that the influence of apology on SBP recovery depended upon the hostility level of the participant. Persons who reported that they were high in hostility exhibited a quicker SBP recovery during a 10-minute recovery period if they received an apology than those who did not receive an apology. Comparable effects were not observed among participants with either low or moderate levels of hostility. The Anderson et al. (2006) study provides evidence that a genuine apology facilitates SBP recovery from a stress-evoking task among high hostile people. 
The primary purpose of the current study was to measure cardiovascular reactivity and recovery to a live transgression (as opposed to a recalled transgression) in order to determine the influence of forgiveness on cardiovascular functioning. Based on the previous literature reviewed above, it was hypothesized that DBP recovery would occur more quickly among persons who were more forgiving in comparison to those with lower trait forgiveness scores. The current study also sought to investigate means of facilitating forgiveness through apology. Based on Anderson and colleagues' (2006) work with apology and hostility, it was hypothesized that apologizing to participants after an interpersonal transgression on the part of the experimenter would facilitate a more rapid cardiovascular recovery than those participants not receiving an apology. Sex was also considered as a factor in this study as men and women may differ in their forgiveness behaviors.

\section{Method}

\section{Participants}

Seventy nine participants (29 Men and 50 Women) between the ages of 18 and 24 (inclusive) were recruited from various psychology classes at West Virginia University from the spring 2008 through the spring 2009 semesters. The SONA system was used to recruit participants. The SONA system is an online experimental data management system that is compliant with all federal and WVU IRB regulations. The system allows for the confidential collection of questionnaire data and provides a means for participants to schedule participation in laboratory-based studies. Power analyses were conducted based upon the study reported by Anderson, Linden, and Habra (2006), which used a similar procedure to this proposed study. Although the previous study investigated the effects of apology on individuals with various levels of hostility, hostility is typically inversely related to forgiveness and health-related factors 
(Berry et al., 2005; Lawler et al., 2003) and their study provides the best available estimate for determining effect size. According to the power analysis performed using GPower (Faul et al., 2007), a total sample size of 80 provided adequate power (.93) to detect group differences using the 2 X 2 X 2 design used in this study. Observed power for recovery analyses involving Forgiveness Level in this study was somewhat lower than pre-study estimates (ranging from .066 to .528), though analyses with relatively low power yielded significant results. Participants were excluded if they smoked or used smokeless tobacco daily, had any chronic major health problems (e.g., heart disease, cancer, lung disease), or if they took medications that directly influenced heart rate or blood pressure (e.g., beta blockers, anxiolytics). Participants were asked to refrain from using caffeine or alcohol or exercising vigorously for two hours prior to the experiment. Verbal confirmation was elicited from the participant to confirm that they had refrained from engaging in these confounding behaviors before the experimental session.

\section{Experimental Design}

This study consisted of first selecting a sub-sample of participants who were high and low in forgiveness from a larger study measuring numerous psychosocial and demographic variables. Participants were selected if they scored in approximately the top or bottom $33 \%$ of the distribution of scores on the Forgiving Personality Inventory (Drinnon, Jones, \& Lawler, 2000). Distributions were calculated separately for men and women. Other questionnaires used in the larger study were the Cook-Medley Hostility Questionnaire (Cook \& Medley, 1954), Heartland Forgiveness Scale (Thompson \& Synder, 2003), Kentucky Inventory of Mindfulness Skills (Baer, Smith, \& Allen, 2004), Relationship Questionnaire (Bartholomew \& Horowitz, 1991), Bem Sex-Role inventory-12 (Fernández, Ángeles, \& Del Olmo, 2006), and an item assessing spirituality. 
This study employed a $2 \times 2 \times 2$ between subjects design. The factors were Forgiveness Level (High, Low) determined by scores on the Forgiving Personality Inventory, Apology Condition (Apology, No Apology), and Sex (Men, Women). Primary dependent variables were cardiovascular measures of heart rate, blood pressure, and mean arterial pressure. Secondary variables were measures of affective reactivity and recovery as per participant report on the Multiple Affect Adjective Checklist-Revised (Zuckerman \& Lubin, 1985).

\section{Experimental Measures}

Demographics. A demographics questionnaire (see Appendix A) was used to assess age, sex, the presence of any health problems or medications that may affect the cardiovascular system, and measures of health behaviors (e.g., smoking, alcohol use, exercise behaviors).

Cardiovascular measures. Heart rate was measured via a Polar heart rate monitor model RS800 (Lake Success, New York). This device functions by sending ECG signals detected by a sensor strapped around the participants' chest to a wristwatch receiver positioned in an adjacent room. The wristwatch was directly connected to a computer where it was monitored by the experimenter during data collection. An Industrial and Biomedical Sensors, Inc. SD-700A automated sphygmomanometer (Waltham, MA) was used to measure systolic, diastolic, and mean arterial pressure. This device employs an occluding cuff that contains a microphone for detecting Korotkoff sounds. The automated cuff was positioned over the brachial artery in the participant's left arm. Inflation and deflation of the cuff and detection of Korotkoff sounds was controlled electronically and blood pressure values were displayed digitally and recorded by the experimenter.

Forgiving Personality Inventory. The FPI (see Appendix B) is a 33-item measure with each item rated on a 5-point Likert scale. This measure is designed to assess trait forgiveness and 
has been demonstrated to possess good internal consistency reliability with a coefficient alpha of .93 and an inter-item correlation of .30 . This measure also demonstrates good test-retest reliability with a correlation of .86 over a period of two months (Drinnon, Jones, \& Lawler, 2000; Lawler et al., 2003).

Multiple Adjective Affect Checklist - Revised. The MAACL-R (see Appendix C) consists of a list of 66 adjectives that is capable of measuring state or trait affect dependent upon the instructions given (Zuckerman \& Lubin, 1985). Participants were asked to check the boxes that corresponded to how they felt during the task they just performed and at rest when they first entered the laboratory. Adequate reliability and validity have been demonstrated for this instrument and the shorter version used in this study has been shown to be equivalent to the longer version, with correlations between subscales of the two forms ranging from $.84-.94$ (Lubin et al. 2001). The MAACL-R consists of 5 subscales; Anxiety, Depression, Hostility, Positive Affect, and Sensation Seeking. The average internal consistency reliability score for the 5 subscales was .88 for the short form, which did not significantly differ from the long form (Lubin et al. 2001). This instrument was chosen for this study specifically because of its ability to detect both positive and negative affect in response to the laboratory stress condition. Four of the five subscales were chosen for analysis because of their relation to the types of interpersonal interactions used in this study. These include the Anxiety, Depression, Hostility, and Positive Affect subscales.

Modified Transgression Related Interpersonal Measure. This study used a modified version of the TRIM (see Appendix D) originally developed by McCullough (McCullough \& Witvliet, 2002) to assess state forgiveness during the laboratory protocol. The TRIM is a 12-item Likert scale measure which contains an Avoidance and a Revenge subscale. The internal 
consistencies of these subscales have been reported to be .86 and .90 , respectively. Test-retest reliabilities have been reported to range from .41 to .65 for the two subscales (McCullough et al., 1998), which is not unusual for state measures. The modified version of the TRIM used in this study was developed in a previous psychophysiological study (Hernandez, Larkin, \& Whited, 2009) and was modified to refer to the experimenter instead of a transgressor with whom the participant had a history. In this study, the internal consistency reliability coefficients of the modified TRIM were .91 for both the Avoidance and Revenge subscales and .94 for the total TRIM score.

Post-Experimental Questionnaire The post-experimental questionnaire (see Appendix E) consisted of 6 questions. The first two questions assessed the participant's report of their reactivity and their familiarity with the task. The final four questions assessed the participant's feelings towards the experimenter in order to determine if providing an apology resulted in a more favorable rating of the experimenter.

\section{Procedure}

Participants completed questionnaires online and were invited via email to come into the lab according to their scores on the FPI. Figure 1 graphically displays the laboratory portion of the experimental procedure. Upon entering the laboratory, participants had the study explained to them by the experimenter and were asked to sign approved informed consent and HIPAA authorization forms. The experimenter was dressed in a white lab coat and behaved in a cold, professional, manner and avoided excessive conversation with the participants until their sessions were complete. For the purposes of this study, a male experimenter was used for 14 men and 25 women, and a female experimenter was used for the remaining 15 men and 25 women. The experimenter measured the participants' height and weight and asked if they had refrained 
from alcohol, tobacco, caffeine, and vigorous physical activity for 2 hours prior; all participants reported compliance. Participants were instructed on how to position the Polar monitor and left alone in the monitoring room to strap the Polar monitor around their chest and apply electrode gel. When participants were finished, they alerted the experimenter who then tested to ensure that the monitor was functioning properly. The experimenter then attached the occluding cuff. The experimenter informed participants that they should remain seated with both their feet flat on the floor for 15 minutes of a Rest Period. After 8 minutes into the Rest Period, participants were notified by the experimenter that blood pressure measurements would begin. Blood pressure measurements were taken every 2 minutes for the remainder of the Rest Period. After the Rest Period elapsed, the participants completed the MAACL-R to report how they were currently feeling to establish a measure of resting affect.

Participants were then instructed by the experimenter on the task to be performed during the subsequent Task Period. The task was 5 minutes in duration and involved serial subtraction, a common stressor in cardiovascular reactivity studies. Participants were asked to subtract from 9000 by $7^{\mathrm{s}}$ and report the answer aloud. Participants were informed their answers would be recorded in order to make them more aware that they were being evaluated. As they began counting at minute 0 , blood pressure measurement was initiated and followed every 2 minutes. Thirty seconds after the beginning of the task period, the first harassment was administered by the experimenter through the microphone in a room adjacent to the participant. Two more harassing prompts were administered following the next two blood pressure measurements. These prompts were taken from Anderson, Linden, and Habra, (2006). For the first prompt, the experimenter stated 'Look [participant name] you're subtracting way too slow. You've got to do it much faster. Begin again at 8000." The second prompt was “[participant name], you're still too 
slow and also inaccurate. This can't be your best. Now try it again from 6190." The final prompt was "You're obviously not good enough at doing this, now try harder. Keep going from 5066." For the second and third prompt, the numbers from which participants restarted were chosen specifically to maintain the difficulty of the task and to prevent them from establishing a pattern of counting.

After the Task Period, a second MAACL-R was administered and blood pressure measurements continued for an 11 minute Recovery Period. Within the first two minutes of the recovery period, the experimenter returned to collect the MAACL-R. At this time, the experimenter either apologized to the participant or simply collected the measure and informed the participant of the recovery period. Half of the participants received a scripted apology at that time. Participants were quasi-randomized to the Apology/No Apology groups based on a coin flip, and separate randomization took place for men and women. Participants were randomized to group during or before the study, depending on the distribution of participants between groups. For example, if the group of high forgiving females who received an apology was full, the next participant who was a high forgiving female would not receive an apology. The apology, also taken from Anderson et al. (2006), consisted of the experimenter stating, in person, "[participant name], I'm really sorry for being so rude to you a few minutes ago. If I upset you while you were counting, that is totally my fault. I was speaking to you that way on purpose as part of the experiment. But I do feel bad about this. I'm really much more courteous and professional. I'm sorry." A final MAACL-R was administered at the end of the Recovery Period.

After the recovery period, the experimenter removed the occluding cuff and left the monitoring room so participants could remove the Polar heart rate monitor. Participants then filled out the Modified TRIM and the Experiment Evaluation Survey. Participants were told that 
these surveys would be anonymous in order to give them the opportunity to express their feelings towards the experimenter. Without this deception, the participants may have been unlikely to express a lack of forgiveness of the experimenter for his transgression. When they were finished, participants were fully debriefed. First, the reason for the critical prompts was explained to the participants and an(other) apology was offered. Then, the reason for the study was explained as the experimenter reported that the investigation was aimed at understanding the benefits of apology among people with varying levels of trait forgiveness. Participants received extra credit in their psychology class and ten dollars in cash upon completion of the experimental protocol. They were also asked not to inform their classmates and friends about the purpose of the study. Results

\section{Data Reduction}

Prior to data reduction, blood pressure measurements that did not meet criteria established by Marler, Jacob, Lehoczky, and Shapiro (1988) were reviewed and considered for deletion. According to these criteria, a SBP of greater than 250 or a DBP of greater than 150 were excluded from analysis, along with a SBP of less than 70 or a DBP of less than 45 . A formula provided by the authors also was utilized to determine if the difference between the SBP and DBP (i.e., pulse pressure) was too small to be considered a valid measurement. Due to the fact that Marler and colleagues were working with ambulatory blood pressure measurements, their criteria for deletion are rather liberal. For this study, measurements were deleted and replaced with the mean of adjacent measures, as indicated, if the target measurement deviated significantly from adjacent measures. Some measures that were identified as suspect by Marler and colleagues' criteria were not deleted because they were internally consistent for the 
participant. Overall, 41 measurements of either SBP or DBP out of 2,054 were identified as measurement errors and replaced.

Heart rate data were cleaned using the Polar 810 i software set at a moderate filtering level as described in Wilson, Smith and Holmes (2007). This software replaces likely erroneous values typically observed when participants move excessively or the signal from the Polar Monitor is momentarily lost. A total of 2,024 measurements out of 148,910 (.014\%) were deleted as measurement errors and replaced.

Heart rate measurements were averaged across each minute for each time period of interest (Rest, Task, and each minute of the Recovery Period). Repeated measures analyses of variance were conducted to determine if cardiovascular measures (heart rate, SBP, DBP) were similar before combining the measures across the Rest and Task Periods. Results revealed that rest measurements did not differ for any blood pressure measure measurement at baseline (all $p$ values $>.05$ ), and regression lines for resting heart rate files were observed to have little to no slope at baseline.

Significant minute-to-minute differences were observed during the task period for heart rate, $F(4,308)=26.1, p<.001, \eta_{p}{ }^{2}=.253$ (See figure 2). Paired samples t-tests were used as post-hoc tests and revealed that participants' heart rates increased from minutes 1 to 2 to 3 to 4 (all $p$ values $<.01$ ) and then slowed in rate of increase as minute 4 did not differ from minute 5 $(p=.083)$. Significant measurement-to-measurement differences during the task period also were found for SBP, $F(2,156)=16.4, p<.001, \eta_{p}{ }^{2}=.174$, and DBP, $F(2,156)=3.73, p=.026, \eta_{p}{ }^{2}=$ .046. SBP measurements increased from the first to second to third measurement (Figure 3; all $p$ s $<.05)$, while DBP increased from measurements one to two, $t(1,78)=-2.05, p=.043$, but not from two to three, $t(1,78)=-.617, p=.539$ (Figure 4). 
While these results are interesting, and they demonstrate the efficacy of the harassments, heart rate measurements were combined across the task period for analysis in order to investigate the participants' reactions to the overall transgression as opposed to specific pieces of it. SBP, DBP, and heart rate also were averaged across the Rest period in order to condense the data for analysis, and MAP was calculated from condensed blood pressure averages. In order to obtain an equivalent number of measures during the Recovery periods, heart rate was averaged across adjacent minutes to yield measurements for minutes $1,3,5,7,9$, and 11 , which mirrors blood pressure recordings.

To condense recovery data, averaging across the entire Recovery Period would not preserve the changes in physiological arousal that took place over time. Calculating area under the recovery curve, however, provides a single value for the Recovery Period and allows for a molar analysis of recovery data which reduces the number of comparisons and conserves statistical power. A molecular analysis that investigates each minute of the Recovery Period was also performed, but could be questioned statistically due to the numerous univariate follow-up comparisons. Area under the curve was estimated by calculating excursions using the formula described in Neumann et al. (2004) and Friedberg et al. (2007). For the current study, the formula was:

Excursion $=(0.5 * 120) *(($ cardiovascular measure at recovery minute 1$)+(2 * \mathrm{CV}$ measure at recovery min 3$)+(2 * \mathrm{CV}$ measure at recovery min 5$)+(2 * \mathrm{CV}$ measure at recovery $\min 7)+(2 * \mathrm{CV}$ measure at recovery $\min 9)+(\mathrm{CV}$ measure at recovery min 11))-(CV measure at baseline*480). 
Participants with a larger area under the curve were considered to have a poorer recovery than persons with a lower area under the curve, due to the fact that reductions in physiological arousal result in less area.

\section{Participant Characteristics}

Screening of Forgiveness. Participants' were invited into the lab based on their scores on the Forgiving Personality Inventory. Participants numbering 1,690 were screened (535 Men and 1,155 Women) and 1,036 were invited to come into the laboratory to participate (309 Men and 727 Women; 567 High FPI and 469 Low FPI). The final sample consisted of 47 High FPI participants and 32 Low FPI participants, with scores ranging from 122 to 157 and 73 to 114 , respectively. Laboratory participants were selected from the top and bottom third of the FPI distribution within their sex. It was presumed that men and women would have disparate, but overlapping, FPI distributions and results from the screening sample supported this assumption. The mean (and standard deviation) FPI score for men in the screening sample was 116.0 (16.8) with a range of 68 to 165 , and the mean for women was 121.2 (17.3) with a range of 55 to 165 . For laboratory participants, FPI scores were generally in the higher range of the distribution (Men: $M=123.7, S D=19.5$, Range $=73-156$; Women: $M=124.5, S D=20.1$, Range $=90-157$ ), suggesting that persons higher in forgiveness were more likely to agree to participate in the laboratory portion of the study.

Due to the fact that the FPI distribution was recalculated at several times during the course of the study as more participants completed the screening questionnaires, the participants invited into the lab did not fall exactly within the extreme thirds of the entire screening sample distribution. Men categorized as low in trait forgiveness had scores in the bottom $37.7 \%$ of the distribution and men categorized as high in trait forgiveness had scores in the top $34.8 \%$ of the 
distribution. Women categorized as low in trait forgiveness had scores in the bottom $31.4 \%$ of the distribution and women categorized as high in trait forgiveness had scores in the top 37.1\% of the distribution. Differences in these percentages from $33.3 \%$ correspond to no more than 2 points on the FPI, and 2 participants (a low FPI man with a score of 110 and a high FPI woman with a score of 127) were responsible for the largest deviations from $33.3 \%$.

Demographics and potential covariates. Demographics are displayed in Table 1. Selected categorical demographic variables (i.e. sex, family history of hypertension, hormonal contraceptive use, sex of experimenter) were considered as potential covariates by a series of MANOVAs using all cardiovascular parameters (Rest, Task, Recovery) as dependent variables. Correlation coefficients were calculated between continuous potential covariates (i.e. BMI) and cardiovascular parameters.

Although sex was used in subsequent analyses because of suspected sex differences in Forgiveness Level, it was useful to know the raw influence of sex on cardiovascular activity. The MANOVA investigating sex differences supported using sex as a factor in subsequent SBP analyses, $F(3,75)=6.35, p=.001, \eta_{p}{ }^{2}=.20$. Men $(M=130.2 \mathrm{~mm} \mathrm{Hg}, S D=1.27)$ displayed a higher SBP than women $(M=121.9 \mathrm{~mm} \mathrm{Hg}, S D=1.66)$ during the Rest period, $F(1,77)=18.3$, $p<.001, \eta_{p}{ }^{2}=.19$, and this difference between Men $(M=139.8 \mathrm{~mm} \mathrm{Hg}, S D=2.18)$ and Women $(M=130.2 \mathrm{~mm} \mathrm{Hg}, S D=2.18)$ was present during the Task Period as well, $F(1,77)=$ $12.2, p=.001, \eta_{p}{ }^{2}=.14$. This difference was not present during the recovery period $F(1,77)=$ $0.00, p=.995, \eta_{p}{ }^{2}=.00$. Heart rate differences were not observed between men and women, $F(3$, $74)=2.45, p=.070, \eta_{p}{ }^{2}=.090$, nor were DBP differences observed, $F(3,75)=1.00, p=.40, \eta_{p}{ }^{2}$ $=.04$. It is worthy of note that even though multivariate testing did not demonstrate an effect of sex on heart rate, follow-up univariate analyses revealed a higher heart rate for women $(M=95.6$ 
bpm, $S D=2.26)$ than men $(M=87.4 \mathrm{bpm}, S D=2.94)$ during the Task period $F(1,76)=4.94, p$ $=.029, \eta_{p}^{2}=.061$.

The MANOVA investigating differences in cardiovascular factors related to family history of hypertension and the use of hormonal contraceptives did not support the use of these variables as covariates in subsequent analyses. Family history of hypertension was defined as reporting that a mother or father had hypertension with at least $75 \%$ certainty. Participants who reported an absence of hypertension or a lack of knowledge for both parents were considered not to have a family history. Family history of hypertension was not related to heart rate, $F(3,74)=$ $.297, p=.83, \eta_{p}{ }^{2}=.01, \mathrm{SBP}, F(3,75)=.57, p=.64, \eta_{p}{ }^{2}=.02$, or DBP, $F(3,75)=.02, p=.99$, $\eta_{p}{ }^{2}=.00$. Hormonal contraceptive use was also unrelated to $\mathrm{HR}, F(3,45)=1.17, p=.334, \eta_{p}{ }^{2}=$ .072 , SBP, $F(3,46)=1.43, p=.25, \eta_{p}{ }^{2}=.08$, and DBP, $F(3,46)=.51, p=.68, \eta_{p}{ }^{2}=.03$.

Significant correlations between BMI and cardiovascular indices revealed only one significant relation (Table 2), with BMI related to SBP at rest $(r=.38, p<.001)$. BMI was considered as a covariate in all subsequent SBP analyses, however, due to the fact that baseline SBP was used as a covariate in these analyses and BMI was related to SBP at baseline.

Sex of the experimenter was the final covariate considered. Due to the fact that participants may have reacted differently depending on their sex and the sex of the experimenter, 2 (Participant Sex) by 2 (Experimenter Sex) MANOVAs were performed for each cardiovascular measure. Heart rate analyses revealed no main effect of Experimenter Sex $F(3,72)=.90, p=$ $.45, \eta_{p}{ }^{2}=.04$ or an Experimenter Sex by Participant Sex interaction, $F(3,72)=.14, p=.93, \eta_{p}{ }^{2}=$ .01. Similarly, SBP did not differ based on Experimenter Sex, $F(3,73)=.51, p=.68, \eta_{p}{ }^{2}=.02$, or an interaction between Experimenter and Participant Sex, $F(3,73)=.35, p=.79, \eta_{p}{ }^{2}=.01$. Also, DBP analyses revealed no main effect of Experimenter Sex, $F(3,73)=.44, p=.72, \eta_{p}{ }^{2}=$ 
.02 , or an interaction with Participant Sex, $F(3,73)=1.86, p=.14, \eta_{p}{ }^{2}=.07$. Sex of the experimenter was not used as a covariate in this study.

\section{Resting Cardiovascular Measures}

A series of $2 \times 2 \times 2$ [Forgiveness Level x Apology Condition x Sex] analyses of variance (ANOVAs) were conducted to determine the relation between forgiveness level and sex on each cardiovascular factor (HR, SBP, DBP, and MAP) at rest. Although the apology did not occur until later in the experiment, Apology Condition was included in these analyses to determine if apology groups differed prior to receiving the apology. If any rest analyses yielded an effect of apology it would indicate that the apology groups differed at baseline and randomization did not serve to eliminate these differences. Analysis of SBP using BMI as a covariate revealed a significant main effect for Sex, $F(1,70)=15.1, p<.001, \eta_{p}{ }^{2}=.18$, with men displaying higher covariance adjusted SBPs at rest $(M=122.1 \mathrm{~mm} \mathrm{Hg}, S E=1.85)$ than women $(M=113.4 \mathrm{~mm} \mathrm{Hg}$, $S E=1.24$ ). No other main effects or interactions were significant for SBP (see Appendix F-1). No significant main effects or interaction effects were found for Forgiveness Level, Apology, or Sex for resting DBP, MAP, or heart rate (for ANOVA summary tables see appendix F-1).

\section{Cardiovascular Reactivity to Mental Stress}

A series of $2 \times 2 \times 2$ [Forgiveness Level x Apology Condition x Sex] analyses of covariance (ANCOVAs) were conducted to determine the relation between forgiveness level and sex on each cardiovascular factor (HR, SBP, DBP, and MAP) during the serial subtraction task. Resting measurements were used as covariates in these analyses and Apology Condition, as with the analyses of the rest period, was included to determine if apology groups differed prior to receiving the apology. BMI was also included as a covariate for SBP analyses. There were no 
significant main effects or interaction effects regarding cardiovascular reactivity differences in this study (all $p$ values $>.05$; see Appendix F-2).

\section{Cardiovascular Measures During Recovery}

A series of $2 \times 2 \times 2$ (Forgiveness Level x Apology Condition x Sex) ANCOVAS were conducted to determine the relation between forgiveness level, apology condition, and sex on the area under the curve for each cardiovascular factor (HR, SBP, DBP, and MAP), controlling for resting cardiovascular measures. BMI was also included as a covariate for SBP analyses. For significant findings using area under the curve as a dependent variable, cardiovascular activity across the recovery period was further explored using 2 × 2 × 2 × 6 (Forgiveness Level $\mathrm{x}$ Apology Condition x Sex x Minute) mixed factors ANCOVAs. These analyses are a more molecular investigation of the effects of Apology and Forgiveness level, but are subject to statistical limitations due to the number of follow-up analyses involved and the sample size reduction inherent among these follow-up analyses.

Heart rate. Analyses of heart rate revealed no influence of Forgiveness Level, Sex, or Apology on heart rate recovery (see Appendix F-3a).

Systolic blood pressure. SBP analyses revealed no influence of Forgiveness Level, Sex, or Apology on SBP recovery (all $p$ values > .05; see Appendix F-3b).

Diastolic blood pressure. Analyses of DBP recovery using area under the curve as the dependent variable (See Appendix F-3c) revealed a significant effect of Forgiveness Level, F(1, $70)=4.88, p=.03, \eta_{p}{ }^{2}=.06$, with High FPI persons exhibiting better recovery $(M=8,460.1 \mathrm{~mm}$ $\left.\mathrm{Hg}^{*} \mathrm{sec}, S E=497.5\right)$ than Low FPI persons $(M=10,370.0 \mathrm{~mm} \mathrm{Hg} * \mathrm{sec}, S E=706.3)$. A Sex x Apology Condition interaction, $F(1,70)=9.56, p<.01, \eta_{p}{ }^{2}=.12$, was also observed which demonstrated that men and women responded in opposite manners to the apology. When men 
received an apology their recovery was poorer $\left(M=10,020.0 \mathrm{~mm} \mathrm{Hg}{ }^{*} \mathrm{sec}, S E=831.7\right)$ than men who did not receive an apology $\left(M=7,382.1 \mathrm{~mm} \mathrm{Hg}^{*} \mathrm{sec}, S E=803.2\right), F(1,26)=5.13, p=.03$, $\eta_{p}{ }^{2}=.16$. This is in contrast to women who did not receive an apology $(M=10,440.0 \mathrm{~mm}$ $\left.\mathrm{Hg}^{*} \mathrm{sec}, \mathrm{SE}=736.5\right)$, as they displayed a poorer recovery in comparison to women who did receive an apology $\left(M=8,314.1 \mathrm{~mm} \mathrm{Hg}^{*} \mathrm{sec}, S E=733.6\right), F(1,47)=8.71, p<.01, \eta_{p}{ }^{2}=.16$.

Mixed factors ANOVA analyses of DBP revealed a significant 4-way interaction between Forgiveness Level, Apology Condition, Sex, and Minute during the recovery period, $F(5,350)=3.47, p<.01, \eta_{p}{ }^{2}=.05$ (see Appendix F-3d). To further explore this interaction, Forgiveness Level x Apology Condition x Sex ANOVAs were conducted to investigate each minute of the recovery period (see Appendix F-4a for ANCOVA tables and Table 3 for summary of significant DBP findings). Although the Forgiveness Level x Sex x Minute and Sex x Apology interactions and main effect for Forgiveness Level were also significant, further analysis was only done on the significant 4-way interaction, because all factors were subsumed into this interaction effect.

At Minute 1, a significant Apology Condition by Sex interaction was observed, $F(1,70)$ $=8.73, p<.01, \eta_{p}{ }^{2}=.111$. Further exploration of this interaction revealed that Apology Condition affected both men, $F(1,26)=4.44, p=.04, \eta_{p}{ }^{2}=.15$ and women, $F(1,47)=6.65, p=$ $.01, \eta_{p}{ }^{2}=.12$, but in opposite directions (See Figure 5). Men who received an apology displayed a higher DBP at recovery minute $1(M=67.2 \mathrm{~mm} \mathrm{Hg}, S E=2.47)$ than men who did not receive an apology $(M=60.0 \mathrm{~mm} \mathrm{Hg}, S E=2.38)$, whereas women who received an apology displayed a lower DBP $(M=63.3 \mathrm{~mm} \mathrm{Hg}, S E=2.33)$ than women who did not receive an apology $(M=$ $71.9 \mathrm{~mm} \mathrm{Hg}, S E=2.42)$. 
At Minute 3, a significant Forgiveness Level x Apology Condition x Sex interaction was observed for DBP, $F(1,70)=5.55, p=.02, \eta_{p}{ }^{2}=.07$. Follow-up analyses investigated the relation between Forgiveness Level and Apology Condition for each sex (see Appendix F-5a). For men, there was no significant effect of Apology Condition or Forgiveness on DBP (all $p \mathrm{~s}>$ $.05)$. For women, however, there was a significant interaction between Forgiveness Level and Apology Condition $F(1,45)=5.97, p=.02, \eta_{p}{ }^{2}=.12$. Further analyses indicated that presence of apology did not influence low forgiving women's DBPs, $F(1,21)=.20, p=.66, \eta_{p}{ }^{2}=.01$, but apology did influence DBPs of high forgiving women, $F(1,23)=8.75, p<.01, \eta_{p}{ }^{2}=.28$. These results indicated that only high forgiving women displayed a lower DBP at minute 3 after receiving an apology (see Figure 6).

Although no significant main effects or interactions were observed at Minute 5 (see Appendix F-4a), a significant 3-way interaction was observed at Minute 7 of the recovery period, $F(1,70)=5.47, p=.02, \eta_{p}{ }^{2}=.07$. Follow-up analyses investigated the relation between Forgiveness Level and Apology Condition for each sex (see Appendix F-5b). Although there were no significant main effects or interactions for men, a significant main effect of Apology Condition on DBP was observed for women during recovery Minute $7, F(1,45)=9.46, p<.01$, $\eta_{p}{ }^{2}=.17$ (see Figure 7). Women who received an apology displayed lower DBPs $(M=63.7 \mathrm{~mm}$ $\mathrm{Hg}, S E=1.4)$ than women who did not receive an apology $(M=70.0 \mathrm{~mm} \mathrm{Hg}, S E=1.5)$. The main effect of Forgiveness Level also approached significance. High forgiving women exhibited lower DBPs $(M=64.9 \mathrm{~mm} \mathrm{Hg}, S E=1.42)$ than low forgiving women $(M=68.8 \mathrm{~mm} \mathrm{Hg}, S E=$ $1.49)$.

While no significant main effects or interactions were observed at Minute 9, all 2-way interactions were significant at Minute 11, and the 3-way interaction approached significance, 
$F(1,70)=3.60, p=.06, \eta_{p}{ }^{2}=.05$, (see Appendix F-4a). Due to the complex nature of interpreting 3 overlapping 2-way interactions, the 3 -way interaction was broken down via posthoc tests (see Appendix F-5c). Within the sexes, men who received an apology displayed higher DBPs $(M=72.6 \mathrm{~mm} \mathrm{Hg}, S E=3.3)$ than men who did not receive an apology $(M=61.9 \mathrm{~mm} \mathrm{Hg}$, $S E=2.8), F(1,24)=6.09, p=.02, \eta_{p}{ }^{2}=.20$. A significant main effect of Apology Condition was also observed for women, except in the opposite direction, $F(1,45)=6.73, p=.01, \eta_{p}{ }^{2}=$ .13; women who received an apology displayed lower DBPs $(M=64.8 \mathrm{~mm} \mathrm{Hg}, S E=1.3)$ than women who did not receive an apology $(M=69.5 \mathrm{~mm} \mathrm{Hg}, S E=64.7$; see Figure 8).

Mean arterial pressure. MAP recovery area under the curve analyses (See Appendix F3e) revealed a significant effect of Forgiveness Level, $F(1,70)=3.96, p=.05, \eta_{p}{ }^{2}=.05$, with High FPI persons exhibiting better recovery $(M=8,460.1 \mathrm{~mm} \mathrm{Hg} * \mathrm{sec}, S E=497.5)$ than Low FPI persons $(M=10,370.0 \mathrm{~mm} \mathrm{Hg} * \mathrm{sec}, S E=706.3)$. A Sex x Apology Condition interaction, $F(1,70)=9.63, p<.01, \eta_{p}{ }^{2}=.12$, was also observed which demonstrated that men and women responded in opposite manners to the apology. When men received an apology their recovery was poorer $(M=11,970.0 \mathrm{mmHg} * \mathrm{sec}, S E=557.2)$ than men who did not receive an apology $(M$ $=9,955.0 \mathrm{mmHg} * \mathrm{sec}, S E=538.2), F(1,26)=6.71, p=.02, \eta_{p}{ }^{2}=.20$. In contrast, women who did not receive an apology $(M=12,830.0 \mathrm{~mm} \mathrm{Hg} * \mathrm{sec}, S E=590.3)$ displayed a poorer recovery in comparison to women who did receive an apology $(M=10,660.0 \mathrm{~mm} \mathrm{Hg} * \mathrm{sec}, S E=567.1)$, $F(1,47)=7.00, p=.01, \eta_{p}^{2}=.13$.

Similar to DBP, mixed factors ANOVA analyses of MAP lending a more molecular analysis of the recovery period, revealed a significant 4-way interaction between Forgiveness Level, Apology Condition, Sex, and Minute of the recovery period, $F(5,350)=2.41, p=.04, \eta_{p}{ }^{2}$ $=.03$ (see Appendix F-3f). To further explore this interaction, Forgiveness Level x Apology 
Condition $\mathrm{x}$ Sex ANCOVAs were conducted to investigate each minute of the recovery period (see Appendix F-4b for ANCOVA summary tables and Table 3 for summary of significant findings).

At Minute 1, a significant Apology Condition x Sex interaction was observed for MAP, $F(1,70)=11.66, p<.001, \eta_{p}{ }^{2}=.14$. Further exploration of this interaction revealed Apology Condition influenced men, $F(1,26)=10.89, p<.013, \eta_{p}{ }^{2}=.29$, and women, $F(1,47)=4.88, p=$ $.03, \eta_{p}{ }^{2}=.09$, differently (See Figure 9). When men received an apology they displayed a higher $\operatorname{MAP}(M=93.5 \mathrm{~mm} \mathrm{Hg}, S E=1.86)$ than if they did not receive an apology $(M=84.9 \mathrm{~mm} \mathrm{Hg}$, $S E=1.79)$. Conversely, when women received an apology $(M=85.1 \mathrm{~mm} \mathrm{Hg}, S E=1.89)$ they displayed a lower MAP than when they did not receive an apology $(M=91.1 \mathrm{~mm} \mathrm{Hg}, S E=$ 1.97).

At Minute 3, a significant Forgiveness Level x Apology Condition x Sex interaction was observed for MAP $F(1,70)=5.36, p=.02, \eta_{p}{ }^{2}=.07$ (see Appendix F-4b). Follow-up ANCOVAs investigated the relation between Forgiveness Level and Apology Condition for each sex (see Appendix F-6). For men, there was no significant effect of Apology Condition or Forgiveness on MAP (all $p \mathrm{~s}>.05$ ). For women, however, there was a significant interaction between Forgiveness Level and Apology Condition, $F(1,45)=5.33, p=.03, \eta_{p}{ }^{2}=.11$,. Further analyses indicated that women with low forgiveness levels did not differ in MAP based on apology, $F(1,21)=.118, p=.74, \eta_{p}{ }^{2}=.01$, but high forgiving women did differ, $F(1,23)=8.56$, $p<.01, \eta_{p}{ }^{2}=.27$. These results indicated that high forgiving women displayed lower MAPs at Minute 3 when receiving an apology $(M=77.8 \mathrm{~mm} \mathrm{Hg}, S E=2.09)$ in comparison to low forgiving women $(M=86.1 \mathrm{~mm} \mathrm{Hg}, S E=1.93$; see Figure 10). 
Although Minutes 5, 7, and 9 revealed no significant main effects or interactions (see Appendix F-4b), Minute 11 revealed an Apology Condition by Sex interaction $F(1,70)=17.11$, $p<.001, \eta_{p}{ }^{2}=.206$. There was no significant difference in the effect of apology for men, although the relation approached significance in the same direction as it did in minute $1, F(1,26)$ $=4.10, p=.05, \eta_{p}{ }^{2}=.14$. When women received an apology, however, their MAP was lower $(M$ $=85.1 \mathrm{~mm} \mathrm{Hg}, S E=892)$ than when they did not receive an apology, $(M=91.1 \mathrm{~mm} \mathrm{Hg}, S E=$ 1.97), $F(1,47)=4.88, p=.03, \eta_{p}^{2}=.09($ see Figure 11$)$.

\section{Measures of Affect}

A series of ANOVAs were conducted to investigate the relation between Forgiveness Level, Apology Condition, and Sex on measures of affect; Anxiety, Depression, Hostility, and Positive Affect (For means and standard deviations see Table 4). ANOVAs for each subscale of the MAACL-R following the Rest Period revealed only an effect of Sex, $F(1,70)=3.95, p<.01$, $\eta_{p}{ }^{2}=.19$ on report of Positive Affect. Men reported higher Positive Affect at Rest $(M=7.69, S E$ $=4.03)$ than women $(M=4.28, S E=2.52$; See Appendix F-7a). For the second MAACL-R, which directly followed the task, initial levels of affect were included as covariates. Across all measures of affect, no significant differences were found (See Appendix F-7b).

For the final MAACL-R occurring at the end of the Recovery Period, significant effects were found for Depression, Hostility, and Positive Affect (See Appendix F-7c; For covariance adjusted means and standard errors see Table 4). Apology Condition, Forgiveness Level, and Sex interacted to influence depression, $F(1,70)=5.38, p=.02, \eta_{p}{ }^{2}=.07$, but simple main effects analyses did not reveal the nature of this interaction. Further exploration revealed the nature of the interaction; however these results should be regarded as tenuous due to limited statistical power. Residuals resulting from a regression analysis of the resting MAACL-R predicting the 
recovery MAACL-R were calculated and standardized to improve normality of the distribution. Analysis of these residualized change scores revealed a comparable 3-way interaction (See Appendix F-7d). Follow up simple main effects analyses demonstrated that Forgiveness Level interacted with Apology Condition among men $F(1,25)=4.45, p<.05, \eta_{p}{ }^{2}=.15$, but neither variable, alone or as an interaction, $F(1,46)=1.41, p=.24, \eta_{p}{ }^{2}=.03$, was significant among women. Mean comparisons demonstrated that men who received an apology did not differ based on Forgiveness Level $F(1,12)=.41, p=.53, \eta_{p}{ }^{2}=.03$; however, among men who did not receive an apology, Low Forgiveness men reported higher depression scores than men of High Forgiveness, $F(1,13)=4.99, p=.04, \eta_{p}^{2}=.28$.

Ratings of Hostility during the Recovery Period differed based on Apology Condition, $F(1,70)=5.52, p=.02, \eta_{p}{ }^{2}=.07$, and Forgiveness Level $F(1,70)=6.25, p<.01, \eta_{p}{ }^{2}=.10($ For covariance adjusted means and standard errors see Table 4). Persons who received an apology reported lower hostility $(M=.429, S E=.166)$ than persons who did not receive an apology $(M=$ $.955, S E=.150)$. Also, High FPI participants reported lower hostility $(M=.327, S E=.128)$ than Low FPI participants $(M=1.01, S E=.183)$. Forgiveness Level and Apology Condition did not interact, $F(1,70)=.991, p=.32, \eta_{p}{ }^{2}=.01$. Ratings of Positive Affect also varied based on Apology Condition, $F(1,70)=5.33, p=.02, \eta_{p}{ }^{2}=.07$, with persons who received an apology reporting a higher positive affect $(M=4.48, S E=.504)$ than persons who did not receive an $\operatorname{apology}(M=2.92, S E=.457)$.

\section{Measure of State Forgiveness}

The TRIM is typically used by asking a person to reflect on a past transgressor and fill out the measure with that specific person in mind. In the current study, participants were asked to complete the questionnaire in reference to the experimenter. A pair of $2 \times 2 \times 2$ ANOVAs 
investigated the influence of Apology Condition, Forgiveness Level, and Sex on the Avoidance and Revenge subscales of the TRIM (For means and standard deviations see Table 4). No main effects or interaction effects were significant for this measure (all $p$ values $>.05$; see Appendix F-8).

\section{Post Experimental Questionnaire}

The Post Experimental Questionnaire (Appendix E) was analyzed in the same manner as the TRIM using $2 \times 2 \times 2$ ANOVAs in order to look at each individual item and determine how participants perceived the task and what they thought of the experimenter's behavior during the experiment (For means and standard deviations see Table 4). Only one significant main effect was observed on analyses of the Post Experimental Questionnaire (all others p values > .05; see Appendix F-9). Apology affected participants' perception of how supportive the experimenter was after the math task was completed. Participants who received an apology considered the experimenter to be more supportive $(M=4.55, S D=.714)$ than those who did not receive an $\operatorname{apology}(M=3.00, S D=1.12), F(1,71)=48.3, p<.001, \eta_{p}^{2}=.405$.

\section{Discussion}

The purpose of this study was to provide a better understanding of the influence of forgiveness and apology on cardiovascular reactivity and recovery. Prior research supported the hypothesis that forgiveness influenced blood pressure reactivity and recovery, especially DBP recovery (Lawler et al., 2003; Witvliet et al., 2001). Prior research typically used scripts or anger recall as methods of re-visiting transgressions in the laboratory, but the current study is the first to use a live transgression that occurred in the laboratory and specifically investigated forgiveness. This provided the advantage of measuring physiology at the time when participants had the opportunity to forgive, as opposed to asking them to re-experience an earlier 
transgression. A second advantage is that it standardized the transgression so all participants had the same experience; severity of the transgression was not a confounding factor. If participants had been asked to recall a transgression, the severity of their recalled events may have varied from a sexual assault to a snide comment. The current study was also unique because it incorporated an apology for the aforementioned transgression, which had not been included in prior investigations of the physiology of forgiveness. As the current study captured the process of forgiveness from a period of time prior to the transgression, in response to the transgression, and following the transgression, the study protocol permitted the assessment of both participants' responses during the transgression (e.g., reactivity) and immediately following the transgression (e.g., recovery).

\section{Cardiovascular Reactivity and Forgiveness}

Reactivity differences in high and low forgiving participants did not emerge, which is in contrast to the work of Lawler et al. (2003) and Witvliet et al. (2001). This is likely due to the manner in which the transgression was experienced in the current study. Because a live transgression was utilized instead of a reflection on a historic one, participants did not have the opportunity to engage in the biopsychosocial changes that presumably take place during the process of forgiveness. If they had reflected on a historic transgression, those who had already engaged in the process of forgiveness, especially those with high levels of trait forgiveness may have exhibited lower reactions to its recollection than those who had yet to forgive. In contrast to previous work, the current study forced participants to engage in the process of forgiveness within the laboratory session in response to a 'new' interpersonal transgression. Using this approach, differences in reactivity between high and low forgiving participants were not really expected, as those participants who were able to forgive the transgression were not provided time 
to work through the process of forgiveness. If forgiveness was associated with reductions in cardiovascular arousal, the most interesting findings would occur during the immediate period following the transgression, the recovery period.

\section{Cardiovascular Recovery}

In contrast to the lack of significant group differences in physiological and affective response magnitude to the transgression observed in this study, several significant group differences were observed during the recovery period. In brief, these significant differences during recovery illustrated two phenomena. First, the DBP and MAP profiles during portions of the recovery period were different for men and women, with women showing DBP and MAP reductions following receipt of the apology, and men showing the opposite pattern. Second, level of trait forgiveness moderated the DBP and MAP recovery from the transgression following the apology, but only among women. Sex differences in response to the apology and the moderation of response by trait forgiveness are discussed separately.

Sex Differences in Response to Apology. Although apology resulted in lower DBP and MAP among women, it had the opposite effect among men. This result is rather counterintuitive on the surface, but must be interpreted based on other factors surrounding this study. The distribution of men's FPI scores in the screening sample must first be considered. Men reported lower trait forgiveness scores than women, which indicates that perhaps a certain level of forgiveness is necessary in order for an apology to be helpful, and that level was not reached by most participants in the sample of men. Men may not have had the predilection to forgive readily, and therefore may have been primed to find the apology disingenuous, thus resulting in a poorer recovery in relation to their counterparts who did not receive an apology. An alternate explanation for the significant increase in DBP and MAP among men who received apologies 
during the final minute of the Recovery Period is that these men were more anxious to be finished with the study. They were told how long the rest period would be and may have been anticipating the end of the study. However, it is unclear how receiving an apology would have increased the tendency to anticipate the end of the study.

A final consideration relates to how men and women interpreted the specific transgression employed in this study. Men may have been less likely to label the harassment as a negative experience or transgression to the degree that it required a verbal apology. Men who received an apology, however, were made aware by the delivery of an apology that the preceding experience was indeed a transgression, something they may not have considered until that point. It may have been that men considered the harassment to be of small consequence if left alone, but the apology caused them to reinterpret the transgression in a more negative and offensive light.

Moderation of Recovery by Trait Forgiveness among Women. Though the area under the curve analyses demonstrated a main effect of forgiveness level, this result was only present in the third minute of the molecular investigation of the recovery period. The timing of the Sex by Apology by Forgiveness interaction at Minute 3 is most interesting, as this was the first measurement after all participants had received the apology (or not) and had at least one minute to think about the apology without engaging in any competing cognitive activity like completing the MAACL-R or listening to the apology. Temporally, Minute 3 is the equivalent of "accepting" or "not accepting" the apology and appears to carry the majority, if not all, of the variance accounted for by Forgiveness Level. Using DBP and MAP as physiological indicators of acceptance, it appears that the apology was only accepted this soon after the transgression by women with high trait forgiveness. Men, and women with low trait forgiveness, did not appear to 
immediately benefit from the apology physiologically. In this regard, apology assists in overcoming interpersonal transgressions, but only among women who have a predilection for forgiveness.

The lack of significant differences for SBP and heart rate recovery is not surprising. These physiological indicators are more commonly associated with the quicker increases and decreases characteristic of reactivity as opposed to recovery (Chida \& Hamer, 2008). In studying phenomena like grudges that can last years or even lifetimes, it becomes much more important to examine physiological indictors that are more long-lasting in nature, and represent average cardiovascular stress (i.e. MAP). DBP, unlike SBP and HR, is much less representative of the cardiac stress response and more reflective of alterations in the vasculature (e.g., vasoconstriction; Andreassi, 2007 p. 389)

Forgiveness and Physiological Health

In order to investigate how the results of the current study relate to long-term health outcome, a discussion of these results in relation to the hypotheses generated by McEwen's theory of allostatic load is warranted. Two specific pathways through which stress leads to allostatic load were examined in the current study: the exaggerated reactivity to stress hypothesis and the delayed recovery from stress hypothesis. Prior studies that have used a recall interview more appropriately test the exaggerated reactivity hypothesis and have found attenuated physiological reactivity among persons with high trait forgiveness (i.e. Friedberg et al., 2006; Lawler et al., 2003; Witvliet et al., 2001). The current study failed to support this hypothesis. However, as stated previously, the methodology employed in the current study was quite different from previous studies in that it exposed all participants to a 'new' transgression. As 
such, one's past history with forgiveness had very little influence on how one responds during exposure to new transgressions.

The current study pertains more to the delayed recovery hypothesis as a mechanism through which stress results in allostatic load. While this hypothesis received some support in the current study, it was only observed when a forgiveness enhancement (i.e. apology) was delivered, and only among women.

Affect

The effect of trait forgiveness on affective report following the recovery period was consistent with expectations based on current conceptualizations of forgiveness and on the results of physiological measures. High trait forgiveness and receiving an apology were associated with lower hostility ratings for the recovery period, and an apology also resulted in higher positive affect ratings. It is interesting to note that Apology Condition and participant sex did not interact for hostility and positive affect as they did in the physiological data. Given the somewhat lower than anticipated power observed in the current study, main effects for Sex or interactions between Sex and Apology may have been less observable. Despite these issues, men who are low in forgiveness who did not receive an apology reported higher depression scores at the end of recovery period than men who were high in forgiveness. Though men who did not receive an apology displayed a better cardiovascular recovery, there is evidence that they experienced a higher depressive affective response than men who received an apology, but only if they were not protected by a higher trait forgiveness. In this regard, this finding indicates that both situational (not receiving an apology) and dispositional (low forgiveness) factors are associated with dysphoric affective responses to stress.

State Forgiveness 
Results for the TRIM are surprising as variations in state unforgiveness were expected in relation to trait forgiveness and especially in relation to the receiving of an apology. Further inspection of the data revealed that $27 \%$ of participants marked the lowest possible score for each item on the TRIM and only $49 \%$ scored 3 points above the minimum score for the measure. This indicated that either the TRIM assessed a level of unforgiveness generally too high to be elicited from the relatively minor harassment experience from the experimenter or the participants were intent on quickly completing their final measure of the experiment before leaving the laboratory. It is also possible that the level of 'unforgiveness' evoked in this study dissipated by the time responses on the TRIM were obtained.

\section{Perceptions of the Task and the Experimenter}

The post-task questionnaire indicated that all participants found the task equally stressful and had equivalent prior experience with a similar task. These data help to eliminate the possible confound of variations in participant comfort/discomfort with the task. The questionnaire also indicated that receipt of the apology influenced the participants' perception of the experimenter following the task, as participants who received an apology rated the experimenter as more supportive. These results indicated that the apology was the operative factor in altering perception of the experimenter, as opposed to trait forgiveness. Apology and Forgiveness Level did not influence participants' view of the experimenter during the task. This indicated that the experimental manipulation worked to deliver a comparable transgression to all study participants and that the apology manipulation also worked following task completion.

Participants' ratings of the experimenter following the recovery period may grant some insight into the active mechanism of the apology script. The apology was a "shot gun" approach to forgiveness that included several elements including; taking responsibility for the participants' 
feelings, saying the words "I'm sorry," attributing behavior to the environment as opposed to a personal trait, and demonstrating remorse. The fact that participants did not differ in their view of how much the experimenter enjoyed harassing them suggests that the participants did not undergo an attributional change, thus leaving other factors in the "shot gun" apology as potential mechanisms of action.

\section{Limitations of the Study}

Like all experimental work, there were some limitations to this study. First, the study was limited through the distribution of sample characteristics, in particular the unequal samples of men and women accepting invitations to participate in the study. Women of high and low forgiveness volunteered to come into the laboratory at roughly equivalent rates. Men, however, were less likely to volunteer to participate, and low forgiveness men were less likely than high forgiving men to come into the laboratory. While the results for sex differences in this study are quite interesting, it is unclear whether they would be replicated with a larger sample of low forgiveness men. It is not possible to determine if the sample of low forgiving men used in this study is representative of this group in the general population. They were much more difficult to recruit as study participants, and the overall number of them who completed the study was lower than other participants. If future research explores sex differences in response to forgiveness, as warranted by findings from this study, a greater effort will need to be made to identify comparable sample sizes of men and women.

A related limitation is the use of different cutoff scores on the FPI for men and women for categorization into high and low forgiving groups. Although it was certainly justifiable to use sex-specific norms for categorizing men and women into high and low forgiving groups, this decision resulted in differing trait forgiveness scores among groups. In this regard, the low 
forgiveness women were actually somewhat higher in forgiveness than the low forgiveness men, and the high forgiveness women were actually somewhat higher in forgiveness than the high forgiveness men. Based upon the findings observed in this study, it is impossible to ascertain whether the Forgiveness Level by Apology interaction observed among women but not men was a true sex difference or due to their differential levels of forgiveness.

Another limitation of this study was the timing of the delivery of the apology, which varied between participants due to the length of time taken to complete the MAACL-R. Although the approach chosen standardized the length of time following completion of the task that the recovery measures were taken, the variability in apology delivery made interpretation of minute measures difficult. This was particularly a problem for Minute 1 measures, as participants who completed the MAACL-R quickly would have received (or not) the apology by Minute 1 and participants who took some time to complete the MAACL-R were still completing it during the Minute 1 measurement period. Future studies should attempt to standardize this portion of the study protocol, perhaps by providing waiting to deliver the apology until the Minute 1 measurement has been completed.

A final limitation involves the continuous versus periodic nature of heart rate and blood pressure measurement, respectively. Heart rate is a much more robust measurement for handling complications such as movement error and signal loss, because a loss of a few beats does not have a large effect on any given minute's average heart rate. Blood pressure measurements occurred every two minutes so as not to aggravate the participants and to permit their arms to perfuse with blood before the next measurement occurred. An error in a blood pressure measurement resulted in a significant loss of data, especially for the recovery period when each measure was of experimental interest. The use of a continuous blood pressure measuring device 
such as a Finometer ${ }^{\circledR}$ (Finapres Medical Systems, Amsterdam, The Netherlands) may give a more accurate and robust representation of blood pressure recovery, and minimize problems associated with invalid blood pressure measures. Despite this limitation, the proportion of blood pressure measures that were lost in the current study was minimal and not thought to impact the outcome of study findings.

\section{Future Directions}

This study holds several implications for future research. Primarily, it speaks to the importance of future studies considering the difference between an original transgression and reexperiencing a prior transgression through recall. It also demonstrates that in reference to an original transgression, trait forgiveness may need to be activated by some state forgivenessenhancing event, such as an apology. This fact should be considered in future research that goes on to investigate "live" forgiveness manipulations. One possible venue for this type of investigation is with romantic partners. Measuring reactivity and recovery following a marital argument would provide a naturalistic investigation of the physiology of forgiveness and allow for further investigation into the physiological effects of apology.

Apology itself is an important area of future research. It would be highly useful to ascertain the components of an apology that are effective in producing a physiological forgiveness response. According to the current study, this is especially true for men. Evidence is suggestive that men were physiologically aroused both immediately and for some time after the apology was delivered. Investigating which components of the apology were efficacious for women, and detrimental for men, would allow for a tailoring of the apology based on sex. Future research should also investigate how an apology may need to be tailored based on developmental model of forgiveness as per Huang and Enright (2000). Persons of a lower developmental level 
may need an apology that demonstrates that the transgressor has been punished for their transgression while persons of the highest developmental level may not even need an apology in order to show the beneficial effects of forgiveness.

The procedure used in the current study also lends itself to examining other empirical questions using this novel paradigm. For one, other trait measures besides the FPI may be useful in understanding the physiology of forgiveness. Measures that investigate not only trait forgiveness of others, but also trait forgiveness of self may be useful. For trait measures of forgiveness, a milder version of the TRIM may have been more sensitive and avoided the apparent floor effect observed in the current study. A final future modification of the current study would be to utilize a different transgression. This could be done by giving similar critical feedback to a different task, or changing the task altogether. A task with a more ambiguous indicator of performance may be the most appropriate change, as participants in the current study may have deemed their performance adequate and considered the harassment to have been somewhat contrived. Also, the task used in this study constituted a minor transgression which may not speak to the extent of psychophysiological changes that may occur after a major transgression akin more to trauma rather than to a daily hassle.

The results of the results of this study hold applications to clinical practice, which is a subject of future study. The use of apology in persons' daily lives may be more complicated to apply practically than originally thought when considering the fact that the components of the apology may need to be altered based on the situation and the person to whom the apology is being made. The current study suggests that males require a different type of apology, perhaps even a non-verbal one, in order to benefit from it. An investigation of interventions designed to 
teach persons to elicit and provide effective apologies, as well as the effect of this intervention on psychophysiological factors, is warranted.

\section{Conclusions}

This study examined the cardiovascular response to forgiveness, as influenced by apology, in order to determine a link between forgiveness and health via autonomic activity. Results supported the influence of forgiveness and apology on cardiovascular recovery for women, who displayed better DBP and MAP recovery directly following the apology if they were high in forgiveness and received an apology. Apology alone influenced men and women differently at several points during recovery following the transgression. This study makes an important contribution to the literature because these results were obtained following an actual transgression that occurred in the laboratory. The recovery data document the physiological effects of the forgiveness process as it occurs and indicate that men, and women of low forgiveness, may carry a higher allostatic load following an interpersonal transgression. Moving forward with forgiveness research may eventually lead to interventions tailored specifically to groups of persons with poor physiological recovery from transgression, and thus positively affect the physical and social health of these individuals. 


\section{References}

Anderson, J. C., Linden, W., \& Habra, M. E. (2006). Influence of apologies and trait hostility on recovery from anger. Journal of Behavioral Medicine 29(4), 347-358.

Andreassi, J. (2007). Psychophysiology: Human behavior \& physiological response (5th ed.). Mahwah, NJ US: Lawrence Erlbaum Associates Publishers.

Bachman, G. F., \& Guerrero, K. L. (2006). Forgiveness, apology, and communicative responses to hurtful events. Communication Reports, 19(1), 45-56.

Baer, R., Smith, G., \& Allen, K. (2004). Assessment of Mindfulness by Self-Report: The Kentucky Inventory of Mindfulness Skills. Assessment, 11(3), 191-206.

Bartholomew, K., \& Horowitz, L. (1991). Attachment styles among young adults: A test of a four-category model. Journal of Personality and Social Psychology, 61(2), 226-244.

Berry, J. W., Worthington, E. L., O’Connor, L. E., Parrott, L., Wade, N. G. (2005). Forgiveness, vengeful rumination and affective traits. Journal of Personality, 73(1), 183-225.

Berry, J. W., \& Worthington, E. L. Jr. (2001). Forgiveness, relationship quality, stress while imagining relationship events, and physical and mental health. Journal of Counseling Psychology, 48(4).

Burns, J. W., Bruehl, S., \& Caceres, C. (2004). Anger management style, blood pressure reactivity, and acute pain sensitivity: Evidence for 'trait x situation' models. Annals of Behavioral Medicine, 27(3), 195-204.

Burns, J. W., Evon, D., \& Strain-Saloum, C. (1999). Repressed anger and patterns of cardiovascular, self-report and behavioral responses: Effects of harassment. Journal of Psychosomatic Research, 47(6), 569-581.

Chida, Y., \& Hamer, M. (2008). Chronic psychosocial factors and acute physiological responses to laboratory-induced stress in healthy populations: A quantitative review of 30 years of investigations. Psychological Bulletin, 134(6), 829-885.

Cook, W. W., and Medley, D. M. (1954). Proposed hostility and pharisaic-virtue scales for the MMPI. Journal of Applied Psychology 38, 414-418.

Cooper, D. C., \& Waldstein, S. R. (2004). Hostility differentially predicts cardiovascular risk factors in African American and White young adults. Journal of Psychosomatic Research, 57(5), 491-499.

Darby, B. W., \& Schlenker, B. R. (1982). Children's reactions to apologies. Journal of Personality and Social Psychology, 43, 742-753.

Drinnon, J. R., Jones, W. H., and Lawler, K. A. (2000). Measurement of forgiveness. Paper presented at Society of Personality and Social Psychology, Nashville, TN.

Emmons, R. A. (2000). Personality and forgiveness. In M. E. McCullough, K. I. Pargament, \& C. E. Thoresen (Eds.), Forgiveness: Theory, Research, and Practice (pp. 254-280). New York, NY: Guilford Press.

Ekstedt, M., Åkerstedt, T., \& Söderström, M. (2004). Microarousals during sleep are associated with increased levels of lipids, cortisol and blood pressure. Psychosomatic Medicine, 66(6), 925-931.

Enright, R. D., Santos, M. J. D., \& Al-Mabuk, R. (1989). The adolescent as forgiver. Journal of Adolescence, 12, 95-110.

Faul, F., Erdfelder, E., Lang, A.-G., \& Buchner, A. (2007). G*Power 3: A flexible statistical power analysis program for the social, behavioral, and biomedical sciences. Behavior Research Methods, 39, 175-191. 
Fernández, J., Quiroga, M., \& Del Olmo, I. (2006). Is Sexual Attraction Independent of the Instrumental and Expressive Traits?. The Spanish Journal of Psychology, 9(2), 162-170.

Friedberg, J., Suchday, S., \& Shelov, D. (2007). The impact of forgiveness on cardiovascular reactivity and recovery. International Journal of Psychophysiology, 65(2), 87-94.

García-León, A., Robles, H., \& Vila, J. (2003). Relative effects of harassment, frustration, and task characteristics on cardiovascular reactivity. International Journal of Psychophysiology, 47(2), 159-173.

Gordon, K. C., Baucom, D. H., \& Snyder, D. K. (2000). The use of forgiveness in marital therapy. In M. E. McCullough, K. I. Pargament, \& C. E. Thoresen (Eds.), Forgiveness: Theory, Research, and Practice (pp. 254-280). New York, NY: Guilford Press.

Hernandez, D. H., Larkin, K. T., \& Whited, M. C. (2009). Cardiovascular response to interpersonal provocation and mental arithmetic among high and low hostile young adult males. Applied Psychophysiology and Biofeedback, 34, 27-35

Huang, S. T., \& Enright, R. D. (2000). Forgiveness and anger-related emotions in Taiwan: Implications for therapy. Psychotherapy, 37(1), 71-79.

Kiecolt-Glaser, J. K., \& Glaser, R. (1992). Stress and the immune system: Human studies. American Psychiatric Press Review of Psychiatry, 11, 169-180.

Larkin, K. T. (2005). Stress and hypertension: Examining the relation between psychological stress and high blood pressure. New Haven and London: Yale University Press.

Lawler, K. A., Younger, J. W., Piferi, R. L., Jobe, R. L., Edmondson, K. A., \& Jones, W. J. (2005). The unique effects of forgiveness on health: An exploration of pathways. Journal of Behavior Medicine, 28(2), 157-167.

Lawler, K. A., Younger, J. W., Piferi, R. L., Billington, E., Jobe, R.., Edmondson, K., \& Jones, W. H. (2003). A change of heart: Cardiovascular correlates of forgiveness in response to interpersonal conflict. Journal of Behavior Medicine, 26(5), 373-393.

Lubin, B., Van Whitlock, R., Reddy, D., Petren, S. (2001). A comparison of the short and long forms of the multiple affect adjective checklist - revised. Journal of Clinical Psychology, 57, 411-416.

Malcolm, W. M., \& Greenberg L. S. (2000). Forgiveness as a process of change in individual psychotherapy. In M. E. McCullough, K. I. Pargament, \& C. E. Thoresen (Eds.), Forgiveness: Theory, Research, and Practice (pp. 254-280). New York, NY: Guilford Press.

Marler, M. R., Jacob, R. G., Lehoszky, J.P., Shapiro, A. P. (1988). The statistical analysis of treatment effects in 24-hour ambulatory blood pressure recordings. Statistics in Medicine, 7, 697-716.

McCullough M. E., Pargament K. I., \& Thoresen C. E. (2000). The psychology of forgiveness: History, conceptual issues, and overview. In M. E. McCullough, K. I. Pargament, \& C. E. Thoresen (Eds.), Forgiveness: Theory, Research, and Practice (pp. 254-280). New York, NY: Guilford Press.

McCullough, M. E., \& Witvliet, C. V. (2002). The psychology of forgiveness. In C. R. Snyder \& S. J. Lopez (Eds.), Handbook of Positive Psychology. (pp. 446-458). New York, NY: Oxford University Press.

McCullough M. E., Hoyt, W. T., \& Rachal, K. C. (2000). What we know (and need to know) about assessing forgiveness constructs. In M. E. McCullough, K. I. Pargament, \& C. E. Thoresen (Eds.), Forgiveness: Theory, Research, and Practice (pp. 254-280). New York, NY: Guilford Press. 
McCullough, M. E., Rachal, K. C., Sandage, S. J., Worthington, E. L., Brown, S. W., \& Hight, T. L. (1998). Interpersonal forgiving in close relationships: Theoretical elaboration and measurement. Journal of Personality and Social Psychology, 76, 1586-1603.

McCullough, M. E., Worthington, E. L., \& Rachal, K. C. (1997). Interpersonal forgiving in close relationships. Journal of Personality and Social Psychology, 73(2), 321-336.

McEwen, B. S. (1998). Protective and damaging effects of stress mediators. The New England Journal of Medicine, 338, 171-179.

McEwen, B. S., \& Stellar, E. (1993). Stress and the individual: Mechanisms leading to disease, Archives of Internal Medicine, 153, 2093-2101.

McEwen, B. S., \& Wingfield, J. C. (2003). The concept of allostasis in biology and biomedicine. Hormones and Behavior, 43, 2-15.

Melamed, S., Shirom, A., Toker, S., Berliner, S., \& Itzhak, S. (2006). Burnout and risk of cardiovascular disease: Evidence, possible causal paths and promising research directions. Psychological Bulletin, 132(3), 327-353.

Miller, S. B., Dolgoy, L., Friese, M., \& Sita, A. (1998). Parental history of hypertension and hostility moderate cardiovascular responses to interpersonal conflict. International Journal of Psychophysiology, 28(2), 193-206.

Miller, T. Q., Smith, T. W., Turner, C. W., Guijarro, M. L., \& Hallet, A. J. (1996). Meta-analytic review of research on hostility and physical health. Psychological Bulletin, 119(2), 322348.

Mullet, E., \& Girard, M. (2000). Developmental and cognitive points on forgiveness. In M. E. McCullough, K. I. Pargament, \& C. E. Thoresen (Eds.), Forgiveness: Theory, Research, and Practice. (pp. 254-280). New York, NY: Guilford Press.

Nelson, T. L., Palmer, R. F., \& Pederson, N. L. (2004). The metabolic syndrome mediates the relationship between cynical hostility and cardiovascular disease. Experimental Aging Research, 30(2), 163-177.

Neumann, S., Waldstein, S., Sellers, J., Thayer, J., \& Sorkin, J. (2004, November). Hostility and Distraction Have Differential Influences on Cardiovascular Recovery From Anger Recall in Women. Health Psychology, 23(6), 631-640.

Newberg, A. B., d'Aquili, E. G., Newberg, S. K., \& deMarici, V. (2000). The neuropsychological correlates of forgiveness. In M. E. McCullough, K. I. Pargament, \& C. E. Thoresen (Eds.), Forgiveness: Theory, Research, and Practice (pp. 254-280). New York, NY: Guilford Press.

Rye, M. S., et al. (2000). Religious perspectives on forgiveness. In M. E. McCullough, K. I. Pargament, \& C. E. Thoresen (Eds.), Forgiveness: Theory, Research, and Practice (pp. 254-280). New York, NY: Guilford Press.

Selye, H. (1955). Stress and disease. Science, 122, 625-631.

Seybold, K. S., Hill, P. C., Neumann, J. K., \& Chi, D. S. (2001). Physiological and psychological correlates of forgiveness. Journal of Psychology and Christianity, 20(3), 250-259.

Smith, B. D., Cranford, D., \& Green, L. (2001). Hostility and caffeine: Cardiovascular effects during stress and recovery. Personality and Individual Differences, 30(7), 1125-1137.

Smith, T. W. (1992). Hostility and health: Current status of a psychosomatic hypothesis. Health Psychology, 11(3), 139-150.

Smith, T. W., Glazer, K., Ruiz, J. M., \& Gallo, L. C. (2004). Hostility, anger, aggressiveness, and coronary heart disease: An interpersonal perspective on personality, emotion, and health. Journal of Personality, 72(6), 1217-1270. 
Stone, A. A., Mezzacappa, E. S., Donatone, B. A., \& Gonder, M. (1999). Psychosocial stress and social support are associated with prostate-specific antigen levels in men: Results form a community screening program. Health Psychology, 18(5), 482-484.

Thoresen, C. E., Harris, A. H., \& Luskin, F. (2000). Forgiveness and health: An unanswered question. In M. E. McCullough, K. I. Pargament, \& C. E. Thoresen (Eds.), Forgiveness: Theory, Research, and Practice (pp. 254-280). New York, NY: Guilford Press.

Takaku, S. (2001). The effects of apology and perspective taking on interpersonal forgiveness: A dissonance-attribution model of interpersonal forgiveness. The Journal of Social Psychology, 141(4), 494-508.

Thompson, L., \& Synder, C. (2003). Measuring forgiveness. Positive psychological assessment: A handbook of models and measures (pp. 301-312). Washington, DC US: American Psychological Association.

Thompson, Y. L., et al. (2005). Dispositional forgiveness of self, others, and situations. Journal of Personality, 73(2), 313-359.

Thomsen, D., Mehlsen, M., Hokland, M., Viidik, A., Olesen, F., Avlund, K., et al. (2004). Negative Thoughts and Health: Associations Among Rumination, Immunity, and Health Care Utilization in a Young and Elderly Sample. Psychosomatic Medicine, 66(3), 363371.

Thomsen, D., Mehlsen, M., Olesen, F., Hokland, M., Viidik, A., Avlund, K., et al. (2004). Is there an association between rumination and self-reported physical health? A one-year follow-up in a young and an elderly sample. Journal of Behavioral Medicine, 27(3), 215231.

Thoresen, C., Harris, A., \& Luskin, F. (2000). Forgiveness and health: An unanswered question. Forgiveness: Theory, research, and practice (pp. 254-280). New York, NY US: Guilford Press.

Vandervort, D. J. (2006). Hostility and health: Mediating effects of belief systems and coping styles. Current Psychology: Developmental, Learning, Personality, Social, 25(1), 50-66.

Wade, N. G., \& Worthington, E. L. (2005). In search of a common core: A content analysis of interventions to promote forgiveness. Psychotherapy: Theory, Research, Practice, Training, 42(2), 160-177.

Weiner, B., Graham, S., Peter, O., \& Zmuidinas, M. (1991). Public confession and forgiveness. Journal of Personality, 59, 281-312.

Wilson, M., Smith, N., \& Holmes, $P$. (2007). The role of effort in influencing the effect of anxiety on performance: Testing the conflicting predictions of processing efficiency theory and the conscious processing hypothesis. British Journal of Psychology, 98(3), 411-428

Witvliet, C. O., Ludwig, T. E., \& Bauer, D. J. (2002). Please forgive me: Transgressors' emotions and physiology during imagery of seeking forgiveness and victim responses. Journal of Psychology and Christianity, 21(3), 219-233.

Witvliet, C. V., Ludwig, T. E., \& Vander Laan, K. L. (2001). Granting forgiveness or harboring grudges: Implications for emotion, physiology, and health. Psychological Science, 12(2), 117-123.

Whitehead, W. E. (1990). Behavioral medicine approaches to gastrointestinal disorders. Journal of Consulting and Clinical Psychology, 60(4), 605-612. 
Worthington, E. L \& Scherer, M. (2004). Forgiveness is an emotion-focused coping strategy that can reduce health risks and promote health resilience: Theory, review, and hypotheses. Psychology and Health, 19(3), 385-405.

Worthington, E. L., Sandage, S. J., \& Berry, J. W. (2000). Group interventions to promote forgiveness: What researchers and clinicians ought to know. In M. E. McCullough, K. I. Pargament, \& C. E. Thoresen (Eds.), Forgiveness: Theory, Research, and Practice (pp. 254-280). New York, NY: Guilford Press.

Ysseldyk, R., \& Matheson, K. (2007). Rumination: Bridging a gap between forgiveness, vengefulness, and physiological health. Personality and Individual Differences, 42(8), 1537-1584.

Zuckerman, M., \& Lubin, B. (1985). Manual for the multiple affect adjective checklist. San Diego, CA: Educational and Industrial Testing Service. 
Table 1

Demographics

\begin{tabular}{lll}
\hline & \multicolumn{1}{c}{$M(S D)$} & Count(\%) \\
\cline { 2 - 3 } Age (yrs) & $19.43(1.4)$ & \\
Sex & & $29(37 \%)$ \\
$\quad$ Men & & $50(63 \%)$ \\
$\quad$ Women & \\
Race & $5(6 \%)$ \\
$\quad$ Black & & $67(85 \%)$ \\
$\quad$ White & $1(1 \%)$ \\
$\quad$ Hispanic & $3(4 \%)$ \\
$\quad$ Asian & & $1(1 \%)$ \\
$\quad$ Biracial & & $1(1 \%)$ \\
Other & & \\
Hormonal Contraceptives & & $19(38 \%)$ \\
(Women only) & & $31(62 \%)$ \\
$\quad$ No & & \\
$\quad$ Yes & & \\
Family Hx of Hypertension & & \\
$\quad$ No or don't know & & \\
Yes & & \\
BMI & & \\
Resting SBP (mm Hg) & $116.3(9.9)$ & \\
Resting DBP (mm Hg) & $62.9(8.6)$ & \\
Resting MAP (mm Hg) & $80.7(6.7)$ & \\
Resting HR (bpm) & $75.3(12.2)$ & \\
\hline
\end{tabular}


Table 2

Correlations Between Cardiovascular Factors and BMI

\begin{tabular}{lrr}
\hline & \multicolumn{2}{c}{$\begin{array}{c}\text { Body Mass Index } \\
(M=24.0, S D=3.87)\end{array}$} \\
Resting SBP & \multicolumn{2}{c}{$p$} \\
Task SBP & 0.38 & $<.001^{*}$ \\
Recovery SBP & 0.16 & 0.16 \\
Resting DBP & 0.09 & 0.43 \\
Task DBP & 0.06 & 0.62 \\
Recovery DBP & -0.09 & 0.41 \\
Resting HR & -0.18 & 0.11 \\
Task HR & -0.09 & 0.45 \\
Recovery HR & -0.10 & 0.38 \\
$* p<.001$ & 0.02 & 0.89 \\
& &
\end{tabular}


Table 3

Summary of Significant Findings For SBP and DBP at Each Minute of the Recovery Period

\begin{tabular}{|c|c|c|}
\hline \multirow[b]{3}{*}{ Minute of Rec. Period } & \multicolumn{2}{|c|}{ Highest Order Sig. Interaction } \\
\hline & DBP & MAP \\
\hline & & \\
\hline Recovery $\min 1$ & Apol x Sex & Apol x Sex \\
\hline Recovery $\min 3$ & Apol x Forg x Sex & Apol $x$ Forg $x$ Sex \\
\hline Recovery min 5 & no sig. findings & no sig. findings \\
\hline Recovery $\min 7$ & Apol x Forg x Sex & no sig. findings \\
\hline Recovery $\min 9$ & no sig. findings & no sig. findings \\
\hline Recovery min 11 & Apol x Forg x Sex* & Apol x Sex \\
\hline
\end{tabular}


Table 4

Means (and standard deviations/errors) for measures of affect, unforgiveness, and perceptions of the experiment following the recovery period

\begin{tabular}{|c|c|c|c|c|c|c|c|c|}
\hline & \multicolumn{4}{|c|}{ Men } & \multicolumn{4}{|c|}{ Women } \\
\hline & \multicolumn{2}{|c|}{ Apology } & \multicolumn{2}{|c|}{ No Apology } & \multicolumn{2}{|c|}{ Apology } & \multicolumn{2}{|c|}{ No Apology } \\
\hline & Hi FPI & Lo FPI & $\mathrm{Hi} \mathrm{FPI}$ & Lo FPI & $\mathrm{Hi} \mathrm{FPI}$ & Lo FPI & $\mathrm{Hi} \mathrm{FPI}$ & Lo FPI \\
\hline \multicolumn{9}{|l|}{ MAACL-R Rest } \\
\hline Anxiety & $.18(.40)$ & $1.7(1.2)$ & $.50(.71)$ & $.40(.55)$ & $1.6(2.3)$ & $1.1(1.6)$ & $.57(.65)$ & $.60(.97)$ \\
\hline Depression & $.55(.82)$ & $2.0(2.0)$ & $.90(1.1)$ & $.60(.89)$ & $.83(.83)$ & $1.3(1.4)$ & $.43(.51)$ & $.90(.88)$ \\
\hline Hostility & $0.0(0.0)$ & $.33(.58)$ & $.20(.63)$ & $.20(.45)$ & $.42(.79)$ & $.21(.43)$ & $.14(.53)$ & $.10(.32)$ \\
\hline Positive Affect & $8.2(3.9)$ & $6.7(6.4)$ & $7.3(4.2)$ & $8.0(3.4)$ & $5.3(2.8)$ & $3.1(1.7)$ & $4.4(2.4)$ & $4.4(3.0)$ \\
\hline \multicolumn{9}{|l|}{ MAACL-R Task } \\
\hline Anxiety & $4.1(.65)$ & $3.1(1.3)$ & $3.2(.68)$ & $5.5(.96)$ & $4.6(.63)$ & $4.4(.57)$ & $4.7(.51)$ & $3.9(.68)$ \\
\hline Depression & $2.3(.58)$ & $2.2(1.1)$ & $.76(.60)$ & $2.6(.85)$ & $3.4(.55)$ & $2.0(.52)$ & $2.2(.52)$ & $2.0(.60)$ \\
\hline Hostility & $2.5(.60)$ & $2.5(1.1)$ & $2.1(.62)$ & $2.9(.89)$ & $3.0(.58)$ & $3.5(.53)$ & $2.8(.53)$ & $2.9(.63)$ \\
\hline Positive Affect & $-.13(.53)$ & $1.2(.96)$ & $2.4(.54)$ & $.99(.76)$ & $.10(.48)$ & $.20(.47)$ & $.45(.45)$ & $.10(.53)$ \\
\hline \multicolumn{9}{|c|}{ MAACL-R Recovery } \\
\hline Anxiety & $.80(.44)$ & $1.1(.84)$ & $1.1(.46)$ & $1.4(.65)$ & $.70(.43)$ & $1.7(.39)$ & $1.6(.39)$ & $1.9(.46)$ \\
\hline Depression & $.72(.42)$ & $.33(.81)$ & $.37(.43)$ & $2.3(.61)$ & $.59(.40)$ & $1.1(.37)$ & $1.3(.37)$ & $.87(.43)$ \\
\hline Hostility & $.26(.27)$ & $.94(.50)$ & $.40(.28)$ & $1.2(.39)$ & $.24(.26)$ & $.27(.23)$ & $.59(.23)$ & $1.6(.28)$ \\
\hline Positive Affect & $4.4(.84)$ & $4.5(1.5)$ & $4.0(.85)$ & $3.0(1.2)$ & $5.9(.76)$ & $3.1(.75)$ & $3.0(.72)$ & $1.8(.84)$ \\
\hline \multicolumn{9}{|l|}{ TRIM } \\
\hline Avoidance & $11.4(6.2)$ & $13.3(10.1)$ & 10.9(3.9) & $12.2(5.5)$ & $9.4(3.7)$ & $10.8(5.8)$ & $13.7(6.1)$ & 17.1(9.8) \\
\hline Revenge & $7.6(4.5)$ & $6.7(2.1)$ & $5.5(1.3)$ & $6.6(1.8)$ & $5.3(1.2)$ & $5.8(1.8)$ & $6.1(1.9)$ & $5.8(1.8)$ \\
\hline \multicolumn{9}{|c|}{ Perceptions of the Task and Experimenter } \\
\hline How stressful? & $3.1(1.2)$ & $3.7(1.2)$ & $3.0(1.2)$ & $4.0(.70)$ & $4.0(.95)$ & $4.0(.78)$ & $3.6(1.7)$ & $3.6(1.1)$ \\
\hline How often? & $1.6(.81)$ & $2.3(2.3)$ & $2.3(1.3)$ & $1.6(.89)$ & $2.0(1.4)$ & $2.0(1.2)$ & $1.8(.89)$ & $1.7(.82)$ \\
\hline Effectiveness & $2.7(1.4)$ & $2.7(1.5)$ & $3.5(1.4)$ & $2.4(1.1)$ & $2.6(1.3)$ & $2.1(1.2)$ & $2.3(1.3)$ & $2.3(1.3)$ \\
\hline Enjoyment & $1.9(.70)$ & $2.7(.58)$ & $2.9(1.3)$ & $2.4(1.1)$ & $2.6(1.1)$ & $2.1(1.3)$ & $2.4(.84)$ & $2.5(1.2)$ \\
\hline Support during & $1.7(.79)$ & $2.3(2.3)$ & $2.7(.95)$ & $2.2(1.1)$ & $2.1(1.1)$ & $1.9(1.2)$ & $1.7(.99)$ & $1.9(1.3)$ \\
\hline Support after & $4.6(.52)$ & $5.0(0.0)$ & $3.5(1.2)$ & $2.8(.84)$ & $4.7(.65)$ & $4.4(.93)$ & $3.0(1.0)$ & $2.6(1.3)$ \\
\hline
\end{tabular}




\section{Figure Captions}

Figure 1. Graphical representation of experimental procedure.

Figure 2. Average heart rate for each minute of the task period in relation to delivery of harassing statements.

Figure 3. Average SBP for each measurement during the task period in relation to delivery of harassing statements.

Figure 4. Average DBP for each measurement during the task period in relation to delivery of harassing statements.

Figure 5. Apology Condition x Sex interaction at minute 1 for DBP.

Figure 6. Forgiveness Level x Apology Condition interaction with women at minute 3 for DBP. Figure 7. Apology Condition x Sex interaction at minute 7 for DBP.

Figure 8.Apology Condition x Sex interaction at minute 11 for DBP.

Figure 9. Apology Condition x Sex interaction at minute 1 for MAP.

Figure 10. Forgiveness Level $\mathrm{x}$ Apology Condition interaction with women at minute 3 for MAP.

Figure 11.Apology Condition x Sex interaction at minute 11 for MAP. 
RestPeriod

TaskPeriod

RecoveryPeriod

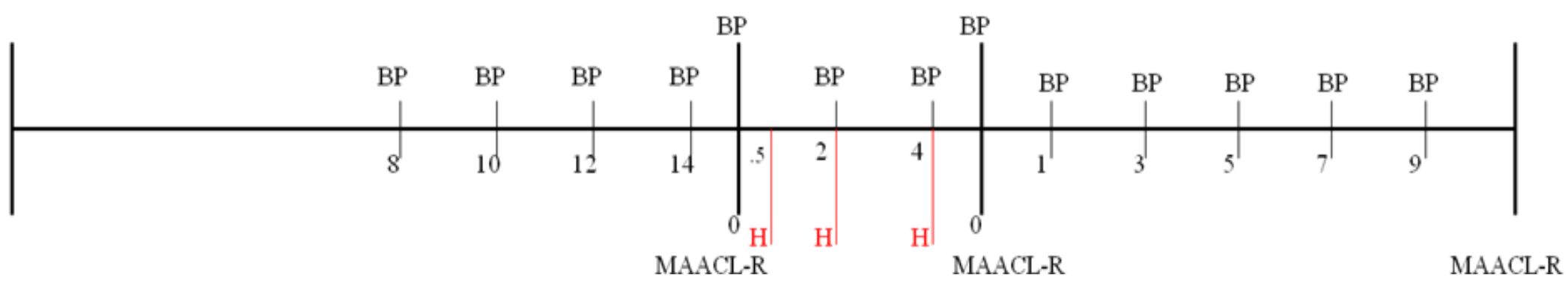

Figure 1 


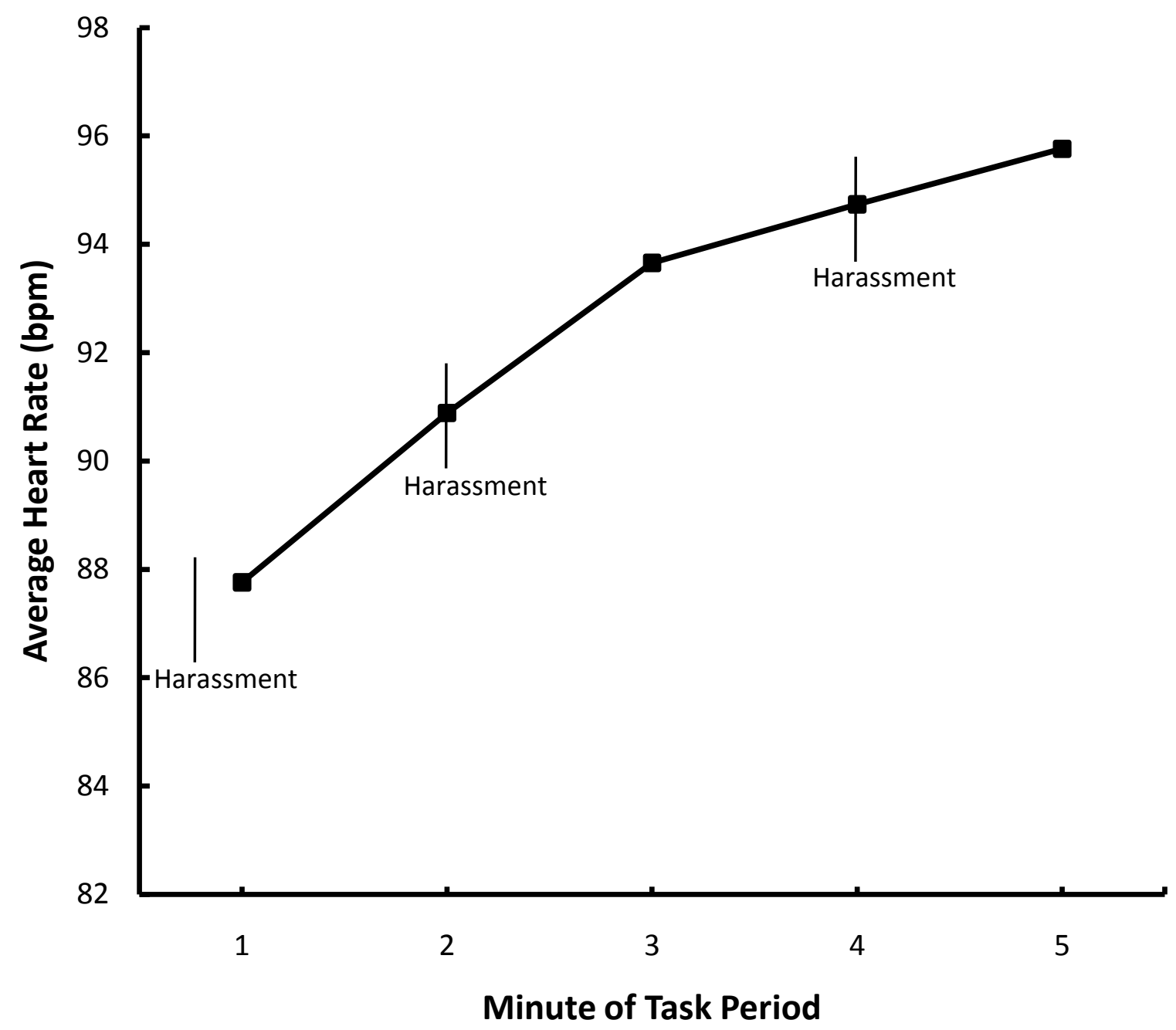

Figure 2 


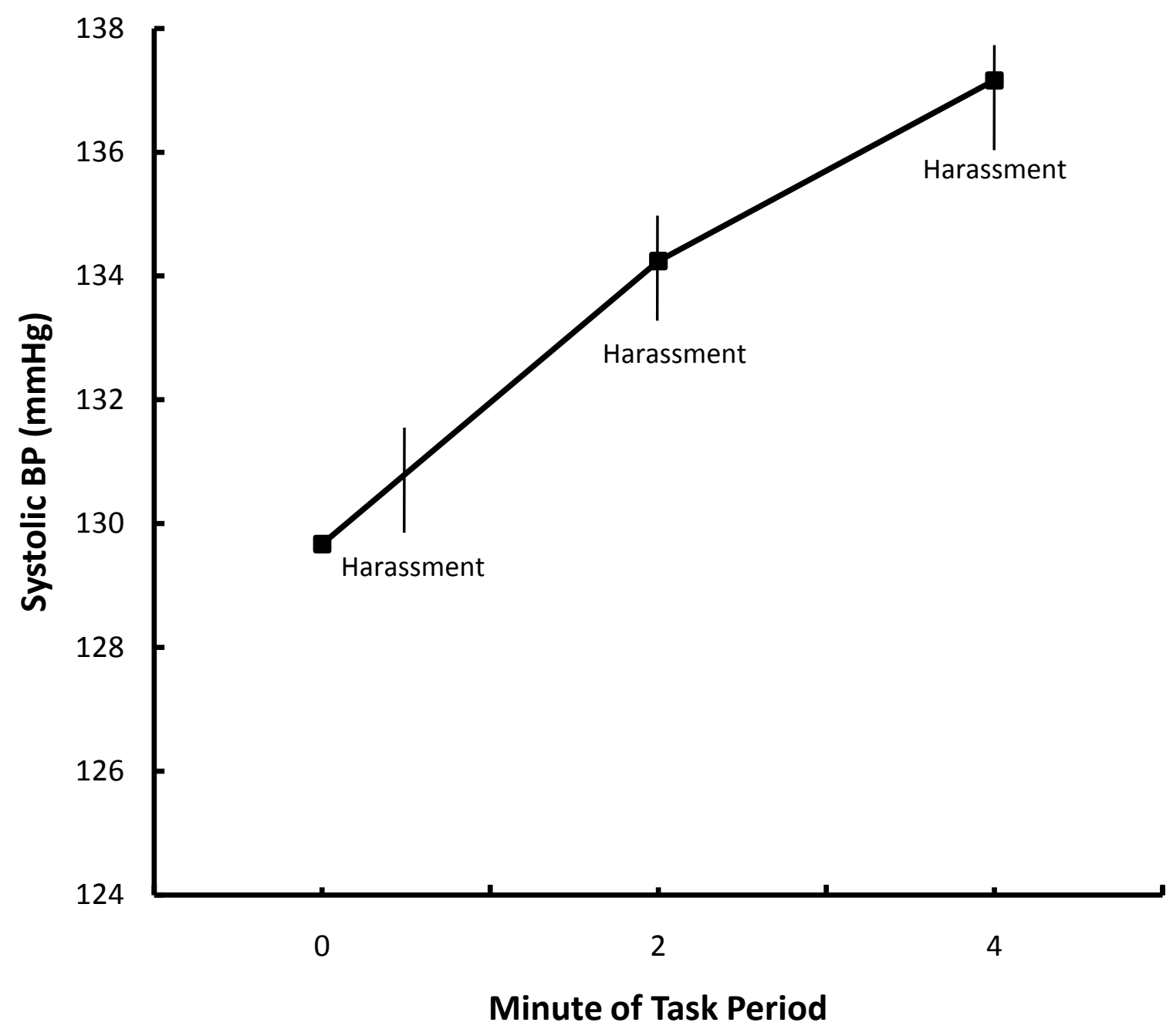

Figure 3 


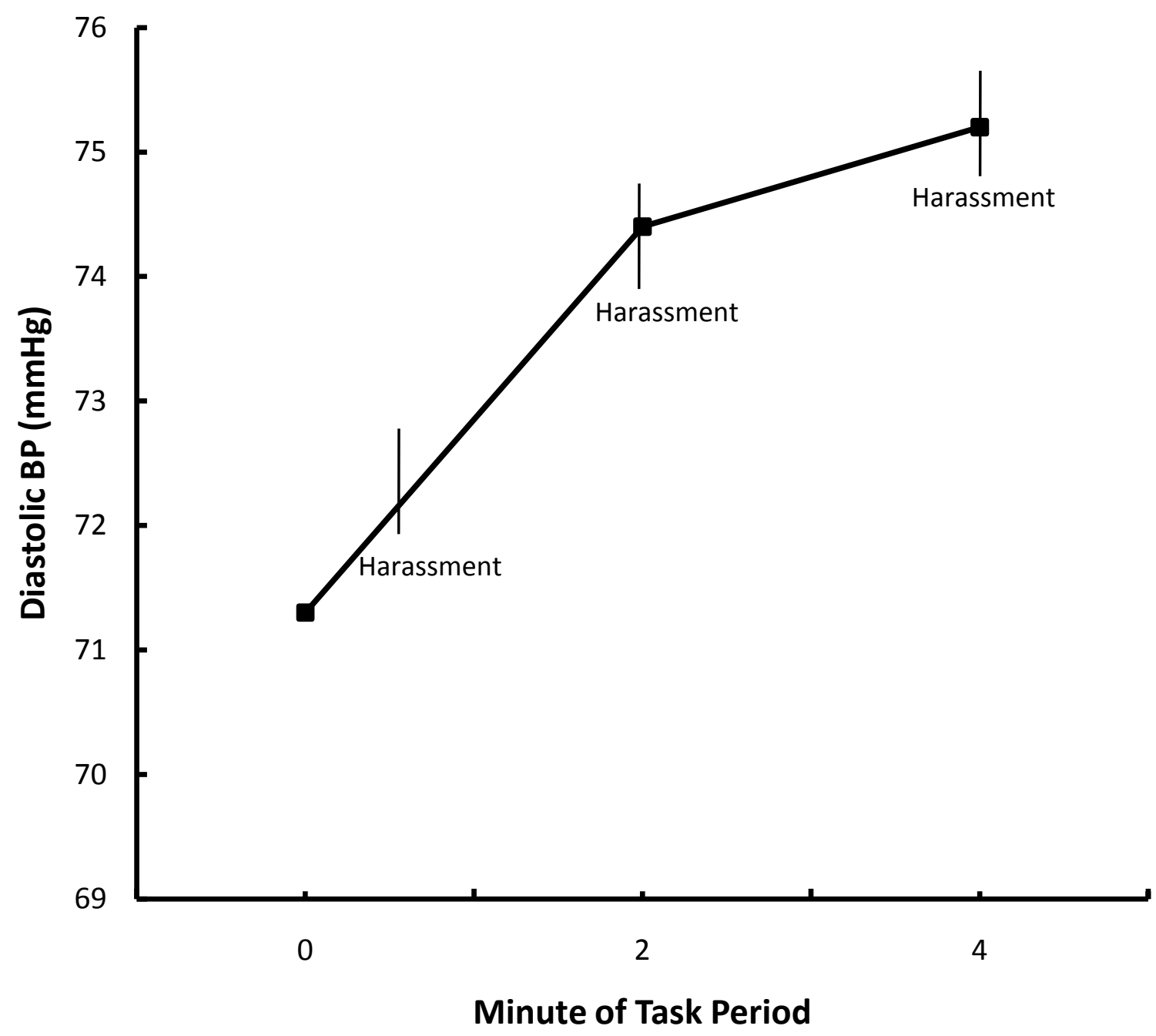

Figure 4 


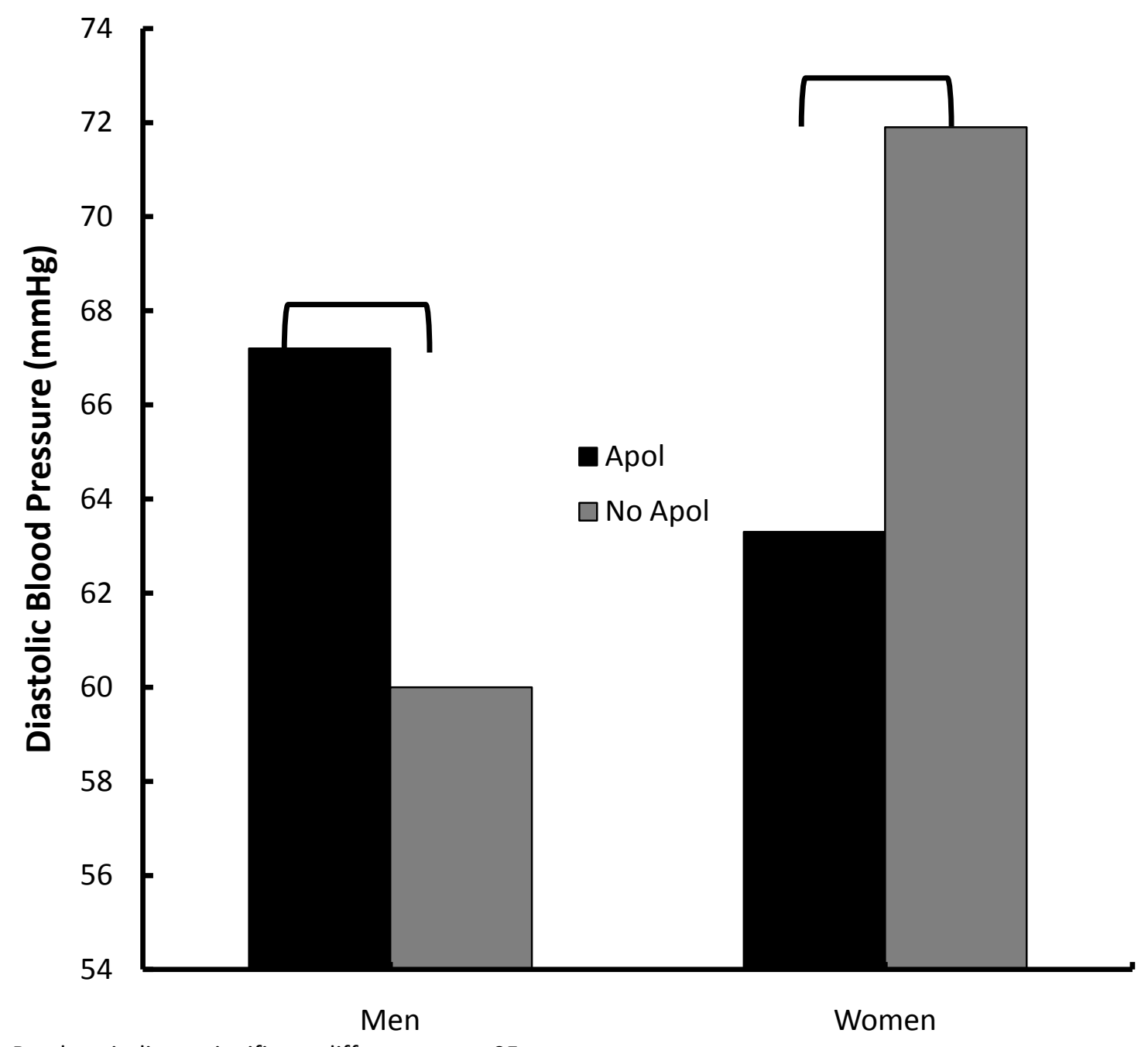

Brackets indicate significant difference, $p<.05$

Figure 5 


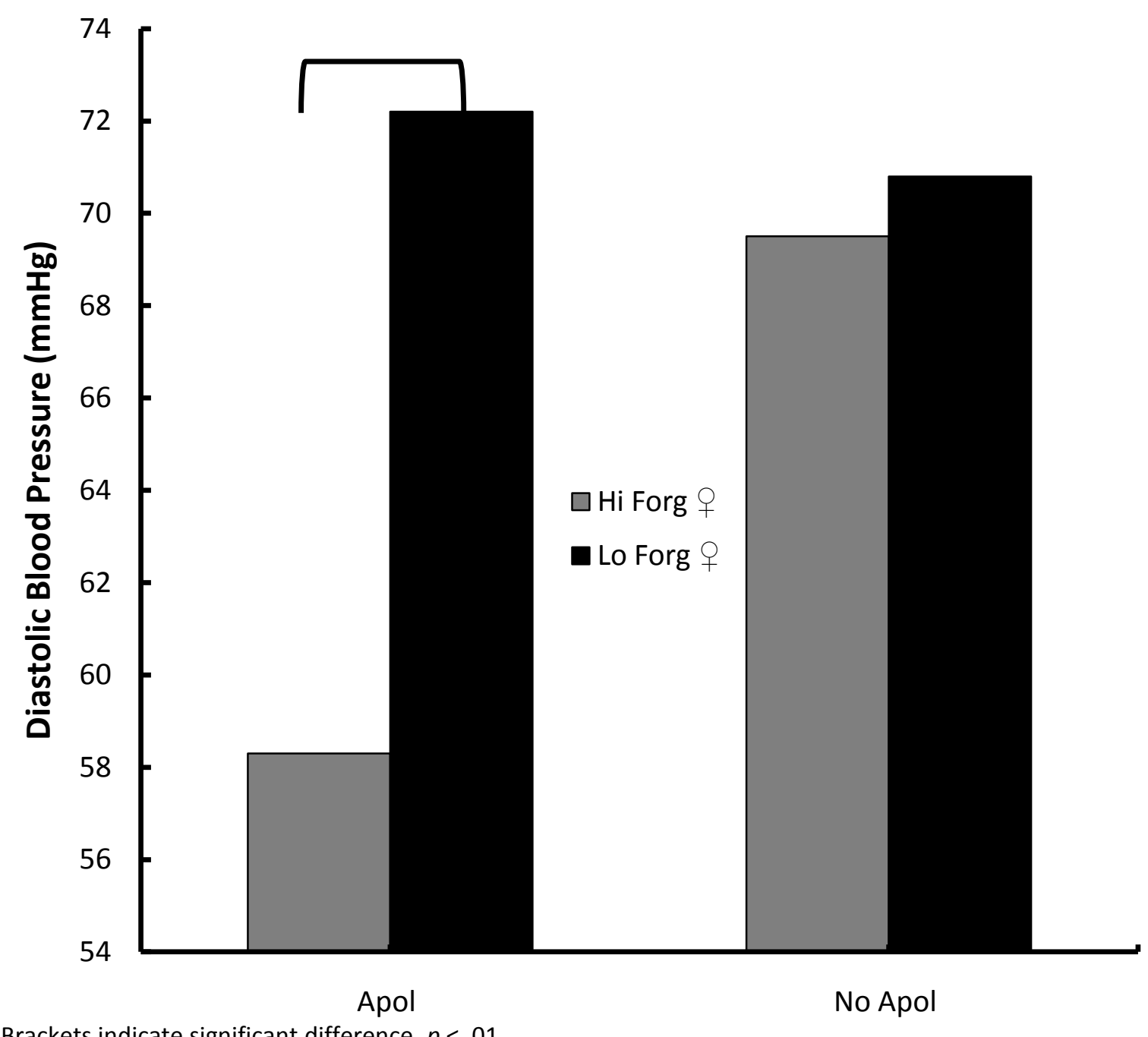

Brackets indicate significant difference, $p<.01$

Figure 6 


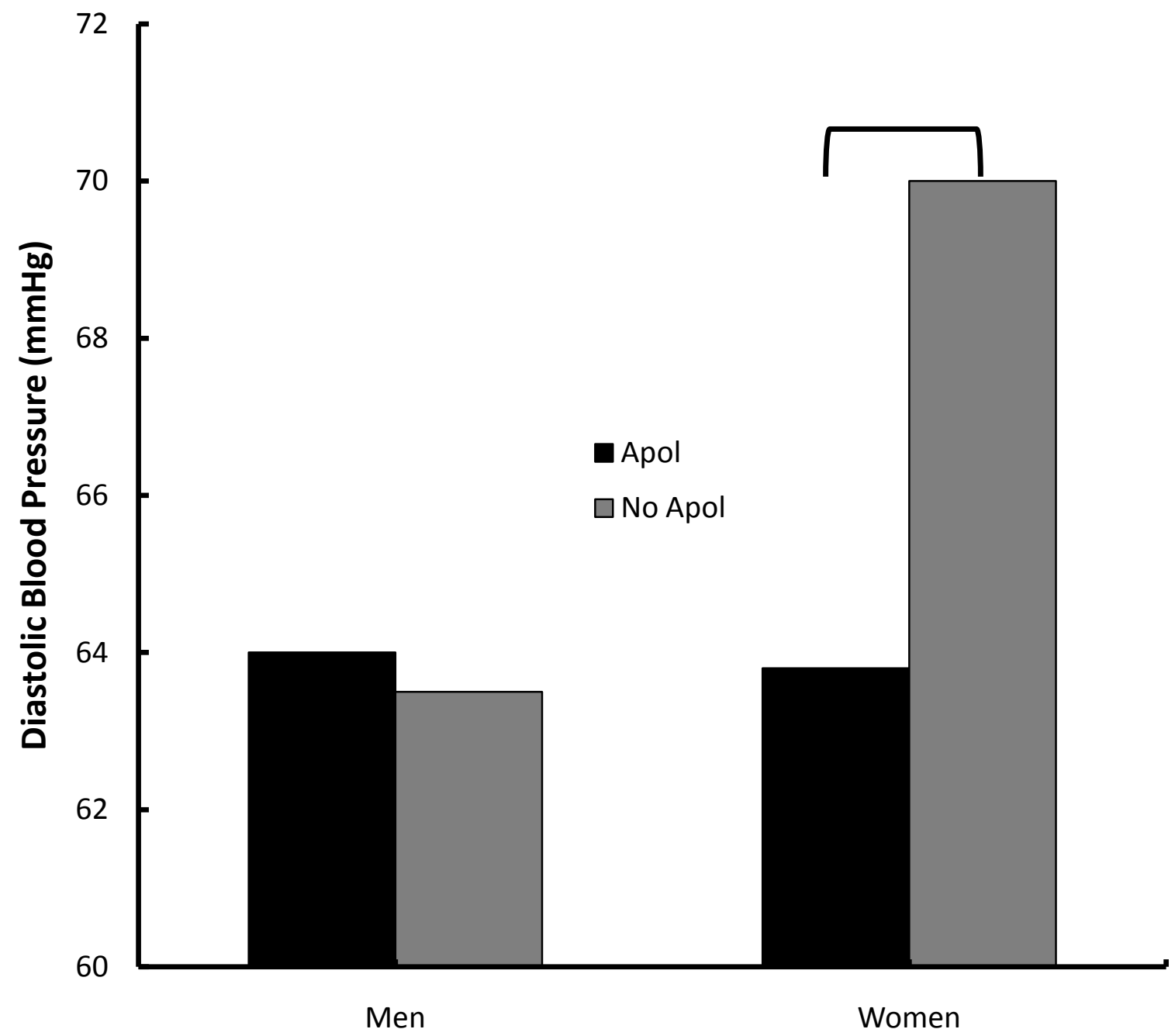

Brackets indicate significant difference, $p<.01$

Figure 7 


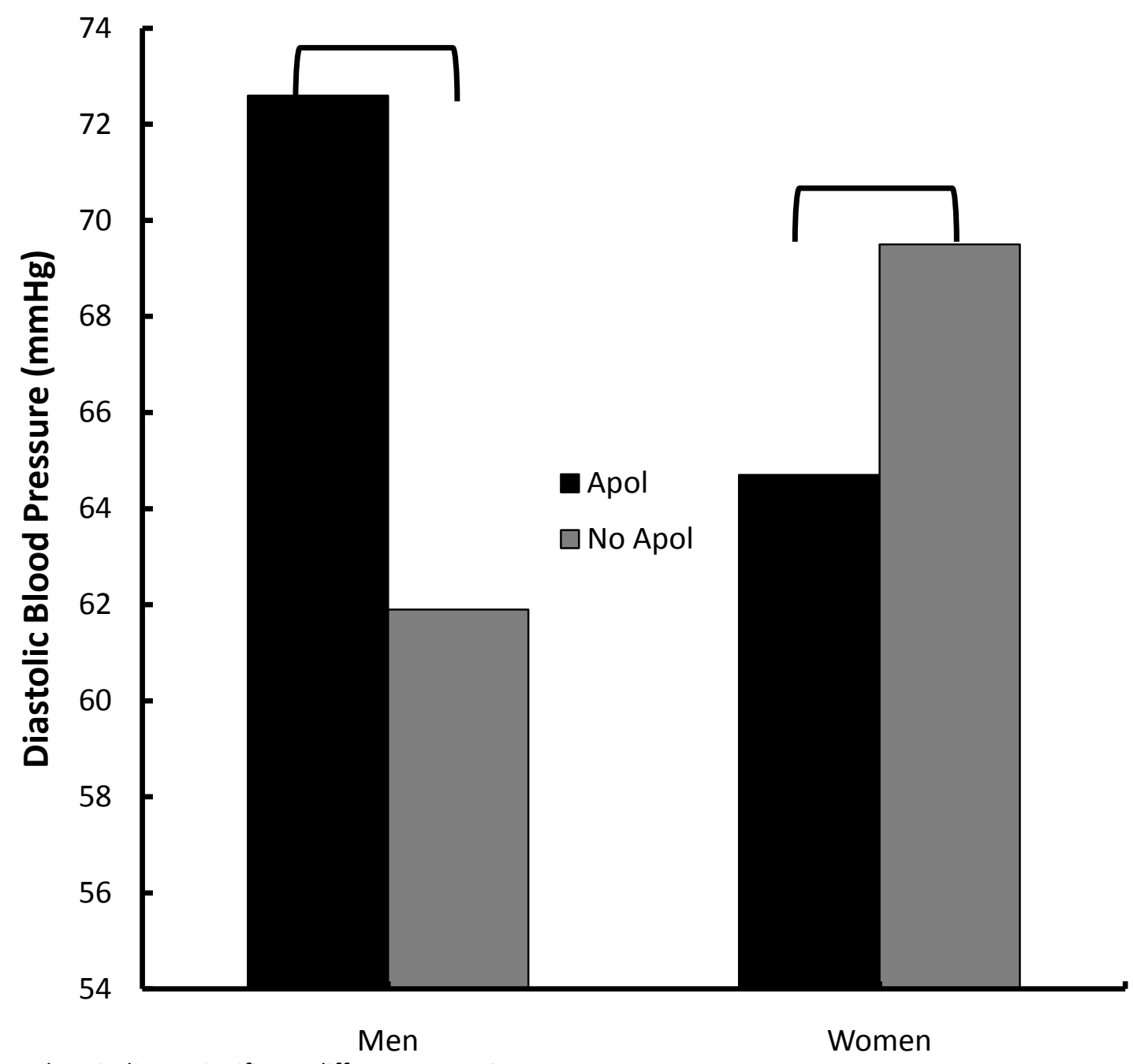

Brackets indicate significant difference, $p<.05$

Figure 8 


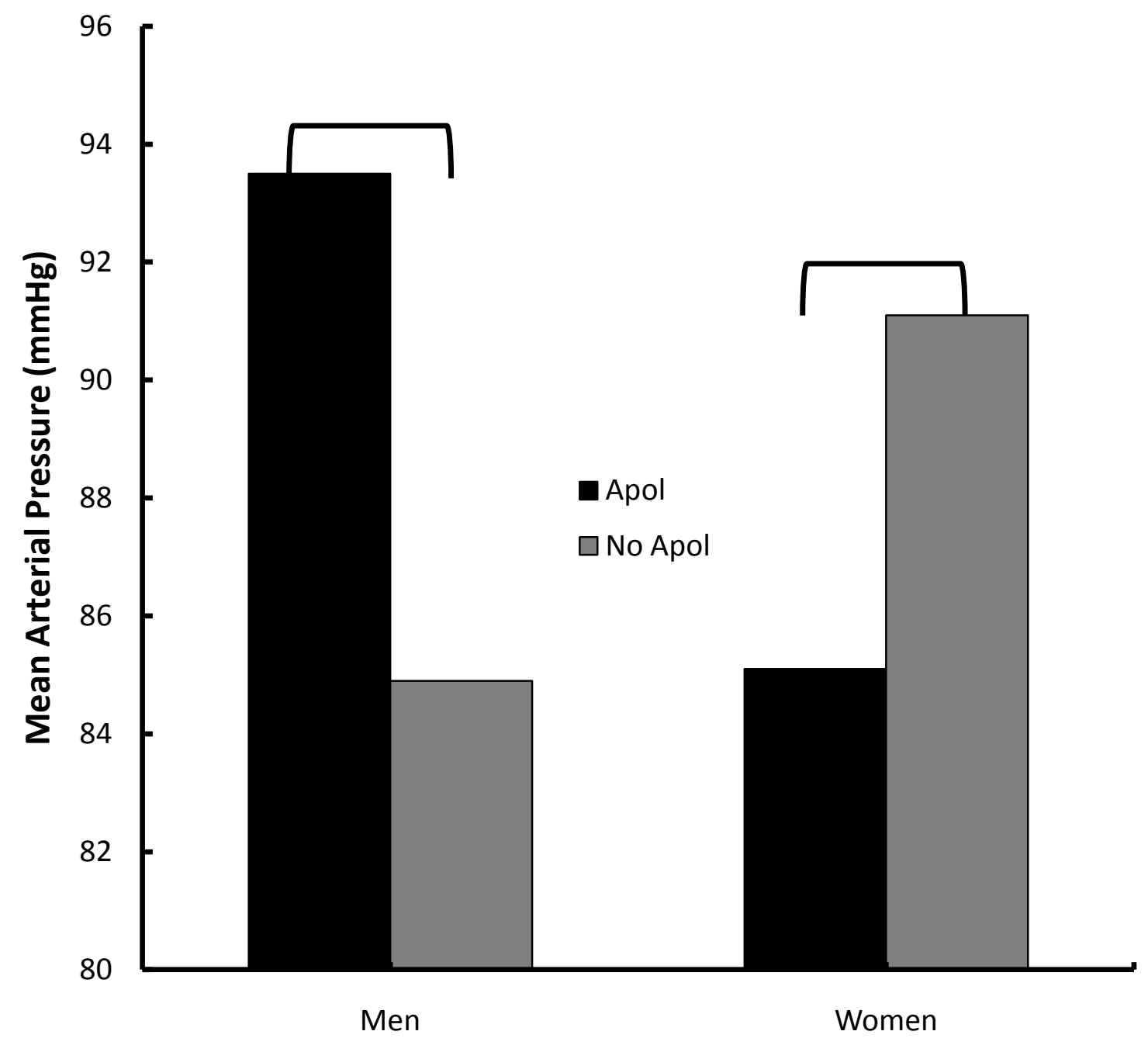

Brackets indicate significant difference, $p<.05$

Figure 9 


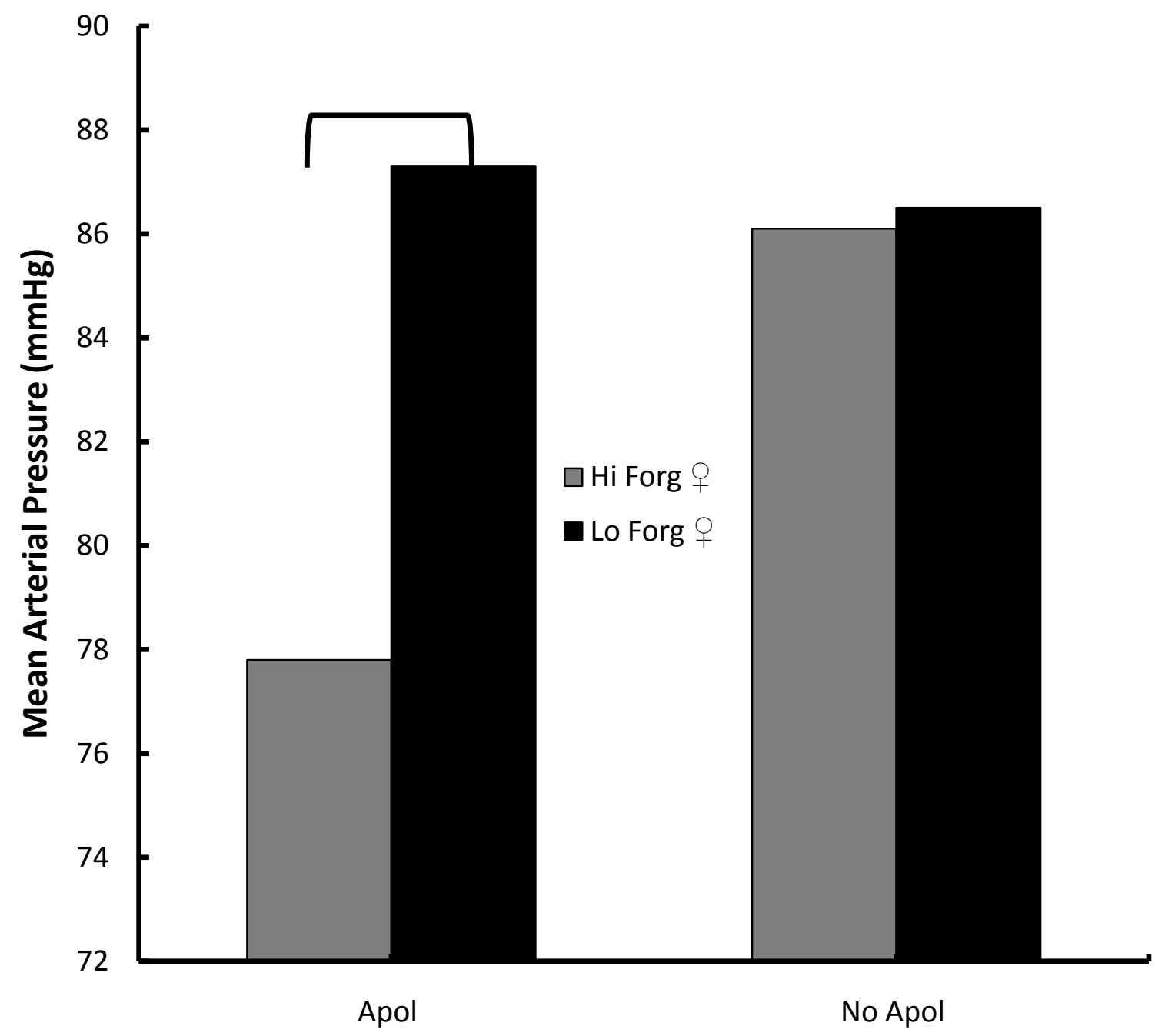

Brackets indicate significant difference, $p<.01$

Figure 10 


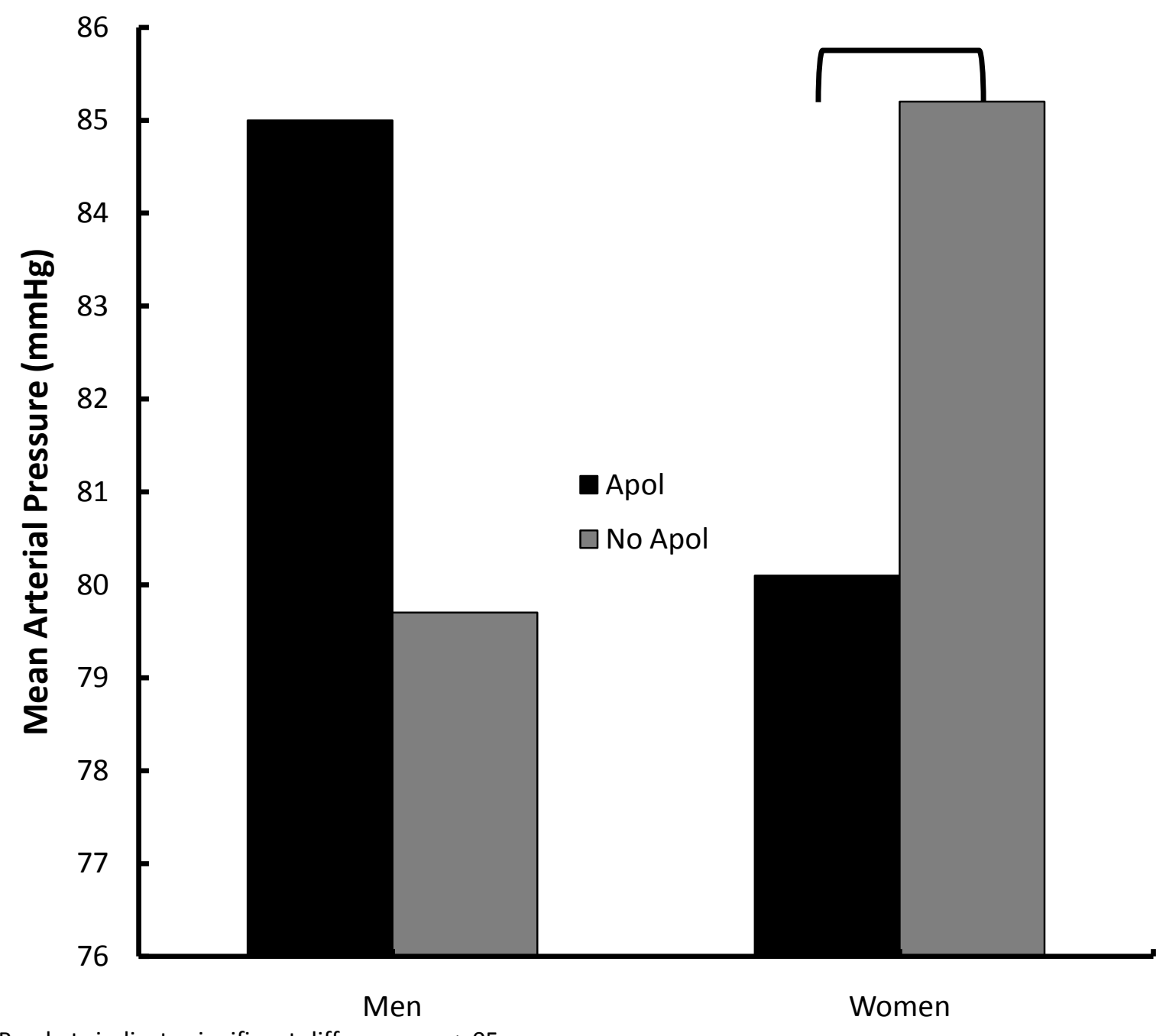

Brackets indicate significant difference, $p<.05$

Figure 11 


\section{Appendix A}

Demographics Questionnaire

SONA code \#:

\section{Your Information:}

Your age

Your sex

$\circ$ Male

$\circ$ Women

Your race

$\circ$ Black

$\circ$ White

$\circ$ Hispanic

$\circ$ Native American

$\circ$ Asian

○ Biracial (specify):

$\circ$ Other

Total years of education you have completed:

$\circ$ High school

$\circ 1$ year college

- 2 years college

- 3 years college

- 4 or more years college

Please describe any cardiovascular related illness that you may have, including high blood pressure:

Please list any other medical or psychiatric problems that you have:

Please list any major surgeries and medical, or psychiatric illnesses you have had in the past. 
Females: When did you start your last menstrual cycle?

$\circ$ I am a Male

$\circ$ less than one week ago

$\circ$ one week ago

$\circ$ two weeks ago

$\circ$ three weeks ago

$\circ$ four weeks ago

$\circ$ more than four weeks ago

$\circ$ I am currently pregnant

Females: Are you currently on birth control (contraceptives).

$\circ$ I am a male

$\circ$ No

$\circ$ Yes

What type of birth control are you taking?

Please list any drugs (legal or otherwise) that you are currently taking including; birth control (contraceptives), heart medications, cold or allergy medications, over the counter medications, asthma medications, Beta-Blockers (i.e. Inderal, Tenormin), psychoactive drugs (i.e. Adderall, Xanax, Haldol, Lithium, Prozac), or diet pills.

On average, how often do you smoke cigarettes?

o never

$\circ$ I am not currently smoking

$\circ$ less than one pack per day

$\circ$ 1-2 packs per day

$\circ$ 2-3 packs per day

$\circ$ greater than 3 packs per day

On average, how often do you use smokeless tobacco?

$\circ$ never

- I am not currently using smokeless tobacco

$\circ$ 1-4 times per day

○ 5-8 times per day

$\circ$ 9-13 times per day

$\circ$ greater than thirteen times per day

How often do you drink alcohol?

$\circ$ never

$\circ$ infrequently (a few drinks per year)

$\circ$ occasionally (1-2 drinks per month) 
○ weekly (1-3 drinks per week)

○ weekly (4-7 drinks per week)

$\circ$ daily (7-14 drinks per week)

$\circ$ daily (more than 14 drinks per week)

How many cups of caffeinated coffee, tea, or soda do you have per day?

o none

- 1-2 cups per day

- 3-4 cups per day

- 5-6 cups per day

० 7-8 cups per day

$\circ$ greater than eight cups per day

How many times per week do you engage in aerobic physical activity?

$\circ$ never

o 1-2 times

o 3-6 times

o 7 or more times

For how long do you typically exercise on each occasion?

o 5-10 minutes

○ 11-15 minutes

○ 16-30 minutes

- 31-60 minutes

○ 61-90 minutes

$\circ$ more than 90 minutes

How many hours of sleep did you get last night?

$\circ$ Less than 4 hours

० 4-5 hours

○ 5-6 hours

○ 6-7 hours

○ 7-8 hours

○ 8-9 hours

$\circ$ greater than 9 hours

\section{Family Information:}

What is your best estimate of your family's total income?

○ Less than 24,999

○ 25,000 to 34,999

○ 35,000 to 49,999

○ 50,000 to 74,999

○ 75,000 to 99,999

- 100,000 to 149,999

$\circ$ Greater than 150,000 
How difficult was it for your parents to make their bill payments when you were young?

o Not difficult at all

o Somewhat difficult (missed a few payments, but rarely)

$\circ$ Very difficult (often missed payments)

o Extremely difficult (could rarely make all their payments and had to choose what bills to pay week-to-week)

Approximately how old is your biological father?

If you are adopted, mark here and report on your biological father or move to the section on your mother's health

What is your father's highest level of education

- Some High School

- Graduated High School

o Some College

- Graduated College

- Some Graduate School

- Obtained Masters Degree

- Obtained Doctoral Degree

What is your father's occupation?

Is he currently living?

$\circ$ yes

o no

Did/does your father have high blood pressure (hypertension)?

o yes

○ no

How certain are you that he did, or did not, have high blood pressure (hypertension)?

○ Absolutely $(100 \%)$ certain

○ Almost (75\%) certain

$\circ$ Not sure at all $(25 \%)$

$\circ$ No information by which to judge $(0 \%)$

Did/does your father have any heart problems such as angina (chest pains), a heart attack, or coronary heart disease?

o yes

$\circ$ no

If yes, please specify if you are able:

How certain are you that he did, or did not, have a heart problem as indicated above?

○ Absolutely $(100 \%)$ certain

$\circ$ Almost (75\%) certain 
Not sure at all $(25 \%)$

$\circ$ No information by which to judge $(0 \%)$

Did/does your father have diabetes?

$\circ$ yes

$\circ$ no

How certain are you that he did, or did not, have diabetes?

o Absolutely (100\%) certain

○ Almost (75\%) certain

$\circ$ Not sure at all $(25 \%)$

$\circ$ No information by which to judge $(0 \%)$

Did/does your father have a kidney disease (other than kidney stones)?

o yes

o no

How certain are you that he did, or did not, have a kidney disease (other than kidney stones)?

○ Absolutely (100\%) certain

$\circ$ Almost $(75 \%)$ certain

$\circ$ Not sure at all $(25 \%)$

$\circ$ No information by which to judge $(0 \%)$

Did/does your father have cancer?

o yes

$\circ$ no

How certain are you that he did, or did not, have cancer?

$\circ$ Absolutely (100\%) certain

○ Almost (75\%) certain

$\circ$ Not sure at all $(25 \%)$

$\circ$ No information by which to judge $(0 \%)$

If you know, please list what type(s) of cancer he had.

Approximately how old is your biological mother?

If you are adopted, mark here ___ and report on your biological mother

What is your mother's highest level of education

- Some High School

- Graduated High School

- Some College

- Graduated College

- Some Graduate School 
- Obtained Masters Degree

- Obtained Doctoral Degree

What is your mother's occupation?

Is she currently living?

$\circ$ yes

$\circ$ no

Did/does your mother have high blood pressure (hypertension)?

o yes

$\circ$ no

How certain are you that she did, or did not, have high blood pressure (hypertension)?

○ Absolutely $(100 \%)$ certain

- Almost (75\%) certain

$\circ$ Not sure at all $(25 \%)$

○ No information by which to judge $(0 \%)$

Did/does your mother have any heart problems such as angina (chest pains), a heart attack, or coronary heart disease?

$\circ$ yes

$\circ$ no

If yes, please specify if you are able:

How certain are you that she did, or did not, have a heart problem as indicated above?

○ Absolutely (100\%) certain

$\circ$ Almost (75\%) certain

$\circ$ Not sure at all (25\%)

$\circ$ No information by which to judge $(0 \%)$

Did/does your mother have diabetes?

$\circ$ yes

$\circ$ no

How certain are you that she did, or did not, have diabetes?

o Absolutely (100\%) certain

$\circ$ Almost (75\%) certain

$\circ$ Not sure at all (25\%)

○ No information by which to judge $(0 \%)$

Did/does your mother have a kidney disease (other than kidney stones)?

$\circ$ yes

$\circ$ no 
How certain are you that she did, or did not, have a kidney disease (other than kidney stones)?

$\circ$ Absolutely $(100 \%)$ certain

$\circ$ Almost (75\%) certain

$\circ$ Not sure at all $(25 \%)$

$\circ$ No information by which to judge $(0 \%)$

Did/does your mother have cancer?

o yes

o no

How certain are you that she did, or did not, have cancer?

$\circ$ Absolutely $(100 \%)$ certain

○ Almost (75\%) certain

$\circ$ Not sure at all $(25 \%)$

○ No information by which to judge $(0 \%)$

If you know, please list what type(s) of cancer she had? 


\section{Appendix B}

\section{FPI}

Contact the author for more information on obtaining this measure. 
Appendix C

MAACL-R

Contact the author for more information on obtaining this measure. 


\section{Appendix D}

\section{ModTRIM-12}

Contact the author for more information on obtaining this measure. 


\section{Appendix E}

\section{Post Experimental Questionnaire}

In comparison with other stressful tasks you encounter in daily life, how stressful was the math challenge?

Not Stressful at All Somewhat Stressful Very Stressful

How often do you encounter tasks like the math challenge you completed today?

Not Often at All $\quad$ Somewhat Often $\quad$ Very Often

The experimenter was instructed to give you feedback to help you perform on the math challenge. How effective was he at helping you to achieve your best performance?

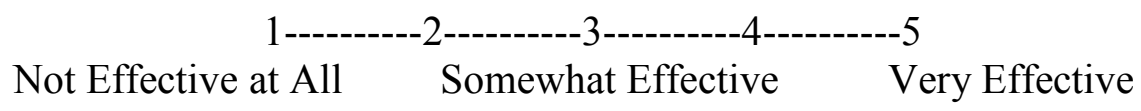

What is your impression of how much the experimenter enjoyed giving you feedback while you did the math task?

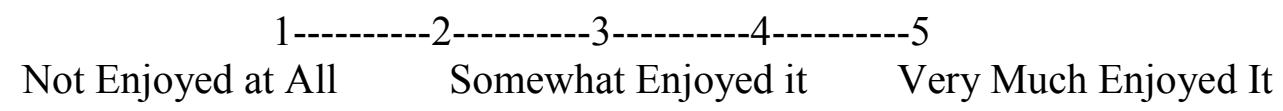

How supportive was the experimenter during completion of the math task?

$$
\text { Not Supportive at All Somewhat Supportive Very Supportive }
$$

How supportive was the experimenter after the math task was completed?

$$
\text { Not Supportive at All Somewhat Supportive Very Supportive }
$$




\section{Appendix F}

1. ANOVAs for each cardiovascular measure at baseline.

\begin{tabular}{|c|c|c|c|c|c|c|}
\hline \multicolumn{7}{|c|}{$\begin{array}{l}\text { Tests of Between Subjects } \\
\text { Effects for heart rate }\end{array}$} \\
\hline & $\mathrm{SS}$ & $\mathrm{DF}$ & MS & $\mathrm{F}$ & $p$ & $\eta_{p}^{2}$ \\
\hline \multicolumn{7}{|l|}{ Source of Variation } \\
\hline Forgiveness Level (Forg) & 18.65 & 1 & 18.65 & 0.12 & 0.73 & 0.00 \\
\hline Sex & 406.68 & 1 & 406.68 & 2.63 & 0.11 & 0.04 \\
\hline Apology Condition (Apol) & 87.12 & 1 & 87.12 & 0.56 & 0.46 & 0.01 \\
\hline Forg $\mathrm{x}$ Sex & 63.97 & 1 & 63.97 & 0.41 & 0.52 & 0.01 \\
\hline Forg x Apology & 162.08 & 1 & 162.08 & 1.05 & 0.31 & 0.02 \\
\hline Sex x Apology & 2.27 & 1 & 2.27 & 0.02 & 0.90 & 0.00 \\
\hline Forg x Apology x Sex & 2.96 & 1 & 2.96 & 0.02 & 0.89 & 0.00 \\
\hline Error & 10986.52 & 71 & 154.74 & & & \\
\hline
\end{tabular}

\section{Tests of Between Subjects}

Effects for SBP

\begin{tabular}{llllll}
$\mathrm{SS}$ & $\mathrm{DF}$ & $\mathrm{MS}$ & $\mathrm{F}$ & $p$ & $\eta_{\mathrm{p}}{ }^{2}$ \\
\hline
\end{tabular}

Source of Variation

\begin{tabular}{lllllll} 
BMI & 692.55 & 1 & 692.55 & 9.27 & 0.00 & 0.12 \\
Forgiveness Level (Forg) & 2.10 & 1 & 2.10 & 0.03 & 0.87 & 0.00 \\
Apology Condition (Apol) & 47.80 & 1 & 47.80 & 0.64 & 0.43 & 0.01 \\
Sex & 1127.32 & 1 & 1127.32 & 15.10 & 0.00 & 0.18 \\
Forg x Apology & 142.58 & 1 & 142.58 & 1.91 & 0.17 & 0.03 \\
Forg x Sex & 97.33 & 1 & 97.33 & 1.30 & 0.26 & 0.02 \\
Sex x Apology & 93.10 & 1 & 93.10 & 1.25 & 0.27 & 0.02 \\
Forg x Apology x Sex & 54.43 & 1 & 54.43 & 0.73 & 0.40 & 0.01 \\
Error & 5227.56 & 70 & 74.68 & & & \\
\hline
\end{tabular}

\begin{tabular}{|c|c|c|c|c|c|c|}
\hline \multicolumn{7}{|c|}{$\begin{array}{l}\text { Tests of Between Subjects } \\
\text { Effects for DBP }\end{array}$} \\
\hline & $\mathrm{SS}$ & DF & MS & $\mathrm{F}$ & $p$ & $\eta_{p}^{2}$ \\
\hline \multicolumn{7}{|l|}{ Source of Variation } \\
\hline Forgiveness Level (Forg) & 55.91 & 1 & 55.91 & 0.73 & 0.40 & 0.01 \\
\hline Sex & 76.89 & 1 & 76.89 & 1.00 & 0.32 & 0.01 \\
\hline Apology Condition (Apol) & 34.43 & 1 & 34.43 & 0.45 & 0.51 & 0.01 \\
\hline Forg $x$ Sex & 17.31 & 1 & 17.31 & 0.23 & 0.64 & 0.00 \\
\hline Forg x Apology & 16.52 & 1 & 16.52 & 0.22 & 0.64 & 0.00 \\
\hline Sex x Apology & 60.72 & 1 & 60.72 & 0.79 & 0.38 & 0.01 \\
\hline Forg x Apology x Sex & 49.83 & 1 & 49.83 & 0.65 & 0.42 & 0.01 \\
\hline Error & 5451.04 & 71 & 76.78 & & & \\
\hline
\end{tabular}




\begin{tabular}{|c|c|c|c|c|c|c|}
\hline \multicolumn{7}{|c|}{$\begin{array}{l}\text { Tests of Between Subjects } \\
\text { Effects for MAP }\end{array}$} \\
\hline & SS & DF & MS & $\mathrm{F}$ & $p$ & $\eta_{\mathrm{p}}^{2}$ \\
\hline \multicolumn{7}{|l|}{ Source of Variation } \\
\hline Forgiveness Level (Forg) & 19.93 & 1 & 19.93 & 0.42 & 0.52 & 0.01 \\
\hline Sex & 45.72 & 1 & 45.72 & 0.97 & 0.33 & 0.01 \\
\hline Apology Condition (Apol) & 2.30 & 1 & 2.30 & 0.05 & 0.83 & 0.00 \\
\hline Forg $x$ Sex & 0.36 & 1 & 0.36 & 0.01 & 0.93 & 0.00 \\
\hline Forg x Apology & 2.56 & 1 & 2.56 & 0.05 & 0.82 & 0.00 \\
\hline Sex x Apology & 7.44 & 1 & 7.44 & 0.16 & 0.69 & 0.00 \\
\hline Forg x Apology x Sex & 1.49 & 1 & 1.48 & 0.03 & 0.86 & 0.00 \\
\hline Error & 3361.36 & 71 & 47.34 & & & \\
\hline
\end{tabular}


2. ANCOVAs investigating reactivity for each cardiovascular measure.

\begin{tabular}{|c|c|c|c|c|c|c|}
\hline \multicolumn{7}{|c|}{$\begin{array}{l}\text { Tests of Between Subjects } \\
\text { Effects for heart rate }\end{array}$} \\
\hline & SS & DF & MS & $\mathrm{F}$ & $p$ & $\eta_{\mathrm{p}}^{2}$ \\
\hline \multicolumn{7}{|l|}{ Source of Variation } \\
\hline Covariate (rest) & 9255.06 & 1 & 9255.06 & 68.44 & 0.00 & 0.50 \\
\hline Forgiveness Level (Forg) & 18.23 & 1 & 18.23 & 0.14 & 0.72 & 0.00 \\
\hline Sex & 265.65 & 1 & 265.65 & 1.97 & 0.17 & 0.03 \\
\hline Apology Condition (Apol) & 0.00 & 1 & 0.00 & 0.00 & 0.99 & 0.00 \\
\hline Forg $x$ Sex & 35.74 & 1 & 35.74 & 0.26 & 0.61 & 0.00 \\
\hline Forg x Apology & 0.42 & 1 & 0.42 & 0.00 & 0.96 & 0.00 \\
\hline Sex x Apology & 28.03 & 1 & 28.03 & 0.21 & 0.65 & 0.00 \\
\hline Forg x Apology x Sex & 3.63 & 1 & 3.63 & 0.03 & 0.87 & 0.00 \\
\hline Error & 9330.52 & 69 & 135.23 & & & \\
\hline
\end{tabular}

\section{Tests of Between Subjects} Effects for SBP

\begin{tabular}{|c|c|c|c|c|c|c|}
\hline & $\mathrm{SS}$ & DF & MS & $\mathrm{F}$ & $p$ & $\eta_{\mathrm{p}}^{2}$ \\
\hline \multicolumn{7}{|l|}{ Source of Variation } \\
\hline Covariate (rest) & 5329.75 & 1 & 5329.75 & 76.00 & 0.00 & 0.52 \\
\hline BMI & 200.39 & 1 & 200.39 & 2.86 & 0.10 & 0.04 \\
\hline Forgiveness Level (Forg) & 13.83 & 1 & 13.83 & 0.20 & 0.66 & 0.00 \\
\hline Apology Condition (Apol) & 8.34 & 1 & 8.34 & 0.12 & 0.73 & 0.00 \\
\hline Sex & 37.70 & 1 & 37.70 & 0.54 & 0.47 & 0.01 \\
\hline Forg x Apology & 16.79 & 1 & 16.79 & 0.24 & 0.63 & 0.00 \\
\hline Forg $x$ Sex & 27.36 & 1 & 27.36 & 0.39 & 0.53 & 0.01 \\
\hline Sex x Apology & 2.67 & 1 & 2.67 & 0.04 & 0.85 & 0.00 \\
\hline Forg x Apology x Sex & 4.45 & 1 & 4.45 & 0.06 & 0.80 & 0.00 \\
\hline Error & 4839.06 & 69 & 70.13 & & & \\
\hline
\end{tabular}

\section{Tests of Between Subjects}

Effects for DBP

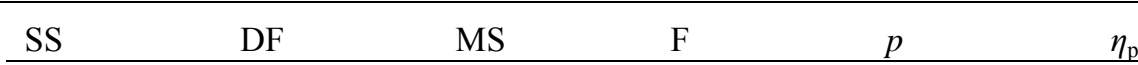

Source of Variation

\begin{tabular}{lllllll} 
Covariate (rest) & 2848.79 & 1 & 2848.79 & 37.74 & 0.00 & 0.35 \\
Forgiveness Level (Forg) & 213.22 & 1 & 213.22 & 2.83 & 0.10 & 0.04 \\
Sex & 0.48 & 1 & 0.48 & 0.01 & 0.94 & 0.00 \\
Apology Condition (Apol) & 2.93 & 1 & 2.93 & 0.04 & 0.84 & 0.00 \\
Forg x Sex & 8.49 & 1 & 8.49 & 0.11 & 0.74 & 0.00 \\
Forg x Apology & 73.80 & 1 & 73.80 & 0.98 & 0.33 & 0.01 \\
Sex x Apology & 240.58 & 1 & 240.58 & 3.19 & 0.08 & 0.04 \\
Forg x Apology x Sex & 21.13 & 1 & 21.13 & 0.28 & 0.60 & 0.00 \\
Error & 5283.41 & 70 & 75.48 & & & \\
\hline
\end{tabular}




\begin{tabular}{|c|c|c|c|c|c|c|}
\hline \multicolumn{7}{|c|}{$\begin{array}{l}\text { Tests of Between Subjects } \\
\text { Effects for MAP }\end{array}$} \\
\hline & SS & DF & MS & $\mathrm{F}$ & $p$ & $\eta_{\mathrm{p}}^{2}$ \\
\hline \multicolumn{7}{|l|}{ Source of Variation } \\
\hline Covariate (rest) & 1883.47 & 1 & 1883.47 & 45.20 & 0.00 & 0.39 \\
\hline Forgiveness Level (Forg) & 127.95 & 1 & 127.95 & 3.07 & 0.08 & 0.04 \\
\hline Sex & 20.13 & 1 & 20.13 & 0.48 & 0.49 & 0.01 \\
\hline Apology Condition (Apol) & 7.75 & 1 & 7.75 & 0.19 & 0.67 & 0.00 \\
\hline Forg $\mathrm{x}$ Sex & 1.26 & 1 & 1.26 & 0.03 & 0.86 & 0.00 \\
\hline Forg x Apology & 28.69 & 1 & 28.69 & 0.69 & 0.41 & 0.01 \\
\hline Sex x Apology & 147.61 & 1 & 147.61 & 3.54 & 0.06 & 0.05 \\
\hline Forg x Apology x Sex & 7.94 & 1 & 7.94 & 0.19 & 0.66 & 0.00 \\
\hline Error & 2916.67 & 70 & 41.67 & & & \\
\hline
\end{tabular}


3a. ANCOVA investigating heart rate recovery (Area under the curve analysis)

\begin{tabular}{lllllll}
\hline \begin{tabular}{l} 
Tests of Between Subjects $\begin{array}{llll}\text { Effects for heart rate } \\
\text { Source of Variation }\end{array}$ \\
\cline { 2 - 7 }
\end{tabular} & \multicolumn{7}{l}{ DS } & MS & F & $p$ & $\eta_{\mathrm{p}}{ }^{2}$ \\
\hline Intercept & $5.23 \mathrm{E} 7$ & 1 & $5.23 \mathrm{E} 7$ & 8.48 & 0.01 & 0.11 \\
Covariate (rest) & $4.58 \mathrm{E} 7$ & 1 & $4.58 \mathrm{E} 7$ & 7.41 & 0.01 & 0.10 \\
Forg & 1786614.08 & 1 & 1786614.08 & 0.29 & 0.59 & 0.00 \\
Sex & 7062.34 & 1 & 7062.34 & 0.00 & 0.97 & 0.00 \\
Apol & 2477975.47 & 1 & 2477975.47 & 0.40 & 0.53 & 0.01 \\
Forg x Sex & 1980888.20 & 1 & 1980888.20 & 0.32 & 0.57 & 0.01 \\
Forg x Apology & 617535.42 & 1 & 617535.42 & 0.10 & 0.75 & 0.00 \\
Sex x Apology & 459118.54 & 1 & 459118.54 & 0.07 & 0.79 & 0.00 \\
Forg x Apology x Sex & $1.77 \mathrm{E} 7$ & 1 & $1.77 \mathrm{E} 7$ & 2.87 & 0.10 & 0.04 \\
Error & $4.26 \mathrm{E} 8$ & 69 & 6173325.66 & & & \\
\hline
\end{tabular}


3b. ANCOVA investigating SBP recovery (Area under the curve analysis)

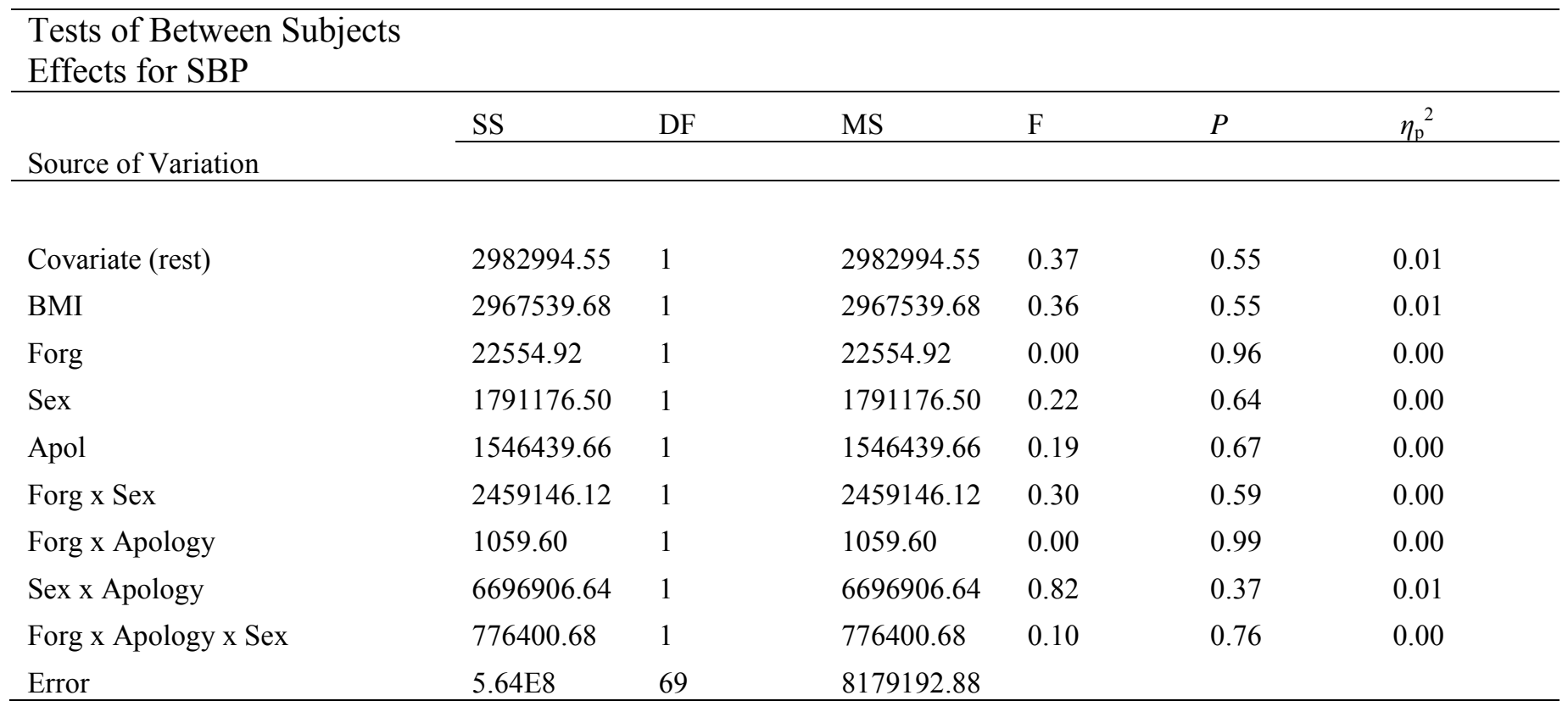


3c. ANCOVA investigating DBP recovery (Area under the curve analysis)

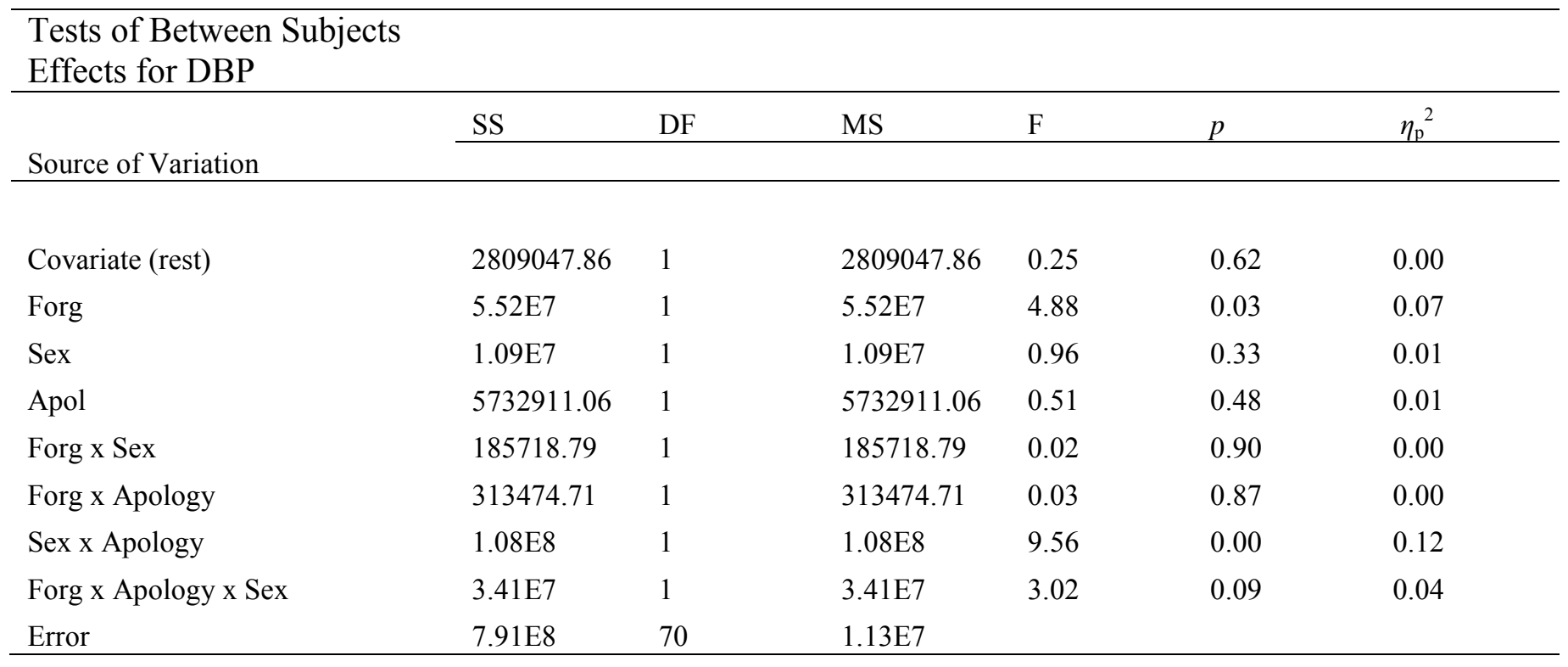


3d. Mixed Factors ANCOVA investigating DBP recovery

\begin{tabular}{|c|c|c|c|c|c|c|}
\hline \multicolumn{7}{|l|}{$\begin{array}{l}\text { Tests of Within Subjects } \\
\text { Effects for DBP }\end{array}$} \\
\hline & SS & DF & MS & $\mathrm{F}$ & $P$ & $\eta_{p}^{2}$ \\
\hline \multicolumn{7}{|l|}{ Source of Variation } \\
\hline Minute (min) & 352.09 & 5 & 70.42 & 1.47 & 0.20 & 0.02 \\
\hline Min $\mathrm{x}$ covariate (rest) & 385.28 & 5 & 77.06 & 1.61 & 0.16 & 0.02 \\
\hline Min x Forgiveness Level (Forg) & 14.71 & 5 & 2.94 & 0.06 & 1.00 & 0.00 \\
\hline Min $x$ Sex & 231.94 & 5 & 46.39 & 0.97 & 0.44 & 0.01 \\
\hline Min x Apology Condition (Apol) & 337.00 & 5 & 67.35 & 1.41 & 0.22 & 0.02 \\
\hline Min $x$ Forg $x$ Sex & 705.24 & 5 & 141.05 & 2.95 & 0.01 & 0.04 \\
\hline Min $x$ Forg $x$ Apol & 269.82 & 5 & 53.96 & 1.13 & 0.35 & 0.02 \\
\hline Min x Apol x Sex & 430.48 & 5 & 86.10 & 1.80 & 0.11 & 0.03 \\
\hline Min $x$ Forg x Apol x Sex & 830.47 & 5 & 166.09 & 3.47 & 0.00 & 0.05 \\
\hline Error & 16735.75 & 350 & 47.82 & & & \\
\hline \multicolumn{7}{|l|}{$\begin{array}{l}\text { Tests of Between Subjects } \\
\text { Effects for DBP }\end{array}$} \\
\hline & SS & DF & MS & $\mathrm{F}$ & $P$ & $\eta_{\mathrm{p}}^{2}$ \\
\hline \multicolumn{7}{|l|}{ Source of Variation } \\
\hline Covariate (rest) & 19013.71 & 1 & 19013.71 & 101.42 & 0.00 & 0.59 \\
\hline Forg & 940.15 & 1 & 940.15 & 5.02 & 0.03 & 0.07 \\
\hline Sex & 138.88 & 1 & 138.88 & 0.74 & 0.39 & 0.01 \\
\hline Apol & 43.59 & 1 & 43.59 & 0.23 & 0.63 & 0.00 \\
\hline Forg $x$ Sex & 1.29 & 1 & 1.29 & 0.01 & 0.93 & 0.00 \\
\hline Forg x Apology & 26.44 & 1 & 26.44 & 0.14 & 0.71 & 0.00 \\
\hline Sex x Apology & 2315.37 & 1 & 2315.37 & 12.35 & 0.00 & 0.15 \\
\hline Forg x Apology x Sex & 289.46 & 1 & 289.46 & 1.54 & 0.22 & 0.02 \\
\hline Error & 13123.26 & 70 & 187.48 & & & \\
\hline
\end{tabular}


3e. ANCOVA investigating MAP recovery (Area under the curve analysis)

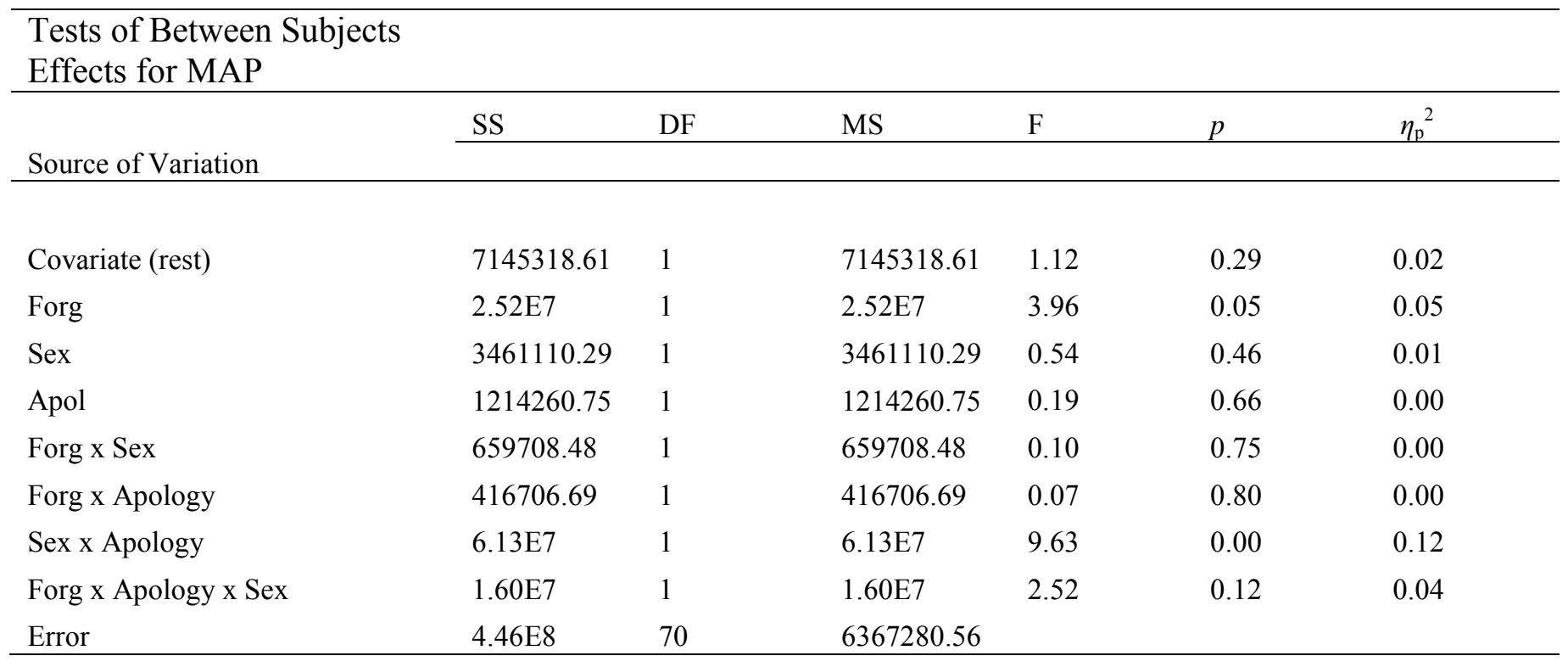




\section{3f. Mixed Factors ANCOVA investigating MAP recovery}

\begin{tabular}{|c|c|c|c|c|c|c|}
\hline \multicolumn{7}{|l|}{$\begin{array}{l}\text { Tests of Within Subjects } \\
\text { Effects for MAP }\end{array}$} \\
\hline & SS & DF & MS & $\mathrm{F}$ & $p$ & $\eta_{p}^{2}$ \\
\hline \multicolumn{7}{|l|}{ Source of Variation } \\
\hline Minute (min) & 300.93 & 5 & 60.19 & 2.05 & 0.07 & 0.03 \\
\hline Min $\mathrm{x}$ covariate (rest) & 209.68 & 5 & 41.94 & 1.43 & 0.21 & 0.02 \\
\hline Min x Forgiveness Level (Forg) & 33.08 & 5 & 6.62 & 0.23 & 0.95 & 0.00 \\
\hline Min $x$ Sex & 72.87 & 5 & 14.57 & 0.50 & 0.78 & 0.01 \\
\hline Min x Apology Condition (Apol) & 146.00 & 5 & 29.14 & 0.99 & 0.42 & 0.01 \\
\hline Min $x$ Forg $x$ Sex & 452.48 & 5 & 90.50 & 3.09 & 0.01 & 0.04 \\
\hline Min $x$ Forg x Apol & 91.07 & 5 & 18.21 & 0.62 & 0.68 & 0.01 \\
\hline Min $x$ Apol x Sex & 399.97 & 5 & 79.99 & 2.73 & 0.02 & 0.04 \\
\hline Min x Forg x Apol x Sex & 352.62 & 5 & 70.53 & 2.41 & 0.04 & 0.03 \\
\hline Error & 10258.14 & 350 & 29.31 & & & \\
\hline \multicolumn{7}{|l|}{$\begin{array}{l}\text { Tests of Between Subjects } \\
\text { Effects for MAP }\end{array}$} \\
\hline & SS & DF & MS & $\mathrm{F}$ & $p$ & $\eta_{p}^{2}$ \\
\hline \multicolumn{7}{|l|}{ Source of Variation } \\
\hline Covariate (rest) & 10413.27 & 1 & 10413.27 & 100.57 & 0.00 & 0.59 \\
\hline Forg & 401.73 & 1 & 401.73 & 3.88 & 0.05 & 0.05 \\
\hline Sex & 36.22 & 1 & 36.22 & 0.35 & 0.56 & 0.01 \\
\hline Apol & 2.13 & 1 & 2.13 & 0.02 & 0.89 & 0.00 \\
\hline Forg $x$ Sex & 16.34 & 1 & 16.34 & 0.16 & 0.69 & 0.00 \\
\hline Forg x Apology & 22.69 & 1 & 22.69 & 0.22 & 0.64 & 0.00 \\
\hline Sex x Apology & 1393.66 & 1 & 1393.66 & 13.46 & 0.00 & 0.16 \\
\hline Forg x Apology x Sex & 151.75 & 1 & 151.75 & 1.47 & 0.23 & 0.02 \\
\hline Error & 7247.66 & 70 & 103.54 & & & \\
\hline
\end{tabular}


4a. ANCOVAs investigating relevant factors at each minute of the recovery period for DBP.

\begin{tabular}{|c|c|c|c|c|c|c|c|}
\hline \multicolumn{8}{|c|}{ Tests of Between Subjects Effects } \\
\hline & Dependent Variable & SS & DF & MS & $\mathrm{F}$ & $p$ & $\eta_{\mathrm{p}}^{2}$ \\
\hline \multicolumn{8}{|l|}{ Source of Variation } \\
\hline \multicolumn{8}{|l|}{ Covariate (rest) } \\
\hline & Recovery min 1 & 2229.98 & 1 & 2229.98 & 19.16 & 0.00 & 0.22 \\
\hline & Recovery min 3 & 1976.10 & 1 & 1976.10 & 24.48 & 0.00 & 0.26 \\
\hline & Recovery min 5 & 4035.86 & 1 & 4035.86 & 60.32 & 0.00 & 0.46 \\
\hline & Recovery $\min 7$ & 3112.43 & 1 & 3112.43 & 57.46 & 0.00 & 0.45 \\
\hline & Recovery $\min 9$ & 3743.51 & 1 & 3743.51 & 78.54 & 0.00 & 0.53 \\
\hline & Recovery $\min 11$ & 4301.13 & 1 & 4301.13 & 70.90 & 0.00 & 0.50 \\
\hline \multicolumn{8}{|l|}{ Apology } \\
\hline & Recovery min 1 & 20.52 & 1 & 20.52 & 0.18 & 0.68 & 0.00 \\
\hline & Recovery $\min 3$ & 0.01 & 1 & 0.01 & 0.00 & 0.99 & 0.00 \\
\hline & Recovery min 5 & 45.46 & 1 & 45.46 & 0.68 & 0.41 & 0.01 \\
\hline & Recovery min 7 & 144.13 & 1 & 144.13 & 2.66 & 0.11 & 0.04 \\
\hline & Recovery min 9 & 24.07 & 1 & 24.07 & 0.51 & 0.48 & 0.01 \\
\hline & Recovery $\min 11$ & 146.15 & 1 & 146.15 & 2.41 & 0.13 & 0.03 \\
\hline \multicolumn{8}{|l|}{ Forgiveness Level } \\
\hline & Recovery min 1 & 183.61 & 1 & 183.61 & 1.58 & 0.21 & 0.02 \\
\hline & Recovery min 3 & 151.37 & 1 & 151.37 & 1.88 & 0.18 & 0.03 \\
\hline & Recovery min 5 & 207.41 & 1 & 207.41 & 3.10 & 0.08 & 0.04 \\
\hline & Recovery $\min 7$ & 87.73 & 1 & 87.73 & 1.62 & 0.21 & 0.02 \\
\hline & Recovery $\min 9$ & 160.08 & 1 & 160.08 & 3.36 & 0.07 & 0.05 \\
\hline & Recovery $\min 11$ & 164.67 & 1 & 164.67 & 2.72 & 0.10 & 0.04 \\
\hline \multicolumn{8}{|l|}{ Sex } \\
\hline & Recovery min 1 & 119.52 & 1 & 119.52 & 1.03 & 0.31 & 0.01 \\
\hline & Recovery $\min 3$ & 64.99 & 1 & 64.99 & 0.81 & 0.37 & 0.01 \\
\hline & Recovery min 5 & 14.71 & 1 & 14.71 & 0.22 & 0.64 & 0.00 \\
\hline & Recovery min 7 & 28.66 & 1 & 28.66 & 0.53 & 0.47 & 0.01 \\
\hline & Recovery $\min 9$ & 77.23 & 1 & 77.23 & 1.62 & 0.21 & 0.02 \\
\hline & Recovery $\min 11$ & 65.70 & 1 & 65.70 & 1.08 & 0.30 & 0.02 \\
\hline \multicolumn{8}{|l|}{ Apology x Forg } \\
\hline & Recovery min 1 & 0.01 & 1 & 0.01 & 0.00 & 0.99 & 0.00 \\
\hline & Recovery min 3 & 17.06 & 1 & 17.06 & 0.21 & 0.65 & 0.00 \\
\hline & Recovery min 5 & 1.50 & 1 & 1.50 & 0.02 & 0.88 & 0.00 \\
\hline & Recovery $\min 7$ & 28.40 & 1 & 28.40 & 0.52 & 0.47 & 0.01 \\
\hline & Recovery $\min 9$ & 0.71 & 1 & 0.71 & 0.02 & 0.90 & 0.00 \\
\hline & Recovery $\min 11$ & 248.60 & 1 & 248.60 & 4.10 & 0.05 & 0.06 \\
\hline \multicolumn{8}{|l|}{ Apology x Sex } \\
\hline & Recovery min 1 & 1015.85 & 1 & 1015.85 & 8.73 & 0.00 & 0.11 \\
\hline & Recovery min 3 & 322.93 & 1 & 322.93 & 4.00 & 0.05 & 0.05 \\
\hline & Recovery $\min 5$ & 192.75 & 1 & 192.75 & 2.88 & 0.09 & 0.04 \\
\hline & Recovery min 7 & 155.74 & 1 & 155.74 & 2.88 & 0.09 & 0.04 \\
\hline & Recovery $\min 9$ & 122.36 & 1 & 122.36 & 2.57 & 0.11 & 0.04 \\
\hline & Recovery $\min 11$ & 936.22 & 1 & 936.22 & 15.43 & 0.00 & 0.18 \\
\hline \multicolumn{8}{|l|}{ Forg x Sex } \\
\hline & Recovery $\min 1$ & 224.17 & 1 & 224.17 & 1.93 & 0.17 & 0.03 \\
\hline & Recovery min 3 & 97.39 & 1 & 97.39 & 1.21 & 0.28 & 0.02 \\
\hline & Recovery min 5 & 74.19 & 1 & 74.19 & 1.11 & 0.30 & 0.02 \\
\hline
\end{tabular}




\begin{tabular}{|c|c|c|c|c|c|c|c|}
\hline & Recovery $\min 7$ & 30.02 & 1 & 30.02 & 0.55 & 0.46 & 0.01 \\
\hline & Recovery min 9 & 5.44 & 1 & 5.44 & 0.11 & 0.74 & 0.00 \\
\hline & Recovery min 11 & 275.33 & 1 & 275.33 & 4.54 & 0.04 & 0.06 \\
\hline \multicolumn{8}{|l|}{ Forg x Apol x Sex } \\
\hline & Recovery min 1 & 0.67 & 1 & 0.67 & 0.01 & 0.94 & 0.00 \\
\hline & Recovery min 3 & 447.69 & 1 & 447.69 & 5.55 & 0.02 & 0.07 \\
\hline & Recovery min 5 & 112.71 & 1 & 112.71 & 1.69 & 0.20 & 0.02 \\
\hline & Recovery $\min 7$ & 296.29 & 1 & 296.29 & 5.47 & 0.02 & 0.07 \\
\hline & Recovery $\min 9$ & 44.19 & 1 & 44.19 & 0.93 & 0.34 & 0.01 \\
\hline & Recovery min 11 & 218.39 & 1 & 218.39 & 3.60 & 0.06 & 0.05 \\
\hline \multicolumn{8}{|l|}{ Error } \\
\hline & Recovery min 1 & 8149.02 & 70 & 116.42 & & & \\
\hline & Recovery min 3 & 5651.79 & 70 & 80.74 & & & \\
\hline & Recovery min 5 & 4683.77 & 70 & 66.91 & & & \\
\hline & Recovery min 7 & 3791.47 & 70 & 54.16 & & & \\
\hline & Recovery min 9 & 3336.59 & 70 & 47.67 & & & \\
\hline & Recovery $\min 11$ & 4246.37 & 70 & 60.66 & & & \\
\hline
\end{tabular}


4b. ANCOVAs investigating relevant factors at each minute of the recovery period for MAP.

\begin{tabular}{|c|c|c|c|c|c|c|c|}
\hline \multicolumn{8}{|c|}{ Tests of Between Subjects Effects } \\
\hline & Dependent Variable & SS & DF & MS & $\mathrm{F}$ & $P$ & $\eta_{\mathrm{p}}^{2}$ \\
\hline \multicolumn{8}{|l|}{ Source of Variation } \\
\hline \multicolumn{8}{|l|}{ Covariate (rest) } \\
\hline & Recovery min 1 & 1071.78 & 1 & 1071.78 & 14.62 & 0.00 & 0.17 \\
\hline & Recovery $\min 3$ & 1208.10 & 1 & 1208.10 & 24.92 & 0.00 & 0.26 \\
\hline & Recovery $\min 5$ & 2121.72 & 1 & 2121.72 & 50.81 & 0.00 & 0.42 \\
\hline & Recovery $\min 7$ & 1759.13 & 1 & 1759.13 & 54.90 & 0.00 & 0.44 \\
\hline & Recovery $\min 9$ & 2166.49 & 1 & 2166.49 & 93.15 & 0.00 & 0.57 \\
\hline & Recovery min 11 & 2295.73 & 1 & 2295.73 & 73.52 & 0.00 & 0.51 \\
\hline \multicolumn{8}{|l|}{ Apology } \\
\hline & Recovery min 1 & 10.24 & 1 & 10.24 & 0.14 & 0.71 & 0.00 \\
\hline & Recovery $\min 3$ & 0.05 & 1 & 0.05 & 0.00 & 0.97 & 0.00 \\
\hline & Recovery min 5 & 19.11 & 1 & 19.11 & 0.46 & 0.50 & 0.01 \\
\hline & Recovery $\min 7$ & 38.20 & 1 & 38.20 & 1.19 & 0.28 & 0.02 \\
\hline & Recovery min 9 & 16.06 & 1 & 16.06 & 0.69 & 0.41 & 0.01 \\
\hline & Recovery $\min 11$ & 64.15 & 1 & 64.15 & 2.05 & 0.16 & 0.03 \\
\hline \multicolumn{8}{|l|}{ Forgiveness Level } \\
\hline & Recovery min 1 & 45.25 & 1 & 45.25 & 0.62 & 0.44 & 0.01 \\
\hline & Recovery min 3 & 78.93 & 1 & 78.93 & 1.63 & 0.21 & 0.02 \\
\hline & Recovery min 5 & 169.32 & 1 & 169.32 & 4.06 & 0.05 & 0.06 \\
\hline & Recovery $\min 7$ & 35.29 & 1 & 35.29 & 1.10 & 0.30 & 0.02 \\
\hline & Recovery $\min 9$ & 46.28 & 1 & 46.28 & 1.99 & 0.16 & 0.03 \\
\hline & Recovery min 11 & 59.73 & 1 & 59.73 & 1.91 & 0.17 & 0.03 \\
\hline \multicolumn{8}{|l|}{ Sex } \\
\hline & Recovery min 1 & 1.68 & 1 & 1.68 & 0.02 & 0.88 & 0.00 \\
\hline & Recovery min 3 & 5.51 & 1 & 5.51 & 0.11 & 0.74 & 0.00 \\
\hline & Recovery min 5 & 5.86 & 1 & 5.86 & 0.14 & 0.71 & 0.00 \\
\hline & Recovery $\min 7$ & 5.91 & 1 & 5.91 & 0.19 & 0.67 & 0.00 \\
\hline & Recovery $\min 9$ & 82.18 & 1 & 82.18 & 3.53 & 0.06 & 0.05 \\
\hline & Recovery min 11 & 7.95 & 1 & 7.95 & 0.25 & 0.62 & 0.00 \\
\hline \multicolumn{8}{|l|}{ Apology x Forg } \\
\hline & Recovery min 1 & 10.70 & 1 & 10.70 & 0.15 & 0.70 & 0.00 \\
\hline & Recovery $\min 3$ & 4.40 & 1 & 4.40 & 0.09 & 0.76 & 0.00 \\
\hline & Recovery min 5 & 0.29 & 1 & 0.29 & 0.01 & 0.93 & 0.00 \\
\hline & Recovery $\min 7$ & 11.74 & 1 & 11.74 & 0.37 & 0.55 & 0.01 \\
\hline & Recovery $\min 9$ & 0.02 & 1 & 0.02 & 0.00 & 0.98 & 0.00 \\
\hline & Recovery min 11 & 86.62 & 1 & 86.62 & 2.77 & 0.10 & 0.04 \\
\hline \multicolumn{8}{|l|}{ Apology x Sex } \\
\hline & Recovery min 1 & 855.01 & 1 & 855.01 & 11.66 & 0.00 & 0.14 \\
\hline & Recovery min 3 & 175.70 & 1 & 175.70 & 3.62 & 0.06 & 0.05 \\
\hline & Recovery min 5 & 101.62 & 1 & 101.62 & 2.43 & 0.12 & 0.03 \\
\hline & Recovery min 7 & 82.46 & 1 & 82.46 & 2.57 & 0.11 & 0.04 \\
\hline & Recovery min 9 & 44.50 & 1 & 44.50 & 1.91 & 0.17 & 0.03 \\
\hline & Recovery $\min 11$ & 534.34 & 1 & 534.34 & 17.11 & 0.00 & 0.20 \\
\hline \multicolumn{8}{|l|}{ Forg x Sex } \\
\hline & Recovery min 1 & 260.89 & 1 & 260.89 & 3.56 & 0.06 & 0.05 \\
\hline & Recovery min 3 & 53.70 & 1 & 53.70 & 1.11 & 0.30 & 0.02 \\
\hline & Recovery min 5 & 44.08 & 1 & 44.08 & 1.06 & 0.31 & 0.02 \\
\hline
\end{tabular}




\begin{tabular}{|c|c|c|c|c|c|c|c|}
\hline & Recovery min 7 & 12.07 & 1 & 12.07 & 0.38 & 0.54 & 0.01 \\
\hline & Recovery min 9 & 0.28 & 1 & 0.28 & 0.01 & 0.91 & 0.00 \\
\hline & Recovery min 11 & 97.80 & 1 & 97.80 & 3.13 & 0.08 & 0.04 \\
\hline \multicolumn{8}{|l|}{ Forg x Apol x Sex } \\
\hline & Recovery $\min 1$ & 5.09 & 1 & 5.09 & 0.07 & 0.79 & 0.00 \\
\hline & Recovery $\min 3$ & 259.79 & 1 & 259.79 & 5.36 & 0.02 & 0.07 \\
\hline & Recovery min 5 & 43.25 & 1 & 43.25 & 1.04 & 0.31 & 0.02 \\
\hline & Recovery min 7 & 111.57 & 1 & 111.57 & 3.48 & 0.07 & 0.05 \\
\hline & Recovery $\min 9$ & 10.65 & 1 & 10.65 & 0.46 & 0.50 & 0.01 \\
\hline & Recovery min 11 & 74.01 & 1 & 74.01 & 2.37 & 0.13 & 0.03 \\
\hline \multicolumn{8}{|l|}{ Error } \\
\hline & Recovery min 1 & 5131.60 & 70 & 73.31 & & & \\
\hline & Recovery min 3 & 3394.02 & 70 & 48.49 & & & \\
\hline & Recovery $\min 5$ & 2923.15 & 70 & 41.76 & & & \\
\hline & Recovery $\min 7$ & 2243.06 & 70 & 32.04 & & & \\
\hline & Recovery min 9 & 1628.04 & 70 & 23.26 & & & \\
\hline & Recovery $\min 11$ & 2185.94 & 70 & 31.23 & & & \\
\hline
\end{tabular}


5a. ANCOVAs investigating Forgiveness Level x Apology x Sex interaction at DBP recovery minute 3.

\section{Tests of Between Subjects Effects for}

DBP of Men

\begin{tabular}{|c|c|c|c|c|c|c|}
\hline & SS & DF & MS & $\mathrm{F}$ & $p$ & $\eta_{\mathrm{p}}^{2}$ \\
\hline \multicolumn{7}{|l|}{ Source of Variation } \\
\hline Covariate (rest) & 983.61 & 1 & 983.61 & 15.24 & 0.00 & 0.39 \\
\hline Forgiveness Level (Forg) & 0.95 & 1 & 0.95 & 0.02 & 0.90 & 0.00 \\
\hline Apology Condition (Apol) & 159.95 & 1 & 159.95 & 2.48 & 0.13 & 0.09 \\
\hline Forg x Apology & 71.07 & 1 & 71.07 & 1.10 & 0.30 & 0.04 \\
\hline Error & 1548.85 & 24 & 64.54 & & & \\
\hline
\end{tabular}

\section{Tests of Between Subjects Effects for} DBP of Women

\begin{tabular}{|c|c|c|c|c|c|c|}
\hline & $\mathrm{SS}$ & DF & MS & $\mathrm{F}$ & $p$ & $\eta_{\mathrm{p}}{ }^{2}$ \\
\hline \multicolumn{7}{|l|}{ Source of Variation } \\
\hline Covariate (rest) & 1110.24 & 1 & 1110.24 & 12.54 & 0.00 & 0.22 \\
\hline Forgiveness Level (Forg) & 422.88 & 1 & 422.88 & 4.78 & 0.03 & 0.10 \\
\hline Apology Condition (Apol) & 260.35 & 1 & 260.35 & 2.94 & 0.09 & 0.06 \\
\hline Forg x Apology & 528.37 & 1 & 528.37 & 5.97 & 0.02 & 0.12 \\
\hline Error & 3985.20 & 45 & 88.56 & & & \\
\hline
\end{tabular}

5b. ANCOVAs investigating Forgiveness Level x Apology x Sex interaction at DBP recovery minute 7.

Tests of Between Subjects Effects for

DBP of Men

\begin{tabular}{|c|c|c|c|c|c|c|}
\hline & SS & DF & MS & $\mathrm{F}$ & $p$ & $\eta_{\mathrm{p}}^{2}$ \\
\hline \multicolumn{7}{|l|}{ Source of Variation } \\
\hline Covariate (rest) & 931.14 & 1 & 931.14 & 15.16 & 0.00 & 0.39 \\
\hline Apology Condition (Apol) & 0.92 & 1 & 0.92 & 0.02 & 0.90 & 0.00 \\
\hline Forgiveness Level (Forg) & 4.83 & 1 & 4.83 & 0.08 & 0.78 & 0.00 \\
\hline Forg x Apology & 165.33 & 1 & 165.33 & 2.69 & 0.11 & 0.10 \\
\hline Error & 1474.48 & 24 & 61.44 & & & \\
\hline
\end{tabular}

\section{Tests of Between Subjects Effects for}

DBP of Women

\begin{tabular}{lllllll}
\hline & $\mathrm{SS}$ & $\mathrm{DF}$ & $\mathrm{MS}$ & $\mathrm{F}$ & $p$ & $\eta_{\mathrm{p}}{ }^{2}$ \\
\cline { 2 - 7 } Source of Variation & \multicolumn{7}{c}{} & & & & & \\
\hline & 2193.20 & 1 & 2193.20 & 42.82 & 0.00 & 0.49 \\
Covariate (rest) & 484.53 & 1 & 484.53 & 9.46 & 0.00 & 0.17 \\
Apology Condition (Apol) & 181.46 & 1 & 181.46 & 3.54 & 0.07 & 0.07 \\
Forgiveness Level (Forg) & 116.39 & 1 & 116.39 & 2.27 & 0.14 & 0.05 \\
Forg x Apology & & & & & &
\end{tabular}


Error

2305.09

45

51.22

5c. ANCOVAs investigating Forgiveness Level x Apology x Sex interaction at DBP recovery minute 11.

Tests of Between Subjects Effects of DBP for Men

\begin{tabular}{lllllll}
\hline & SS & DF & MS & F & $p$ & $\eta_{\mathrm{p}}{ }^{2}$ \\
\cline { 2 - 6 } Source of Variation & \multicolumn{7}{c}{} & & & & \\
\hline & & & & & & 0.26 \\
Covariate (rest) & 829.88 & 1 & 829.88 & 8.48 & 0.01 & 0.20 \\
Apology Condition (Apol) & 596.13 & 1 & 596.13 & 6.09 & 0.02 & 0.12 \\
Forgiveness Level (Forg) & 321.89 & 1 & 321.89 & 3.29 & 0.08 & 0.12 \\
Forg x Apology & 306.39 & 1 & 306.39 & 3.13 & 0.09 & \\
Error & 2349.07 & 24 & 97.88 & & & \\
\hline
\end{tabular}

Tests of Between Subjects Effects of DBP for Women

\begin{tabular}{lllllll}
\hline & SS & DF & MS & F & $p$ & $\eta_{\mathrm{p}}{ }^{2}$ \\
\cline { 2 - 6 } Source of Variation & \multicolumn{7}{c}{} & & & & \\
\hline & & & & & & \\
Covariate (rest) & 3487.76 & 1 & 3487.76 & 83.45 & 0.00 & 0.65 \\
Apology Condition (Apol) & 281.33 & 1 & 281.33 & 6.73 & 0.01 & 0.13 \\
Forgiveness Level (Forg) & 13.09 & 1 & 13.09 & 0.31 & 0.58 & 0.01 \\
Forg x Apology & 0.58 & 1 & 0.58 & 0.01 & 0.91 & 0.00 \\
Error & 1880.79 & 45 & 41.80 & & & \\
\hline
\end{tabular}


6. ANCOVAs investigating Forgiveness Level x Apology x Sex interaction at MAP recovery minute 3.

\begin{tabular}{|c|c|c|c|c|c|c|}
\hline \multicolumn{7}{|c|}{$\begin{array}{l}\text { Tests of Between Subjects Effects of } \\
\text { MAP for Men }\end{array}$} \\
\hline & SS & DF & MS & $\mathrm{F}$ & $p$ & $\eta_{\mathrm{p}}^{2}$ \\
\hline \multicolumn{7}{|l|}{ Source of Variation } \\
\hline Covariate (rest) & 602.03 & 1 & 602.03 & 14.12 & 0.00 & 0.37 \\
\hline Forgiveness Level (Forg) & 0.17 & 1 & 0.17 & 0.00 & 0.95 & 0.00 \\
\hline Apology Condition (Apol) & 70.78 & 1 & 70.78 & 1.66 & 0.21 & 0.07 \\
\hline Forg x Apology & 72.21 & 1 & 72.21 & 1.69 & 0.21 & 0.07 \\
\hline Error & 1023.31 & 24 & 42.64 & & & \\
\hline
\end{tabular}

\section{Tests of Between Subjects Effects of} MAP for Women

\begin{tabular}{lllllll}
\hline & $\mathrm{SS}$ & $\mathrm{DF}$ & $\mathrm{MS}$ & $\mathrm{F}$ & $p$ & $\eta_{\mathrm{p}}{ }^{2}$ \\
\cline { 2 - 6 } Source of Variation & \multicolumn{7}{c}{} & & & & \\
\hline & & & & & & \\
Covariate (rest) & 669.10 & 1 & 669.10 & 13.05 & 0.00 & 0.23 \\
Forgiveness Level (Forg) & 221.34 & 1 & 221.34 & 4.32 & 0.04 & 0.09 \\
Apology Condition (Apol) & 144.47 & 1 & 144.47 & 2.82 & 0.10 & 0.06 \\
Forg x Apology & 273.28 & 1 & 273.28 & 5.33 & 0.03 & 0.11 \\
Error & 2307.68 & 45 & 51.28 & & & \\
\hline
\end{tabular}


7a. Forgiveness Level x Apology x Sex ANOVAs for each subscale of the MAACL-R following the Rest Period.

\section{Tests of Between Subjects}

Effects for Anxiety Subscale

\begin{tabular}{lllllll}
\hline & SS & DF & MS & F & $p$ & $\eta_{\mathrm{p}}{ }^{2}$ \\
\cline { 2 - 6 } Source of Variation & & & & & & \\
\hline & & & & & & \\
Apol & 5.63 & 1 & 5.63 & 3.23 & 0.08 & 0.04 \\
Forg & 0.77 & 1 & 0.77 & 0.44 & 0.51 & 0.01 \\
Sex & 1.11 & 1 & 1.11 & 0.64 & 0.43 & 0.01 \\
Forg x Apology & 1.04 & 1 & 1.04 & 0.60 & 0.44 & 0.01 \\
Sex x Apology & 0.27 & 1 & 0.27 & 0.16 & 0.69 & 0.00 \\
Forg x Sex & 3.32 & 1 & 3.32 & 1.91 & 0.17 & 0.03 \\
Forg x Apology x Sex & 4.30 & 1 & 4.30 & 2.47 & 0.12 & 0.03 \\
Error & 123.68 & 71 & 1.74 & & & \\
\hline
\end{tabular}

\section{Tests of Between Subjects}

Effects for Depression

Subscale

\begin{tabular}{lllllll}
\hline & SS & DF & MS & F & $p$ & $\eta_{p}^{2}$ \\
\cline { 2 - 6 } Source of Variation & & & & & & \\
\hline & 3.21 & 1 & 3.21 & 3.09 & 0.08 & 0.04 \\
Apol & 4.11 & 1 & 4.11 & 3.96 & 0.05 & 0.05 \\
Forg & 0.34 & 1 & 0.34 & 0.33 & 0.57 & 0.01 \\
Sex & 2.87 & 1 & 2.87 & 2.76 & 0.10 & 0.04 \\
Forg x Apology & 0.06 & 1 & 0.06 & 0.06 & 0.81 & 0.00 \\
Sex x Apology & 0.05 & 1 & 0.05 & 0.05 & 0.83 & 0.00 \\
Forg x Sex & 3.00 & 1 & 3.00 & 2.89 & 0.09 & 0.04 \\
Forg x Apology x Sex & 73.68 & 71 & 1.04 & & & \\
Error & &
\end{tabular}

\section{Tests of Between Subjects}

Effects for Hostility

Subscale

\begin{tabular}{lllllll}
\hline & SS & DF & MS & F & $p$ & $\eta_{\mathrm{p}}{ }^{2}$ \\
\cline { 2 - 6 } Source of Variation & & & & & & \\
\hline & & & & & & 0.01 \\
Apol & 0.10 & 1 & 0.10 & 0.37 & 0.55 & 0.00 \\
Forg & 0.01 & 1 & 0.01 & 0.03 & 0.87 & 0.00 \\
Sex & 0.02 & 1 & 0.02 & 0.07 & 0.79 & 0.00 \\
Forg x Apology & 0.03 & 1 & 0.03 & 0.11 & 0.74 & 0.01 \\
Sex x Apology & 0.20 & 1 & 0.20 & 0.74 & 0.39 & 0.01 \\
Forg x Sex & 0.32 & 1 & 0.32 & 1.19 & 0.28 & 0.36 \\
Forg x Apology x Sex & 0.23 & 1 & 0.23 & 0.87 & & \\
Error & 18.96 & 71 & 0.27 & & & \\
\hline
\end{tabular}




\begin{tabular}{|c|c|c|c|c|c|c|}
\hline \multicolumn{7}{|c|}{$\begin{array}{l}\text { Tests of Between Subjects } \\
\text { Effects for Positive Affect } \\
\text { Subscale }\end{array}$} \\
\hline & SS & DF & MS & $\mathrm{F}$ & $p$ & $\eta_{\mathrm{p}}^{2}$ \\
\hline \multicolumn{7}{|l|}{ Source of Variation } \\
\hline Apol & 0.62 & 1 & 0.62 & 0.06 & 0.81 & 0.00 \\
\hline Forg & 8.76 & 1 & 8.76 & 0.86 & 0.36 & 0.01 \\
\hline Sex & 157.04 & 1 & 157.04 & 15.35 & 0.00 & 0.18 \\
\hline Forg x Apology & 18.24 & 1 & 18.24 & 1.78 & 0.19 & 0.02 \\
\hline Sex x Apology & 0.01 & 1 & 0.01 & 0.00 & 0.98 & 0.00 \\
\hline Forg $x$ Sex & 1.88 & 1 & 1.88 & 0.18 & 0.67 & 0.00 \\
\hline Forg x Apology x Sex & 0.00 & 1 & 0.00 & 0.00 & 0.99 & 0.00 \\
\hline Error & 726.61 & 71 & 10.23 & & & \\
\hline
\end{tabular}


7b. Forgiveness Level x Apology x Sex ANCOVAs for each subscale of the MAACL-R following the Task Period.

\section{Tests of Between Subjects}

Effects for Anxiety Subscale

\begin{tabular}{lllllll}
\hline & SS & DF & MS & F & $p$ & $\eta_{p}^{2}$ \\
\cline { 2 - 6 } Source of Variation & & & & & & \\
\hline & & & & & & \\
Covariate (rest) & 59.54 & 1 & 59.54 & 13.09 & 0.00 & 0.16 \\
Apol & 1.20 & 1 & 1.20 & 0.26 & 0.61 & 0.00 \\
Forg & 0.09 & 1 & 0.09 & 0.02 & 0.89 & 0.00 \\
Sex & 3.52 & 1 & 3.52 & 0.77 & 0.38 & 0.01 \\
Forg x Apology & 6.61 & 1 & 6.61 & 1.45 & 0.23 & 0.02 \\
Sex x Apology & 3.66 & 1 & 3.66 & 0.81 & 0.37 & 0.01 \\
Forg x Sex & 4.61 & 1 & 4.61 & 1.01 & 0.32 & 0.01 \\
Forg x Apology x Sex & 13.94 & 1 & 13.94 & 3.06 & 0.08 & 0.04 \\
Error & 318.38 & 70 & 4.55 & & & \\
\hline
\end{tabular}

\section{Tests of Between Subjects}

Effects for Depression

Subscale

\begin{tabular}{lllllll}
\hline & $\mathrm{SS}$ & $\mathrm{DF}$ & $\mathrm{MS}$ & $\mathrm{F}$ & $p$ & $\eta_{\mathrm{p}}{ }^{2}$ \\
\cline { 2 - 6 } Source of Variation & & & & & & \\
\hline & & & & & & \\
Covariate (rest) & 40.04 & 1 & 40.04 & 11.14 & 0.00 & 0.14 \\
Apol & 5.49 & 1 & 5.49 & 1.53 & 0.22 & 0.02 \\
Forg & 0.00 & 1 & 0.00 & 0.00 & 0.98 & 0.00 \\
Sex & 3.01 & 1 & 3.01 & 0.84 & 0.36 & 0.01 \\
Forg x Apology & 9.22 & 1 & 9.22 & 2.57 & 0.11 & 0.04 \\
Sex x Apology & 0.04 & 1 & 0.04 & 0.01 & 0.91 & 0.00 \\
Forg x Sex & 10.08 & 1 & 10.08 & 2.81 & 0.10 & 0.04 \\
Forg x Apology x Sex & 0.58 & 1 & 0.58 & 0.16 & 0.69 & 0.00 \\
Error & 251.51 & 70 & 3.59 & & & \\
\hline
\end{tabular}

Tests of Between Subjects

Effects for Hostility

Subscale

\begin{tabular}{llllll}
$\mathrm{SS}$ & $\mathrm{DF}$ & $\mathrm{F}$ & $p$ & $\eta_{\mathrm{p}}{ }^{2}$ \\
\hline
\end{tabular}

Source of Variation

Covariate (rest)

Apol

Forg

Sex

Forg x Apology

Sex x Apology

Forg x Sex

Forg x Apology x Sex

$37.12 \quad 1$

0.58

2.13

4.53

0.34

0.79

0.02

1.71
37.12

0.58

2.13

4.53

0.34

0.79

0.02

1.71
9.44

0.15

0.54

1.15

0.09

0.20

0.01

0.44
0.00

0.70

0.47

0.29

0.77

0.66

0.94

0.51
0.12

0.00

0.01

0.02

0.00

0.00

0.00

0.01 
Tests of Between Subjects

Effects for Positive Affect

Subscale

\begin{tabular}{|c|c|c|c|c|c|c|}
\hline & $\mathrm{SS}$ & DF & MS & $\mathrm{F}$ & $p$ & $\eta_{\mathrm{p}}{ }^{2}$ \\
\hline \multicolumn{7}{|l|}{ Source of Variation } \\
\hline Covariate (rest) & 5.15 & 1 & 5.15 & 1.86 & 0.18 & 0.03 \\
\hline Apol & 5.86 & 1 & 5.86 & 2.12 & 0.15 & 0.03 \\
\hline Forg & 0.06 & 1 & 0.06 & 0.02 & 0.89 & 0.00 \\
\hline Sex & 10.16 & 1 & 10.16 & 3.67 & 0.06 & 0.05 \\
\hline Forg x Apology & 9.42 & 1 & 9.42 & 3.40 & 0.07 & 0.05 \\
\hline Sex x Apology & 3.78 & 1 & 3.78 & 1.37 & 0.25 & 0.02 \\
\hline Forg x Sex & 0.07 & 1 & 0.07 & 0.02 & 0.88 & 0.00 \\
\hline Forg x Apology x Sex & 4.92 & 1 & 4.92 & 1.78 & 0.19 & 0.03 \\
\hline Error & 193.86 & 70 & 2.77 & & & \\
\hline
\end{tabular}


7c. Forgiveness Level x Apology x Sex ANCOVAs for each subscale of the MAACL-R following the Recovery Period.

\section{Tests of Between Subjects}

Effects for Anxiety Subscale

\begin{tabular}{lllllll}
\hline & $\mathrm{SS}$ & $\mathrm{DF}$ & $\mathrm{MS}$ & $\mathrm{F}$ & $p$ & $\eta_{\mathrm{p}}{ }^{2}$ \\
\cline { 2 - 6 } Source of Variation & \multicolumn{7}{c}{} & & & & & \\
\hline & & & & & & \\
Covariate (rest) & 42.62 & 1 & 42.62 & 20.59 & 0.00 & 0.23 \\
Apol & 2.36 & 1 & 2.36 & 1.14 & 0.29 & 0.02 \\
Forg & 3.96 & 1 & 3.96 & 1.91 & 0.17 & 0.03 \\
Sex & 1.85 & 1 & 1.85 & 0.89 & 0.35 & 0.01 \\
Forg x Apology & 0.36 & 1 & 0.36 & 0.17 & 0.68 & 0.00 \\
Sex x Apology & 0.28 & 1 & 0.28 & 0.13 & 0.72 & 0.00 \\
Forg x Sex & 0.39 & 1 & 0.39 & 0.19 & 0.67 & 0.00 \\
Forg x Apology x Sex & 0.39 & 1 & 0.39 & 0.19 & 0.66 & 0.00 \\
Error & 144.88 & 70 & 2.07 & & & \\
\hline
\end{tabular}

\section{Tests of Between Subjects}

Effects for Depression

Subscale

\begin{tabular}{|c|c|c|c|c|c|c|}
\hline & $\mathrm{SS}$ & DF & MS & $\mathrm{F}$ & $p$ & $\eta_{\mathrm{p}}^{2}$ \\
\hline \multicolumn{7}{|l|}{ Source of Variation } \\
\hline Covariate (rest) & 24.79 & 1 & 24.79 & 13.24 & 0.00 & 0.16 \\
\hline Apol & 4.22 & 1 & 4.22 & 2.25 & 0.14 & 0.03 \\
\hline Forg & 2.46 & 1 & 2.46 & 1.31 & 0.26 & 0.02 \\
\hline Sex & 0.01 & 1 & 0.01 & 0.01 & 0.94 & 0.00 \\
\hline Forg x Apology & 1.81 & 1 & 1.81 & 0.97 & 0.33 & 0.01 \\
\hline Sex x Apology & 1.31 & 1 & 1.31 & 0.70 & 0.41 & 0.01 \\
\hline Forg x Sex & 2.19 & 1 & 2.19 & 1.17 & 0.28 & 0.02 \\
\hline Forg x Apology x Sex & 10.08 & 1 & 10.08 & 5.38 & 0.02 & 0.07 \\
\hline Error & 131.10 & 70 & 1.87 & & & \\
\hline
\end{tabular}

Tests of Between Subjects

Effects for Hostility

Subscale

\begin{tabular}{llllll}
$\mathrm{SS}$ & $\mathrm{DF}$ & $\mathrm{F}$ & $p$ & $\eta_{\mathrm{p}}{ }^{2}$ \\
\hline
\end{tabular}

Source of Variation

Covariate (rest)

Apol

Forg

Sex

Forg x Apology

Sex x Apology

Forg x Sex

Forg x Apology x Sex

$\begin{array}{ll}3.16 & 1 \\ 4.18 & 1 \\ 6.25 & 1 \\ 0.00 & 1 \\ 1.21 & 1 \\ 1.64 & 1 \\ 0.15 & 1 \\ 0.75 & 1\end{array}$

3.16

4.18

6.25

0.00

1.21

1.64

0.15

0.75
4.16

5.52

8.25

0.00

1.60

2.17

0.20

0.99
0.05

0.02

0.01

0.96

0.21

0.15

0.66

0.32 $\eta_{\mathrm{p}}{ }^{2}$

0.06

0.07

0.11

0.00

0.02

0.03

0.00

0.01 
0.76

Tests of Between Subjects

Effects for Positive Affect

Subscale

\begin{tabular}{|c|c|c|c|c|c|c|}
\hline & $\mathrm{SS}$ & DF & MS & $\mathrm{F}$ & $p$ & $\eta_{\mathrm{p}}{ }^{2}$ \\
\hline \multicolumn{7}{|l|}{ Source of Variation } \\
\hline Covariate (rest) & 124.00 & 1 & 124.00 & 17.72 & 0.00 & 0.20 \\
\hline Apol & 37.31 & 1 & 37.31 & 5.33 & 0.02 & 0.07 \\
\hline Forg & 21.60 & 1 & 21.60 & 3.09 & 0.08 & 0.04 \\
\hline Sex & 3.36 & 1 & 3.36 & 0.48 & 0.49 & 0.01 \\
\hline Forg x Apology & 0.18 & 1 & 0.18 & 0.03 & 0.87 & 0.00 \\
\hline Sex x Apology & 5.40 & 1 & 5.40 & 0.77 & 0.38 & 0.01 \\
\hline Forg x Sex & 9.46 & 1 & 9.46 & 1.35 & 0.25 & 0.02 \\
\hline Forg x Apology x Sex & 7.24 & 1 & 7.24 & 1.04 & 0.31 & 0.02 \\
\hline Error & 489.80 & 70 & 7.00 & & & \\
\hline
\end{tabular}


7d. Forgiveness Level x Apology x Sex ANOVAs for the depression subscale of the MAACL-R following the Recovery Period using standardized residuals as a dependent variable.

\section{Tests of Between Subjects}

Effects for Depression

Subscale

\begin{tabular}{lllllll}
\hline & SS & DF & MS & F & $p$ & $\eta_{\mathrm{p}}^{2}$ \\
\cline { 2 - 6 } Source of Variation & & & & & & \\
\hline & & & & & & 0.15 \\
Apol & 2.06 & 1 & 2.06 & 2.16 & 0.03 \\
Forg & 1.53 & 1 & 1.53 & 1.60 & 0.21 & 0.02 \\
Sex & 0.00 & 1 & 0.00 & 0.00 & 0.95 & 0.00 \\
Forg x Apology & 0.85 & 1 & 0.85 & 0.89 & 0.35 & 0.01 \\
Sex x Apology & 0.66 & 1 & 0.66 & 0.69 & 0.41 & 0.01 \\
Forg x Sex & 1.15 & 1 & 1.15 & 1.21 & 0.28 & 0.02 \\
Forg x Apology x Sex & 5.10 & 1 & 5.10 & 5.35 & 0.02 & 0.07 \\
Error & 67.67 & 71 & 0.95 & & & \\
\hline
\end{tabular}


8 Forgiveness Level x Apology x Sex ANOVAs for Avoidance and Revenge subscales of the TRIM.

\begin{tabular}{|c|c|c|c|c|c|c|c|}
\hline \multicolumn{8}{|c|}{ Tests of Between Subjects Effects } \\
\hline & Dependent Variable & SS & DF & MS & $\mathrm{F}$ & $p$ & $\eta_{\mathrm{p}}^{2}$ \\
\hline \multicolumn{8}{|l|}{ Source of Variation } \\
\hline \multicolumn{8}{|l|}{ Apology } \\
\hline & Avoidance & 77.37 & 1 & 77.37 & 1.97 & 0.17 & 0.03 \\
\hline & Revenge & 0.81 & 1 & 0.81 & 0.10 & 0.76 & 0.00 \\
\hline \multicolumn{8}{|l|}{ Forgiveness Level } \\
\hline & Avoidance & 61.30 & 1 & 61.30 & 1.56 & 0.22 & 0.02 \\
\hline & Revenge & 6.14 & 1 & 6.14 & 0.74 & 0.39 & 0.01 \\
\hline \multicolumn{8}{|l|}{ Sex } \\
\hline & Avoidance & 9.87 & 1 & 9.87 & 0.25 & 0.62 & 0.00 \\
\hline & Revenge & 1.03 & 1 & 1.03 & 0.13 & 0.73 & 0.00 \\
\hline \multicolumn{8}{|l|}{ Apology x Forg } \\
\hline & Avoidance & 1.73 & 1 & 1.73 & 0.04 & 0.84 & 0.00 \\
\hline & Revenge & 12.16 & 1 & 12.16 & 1.47 & 0.23 & 0.02 \\
\hline \multicolumn{8}{|l|}{ Apology x Sex } \\
\hline & Avoidance & 141.90 & 1 & 141.90 & 3.60 & 0.06 & 0.05 \\
\hline & Revenge & 27.01 & 1 & 27.01 & 3.27 & 0.08 & 0.04 \\
\hline \multicolumn{8}{|l|}{ Forg x Sex } \\
\hline & Avoidance & 2.10 & 1 & 2.10 & 0.05 & 0.82 & 0.00 \\
\hline & Revenge & 4.95 & 1 & 4.95 & 0.60 & 0.44 & 0.01 \\
\hline \multicolumn{8}{|l|}{ Forg x Apol x Sex } \\
\hline & Avoidance & 6.87 & 1 & 6.87 & 0.17 & 0.68 & 0.00 \\
\hline & Revenge & 0.30 & 1 & 0.30 & 0.04 & 0.85 & 0.00 \\
\hline \multicolumn{8}{|l|}{ Error } \\
\hline & Avoidance & 2795.94 & 71 & 39.38 & & & \\
\hline & Revenge & 586.55 & 71 & 8.26 & & & \\
\hline
\end{tabular}


9. Forgiveness Level x Apology x Sex ANOVAs for each question on the post-experimental questionnaire.

\begin{tabular}{|c|c|c|c|c|c|c|c|}
\hline \multicolumn{8}{|c|}{ Tests of Between Subjects Effects } \\
\hline & Dependent Variable & SS & DF & MS & $\mathrm{F}$ & $P$ & $\eta_{\mathrm{p}}^{2}$ \\
\hline \multicolumn{8}{|l|}{ Source of Variation } \\
\hline \multicolumn{8}{|l|}{ Apology } \\
\hline & How stressful & 0.28 & 1 & 0.28 & 0.21 & 0.65 & 0.00 \\
\hline & How often & 0.33 & 1 & 0.33 & 0.25 & 0.62 & 0.00 \\
\hline & Effectiveness & 0.13 & 1 & 0.13 & 0.07 & 0.79 & 0.00 \\
\hline & Enjoyment & 0.82 & 1 & 0.82 & 0.70 & 0.41 & 0.01 \\
\hline & Support during & 0.25 & 1 & 0.25 & 0.20 & 0.66 & 0.00 \\
\hline & Support after & 42.34 & 1 & 42.34 & 48.25 & 0.00 & 0.41 \\
\hline \multicolumn{8}{|l|}{ Forgiveness Level } \\
\hline & How stressful & 2.59 & 1 & 2.59 & 1.92 & 0.17 & 0.03 \\
\hline & How often & 0.01 & 1 & 0.01 & 0.01 & 0.94 & 0.00 \\
\hline & Effectiveness & 2.40 & 1 & 2.40 & 1.37 & 0.25 & 0.02 \\
\hline & Enjoyment & 0.01 & 1 & 0.01 & 0.01 & 0.92 & 0.00 \\
\hline & Support during & 0.00 & 1 & 0.00 & 0.00 & 0.96 & 0.00 \\
\hline & Support after & 0.87 & 1 & 0.87 & 0.99 & 0.32 & 0.01 \\
\hline \multicolumn{8}{|l|}{ Sex } \\
\hline & How stressful & 2.03 & 1 & 2.03 & 1.50 & 0.22 & 0.02 \\
\hline & How often & 0.14 & 1 & 0.14 & 0.11 & 0.74 & 0.00 \\
\hline & Effectiveness & 3.74 & 1 & 3.74 & 2.14 & 0.15 & 0.03 \\
\hline & Enjoyment & 0.13 & 1 & 0.13 & 0.11 & 0.74 & 0.00 \\
\hline & Support during & 1.88 & 1 & 1.88 & 1.48 & 0.23 & 0.02 \\
\hline & Support after & 1.42 & 1 & 1.42 & 1.62 & 0.21 & 0.02 \\
\hline \multicolumn{8}{|l|}{ Apology x Forg } \\
\hline & How stressful & 0.16 & 1 & 0.16 & 0.12 & 0.73 & 0.00 \\
\hline & How often & 2.09 & 1 & 2.09 & 1.60 & 0.21 & 0.02 \\
\hline & Effectiveness & 0.33 & 1 & 0.33 & 0.19 & 0.67 & 0.00 \\
\hline & Enjoyment & 0.35 & 1 & 0.35 & 0.30 & 0.59 & 0.00 \\
\hline & Support during & 0.46 & 1 & 0.46 & 0.36 & 0.55 & 0.01 \\
\hline & Support after & 1.48 & 1 & 1.48 & 1.68 & 0.20 & 0.02 \\
\hline \multicolumn{8}{|l|}{ Apology x Sex } \\
\hline & How stressful & 1.19 & 1 & 1.19 & 0.88 & 0.35 & 0.01 \\
\hline & How often & 0.19 & 1 & 0.19 & 0.14 & 0.71 & 0.00 \\
\hline & Effectiveness & 0.40 & 1 & 0.40 & 0.23 & 0.64 & 0.00 \\
\hline & Enjoyment & 0.26 & 1 & 0.26 & 0.22 & 0.64 & 0.00 \\
\hline & Support during & 1.29 & 1 & 1.29 & 1.02 & 0.32 & 0.01 \\
\hline & Support after & 0.03 & 1 & 0.03 & 0.04 & 0.85 & 0.00 \\
\hline \multicolumn{8}{|l|}{ Forg x Sex } \\
\hline & How stressful & 2.42 & 1 & 2.42 & 1.79 & 0.19 & 0.03 \\
\hline & How often & 0.01 & 1 & 0.01 & 0.01 & 0.94 & 0.00 \\
\hline & Effectiveness & 0.51 & 1 & 0.51 & 0.29 & 0.59 & 0.00 \\
\hline & Enjoyment & 0.37 & 1 & 0.37 & 0.32 & 0.57 & 0.00 \\
\hline & Support during & 0.02 & 1 & 0.02 & 0.02 & 0.90 & 0.00 \\
\hline & Support after & 0.21 & 1 & 0.21 & 0.23 & 0.63 & 0.00 \\
\hline \multicolumn{8}{|l|}{ Forg x Apol x Sex } \\
\hline & How stressful & 0.12 & 1 & 0.12 & 0.09 & 0.77 & 0.00 \\
\hline & How often & 1.64 & 1 & 1.64 & 1.25 & 0.27 & 0.02 \\
\hline & Effectiveness & 2.13 & 1 & 2.13 & 1.22 & 0.27 & 0.02 \\
\hline
\end{tabular}




$\begin{array}{lllllll}\text { Enjoyment } & 3.48 & 1 & 3.48 & 2.97 & 0.09 & 0.04 \\ \text { Support during } & 2.19 & 1 & 2.19 & 1.73 & 0.19 & 0.02 \\ \text { Support after } & 1.08 & 1 & 1.08 & 1.23 & 0.27 & 0.02\end{array}$

\begin{tabular}{|c|c|c|c|c|}
\hline Error & & & & \\
\hline & How stressful & 95.72 & 71 & 1.35 \\
\hline & How often & 92.97 & 71 & 1.31 \\
\hline & Effectiveness & 124.14 & 71 & 1.75 \\
\hline & Enjoyment & 83.24 & 71 & 1.17 \\
\hline & Support during & 90.14 & 71 & 1.27 \\
\hline & Support after & 62.31 & 71 & 0.88 \\
\hline
\end{tabular}

